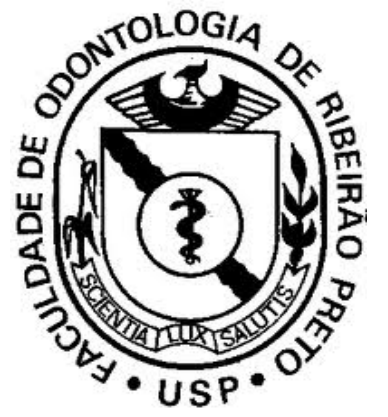

\author{
Universidade de São Paulo \\ Faculdade de Odontologia de Ribeirão Preto \\ Departamento de Odontologia Restauradora
}

Programa de Pós-Graduação em Odontologia Restauradora - Endodontia

\title{
Avaliação da limpeza das paredes em canais radiculares instrumentados pelas técnicas rotatória e self-adjusting file (SAF) associadas ao uso de diferentes quelantes
}

José Antonio Brufato Ferraz

Tese de Doutorado apresentada à Faculdade de Odontologia de Ribeirão Preto da Universidade de São Paulo para a obtenção do grau de Doutor em Ciências - Programa Odontologia Restauradora Área de Concentração: Odontologia Restauradora (opção Endodontia). 



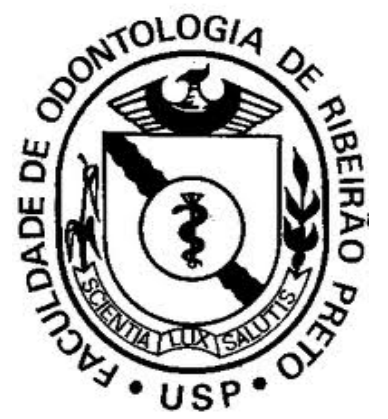

\author{
Universidade de São Paulo \\ Faculdade de Odontologia de Ribeirão Preto \\ Departamento de Odontologia Restauradora
}

Programa de Pós-Graduação em Odontologia Restauradora - Endodontia

\title{
Avaliação da limpeza das paredes em canais radiculares instrumentados pelas técnicas rotatória e self-adjusting file (SAF) associadas ao uso de diferentes quelantes
}

José Antonio Brufato Ferraz

Tese de Doutorado apresentada à Faculdade de Odontologia de Ribeirão Preto da Universidade de São Paulo para a obtenção do grau de Doutor em Ciências-Programa Odontologia Restauradora Área de Concentração; Odontologia Restauradora (opção Endodontia).

Orientador: Prof. Dr. Jesus Djalma Pécora

Ribeirão Preto 
Autorizo a reprodução e divulgação total ou parcial deste trabalho, por qualquer meio convencional ou eletrônico, para fins de estudo e pesquisa, desde que citada a fonte.

Assinatura do autor:

Data:

\section{FICHA CATALOGRÁFICA}

Ferraz, José Antonio Brufato

Avaliação da limpeza das paredes em canais radiculares instrumentados pelas técnicas rotatória e self-adjusting file (SAF) associadas ao uso de diferentes quelantes. Ribeirão Preto, 2012.

149 p.: il.; $28 \mathrm{~cm}$.

Tese de Doutorado, apresentada à Faculdade de Odontologia de Ribeirão Preto da Universidade de São Paulo (FORP-USP). Área de concentração: Odontologia

Restauradora, subárea Endodontia.

Orientador: Prof. Dr. Jesus Djalma Pécora

1. Limpeza. 2. Camada de smear. 3. Self-adjusting file (SAF). 4. Microscopia eletrônica de varredura. 5. Espectrometria de Absorção Atômica. 6. EDTA. 7. Quitosana 

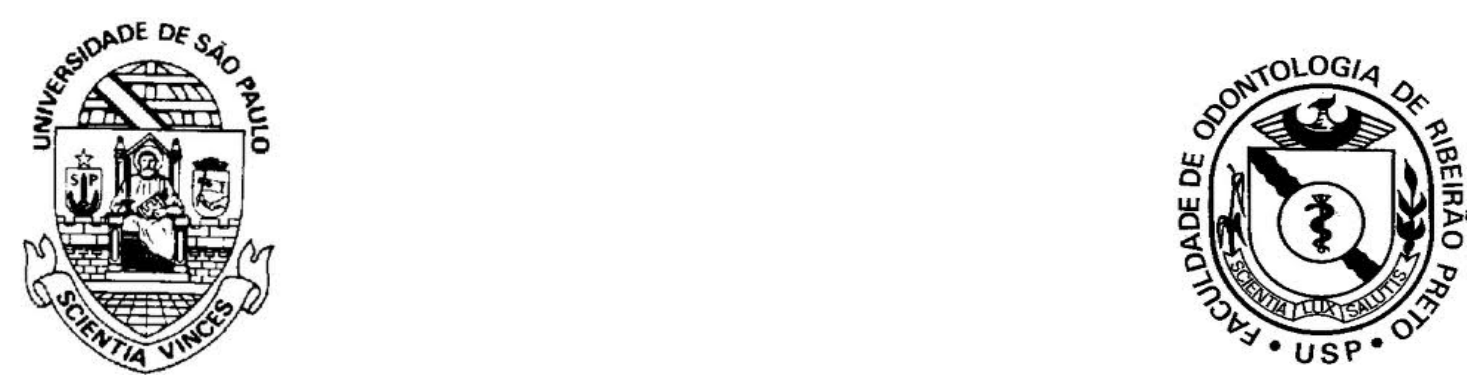

Este trabalho de pesquisa foi realizado no Laboratório de Pesquisa em Endodontia e no Laboratório de Gerenciamento de Resíduos Odontológicos (LAGRO) do Departamento de Odontologia Restauradora da Faculdade de Odontologia de Ribeirão Preto da Universidade de São Paulo. 



\section{Universidade de São Paulo}

Faculdade de Odontologia de Ribeirão Preto

Departamento de Odontologia Restauradora

Programa de Pós-Graduação em Odontologia Restauradora - Endodontia

Folha de Aprovação

Membros da Comissão Julgadora da Tese de Doutorado de José Antonio Brufato Ferraz, apresentada ao Departamento de Odontologia Restauradora - Endodontia, da Faculdade de Odontologia de Ribeirão Preto, Universidade de São Paulo,

Comissão Julgadora:

Prof. Dr. Jesus Djalma Pécora (Orientador)

(Nome / Instituição)

(Nome / Instituição)

(Nome / Instituição)

(Nome / Instituição) 

“...fique em paz com DEUS, seja qual for a forma que você o concebe. $E$, quaisquer que sejam seus trabalhos e aspirações, na confusão ruidosa da vida, mantenha a paz em sua alma. A despeito de todas as fraudes, enganações e sonhos perdidos, este ainda é um mundo belo.

Seja alegre. Esforce-se para ser feliz."

(Max Ehrmann) 



\section{Dedicatória}

A Deus, sempre presente em todos os momentos de minha vida, guiando e iluminando meus caminhos, pela dádiva desta existência.

À memória de meus pais, José Almir Martins Ferraz e Deise Benedita Brufato Ferraz, pela dedicação e orientação na educação de seus filhos, preparando-os para enfrentarem a vida com firmeza e dignidade. 
À minha esposa, Ana Lucia Machado de Oliveira Ferraz, pelo companheirismo, amizade e suporte mútuo em todos bons e maus momentos que passamos até aqui e por saber que estaremos juntos naqueles que virão. Amo você!

A meus filhos, Antonio de Oliveira Ferraz e Francisco de Oliveira Ferraz, por terem norteado minha vida e me ensinado o real significado da palavra amor! Amo vocês!

À minhas irmãs, Marisa Brufato Ferraz, Denise Brufato Ferraz e Heloisa Brufato Ferraz, e sobrinha, Deise Ferraz Capuzzo Jábali, por saber que posso contar com vocês em todos e quaisquer momentos de minha vida. Amo vocês!

A meus sogros, Dr. José Mariano de Oliveira e Lilian Marli Machado de Oliveira; cunhadas, Juliana Machado de Oliveira Martins e Fernanda Machado de Oliveira; cunhado José Antonio Martins, e sobrinha, Maria Eduarda de Oliveira Martins, por me receberem como família.

Ao meu orientador, Prof. Dr. Jesus Djalma Pécora

Com amizade, admiração e respeito gostaria de agradecer-lhe a presença em todos os estágios de minha formação profissional, que fizeram grande diferença em minha vida, e assegurar-Ihe que carrego ensinamentos, muito além de profissionais, inestimáveis aprendidos com o senhor.

MUITO OBRIGADO! 


\section{Agradecimentos}

Ao Prof. Dr. Ricardo Gariba Silva, pela grande admiração de sua capacidade intelectual, postura perante a vida, ensinamentos passados e por sua imprescindível colaboração na finalização deste trabalho;

Ao Prof. Dr. Luis Pascoal Vansan, pela minha introdução à Endodontia Clínica, despertando meu interesse pela área, com quem aprendi a nunca desistir e pela satisfação de poder ter exercido atividade docente ao seu lado;

Ao Prof. Dr. Antônio Miranda da Cruz Filho, pela felicidade de tê-lo tido como colega de trabalho e convivido por muitos anos em atividades clínicas; 
Ao Prof. Dr. Manoel Damião de Sousa- Neto, Coordenador da Pós-Graduação em Endodontia da Faculdade de Odontologia de Ribeirão Preto da Universidade de São Paulo, pelos muitos ensinamentos aprendidos no transcorrer de todos estes anos de convivência;

Aos demais professores do programa de pós-graduação em Endodontia, Prof. Dr. Paulo César Saquy, Prof. Dr. Ricardo Novak Savioli e Profa. Dra. Isabel Cristina Fröner, pelos ensinamentos transmitidos;

Ao amigo Reginaldo Santana da Silva, técnico do Laboratório de Pesquisa em Endodontia da Faculdade de Odontologia de Ribeirão Preto da Universidade de São Paulo, pela amizade, convivência alegre, companheirismo e a pronta disposição em ajudar sempre;

À Profa. Dra. Débora Fernandes Costa Guedes, pela orientação e ajuda na realização da Espectrometria deste trabalho e pelo suporte no transcorrer de todo o curso;

Ao funcionário Carlos Feitosa dos Santos, Secretário do Programa de PósGraduação em Odontologia Restauradora da Faculdade de Odontologia de Ribeirão Preto da Universidade de São Paulo, pela amizade, disposição, orientações, responsabilidade, humildade e apreço dedicado a mim e a todos os demais pósgraduandos;

À colega Luiza Godoi Pitol, técnica do Laboratório de Pesquisa em Endodontia da Faculdade de Odontologia de Ribeirão Preto da Universidade de São Paulo, pela convivência, educação e pronta disposição em contribuir sempre; 
Às funcionárias, Maria Amália Viesti de Oliveira, Maria Isabel Cezário Francisco Miguel e Rosângela Angelini, do Departamento de Odontologia Restauradora da Faculdade de Odontologia de Ribeirão Preto da Universidade de São Paulo, pelo tratamento pessoal e doce com que sempre trataram a todos.

Às funcionárias, Isabel Cristina Galino Sola e Regiane Cristina Moi Sacilotto, secretárias do Setor de Pós-Graduação da Faculdade de Odontologia de Ribeirão Preto da Universidade de São Paulo, pela atenção e orientações concedidas durante a pós-graduação.

À Profa. Dra. Maria Cristina Borsato e funcionária Renata Aparecida Fernandes pelo acesso ao banco de dentes desta escola;

Aos professores, Alexandre Bonini, Artur Rocha Martini, Dr. José Antonio Saadi Salomão, José Estevam Vieira Ozorio, Dr. Rodrigo Gonçalves Ribeiro e cirurgião-dentista Mauro Rosa Faleiros, por tê-los como meus amigos e irmãos por afeição;

Aos parceiros e amigos da VIP-TC, Prof. Danilo Alessandro de Oliveira, Dr. Luis Fernando Jardim, Prof. José Roberto de Freitas. Dr. Eduardo Mendes Gotardo e Fátima Nassif Fachini, pela alegria da convivência, amizade e suporte técnico na parte tomográfica de seleção de dentes deste trabalho;

Aos professores, Prof. Celso Bernardes Sousa Filho e Dr. Silvio Rocha Corrêa da Silva, pela presteza, dedicação e paciência na confecção da análise estatística deste trabalho;

À amiga Profa. Dra. Melissa Andréia Marchesan, pela atenção, carinho e confecção do abstract deste trabalho; 
Ao colega, Prof. Dr. Danilo Mathias Guerisoli, pela amizade e colaboração na execução deste trabalho;

À Faculdade de Odontologia da Universidade de Ribeirão Preto (UNAERP), sua Magnânima Reitora Elmara Lúcia de Oliveira Bonini, coordenadora do Curso de Odontologia Yara Teresinha Corrêa Silva e Sousa e companheiros professores e funcionários Prof. José Carlos Dal Secco Leandrini, Prof. Dr. Rodolfo Jorge Boeck Neto, Prof. Dr. Luis José Floriam, Prof. Dr. Walter Martins Júnior, Prof. Dr. Edson Alfredo, Prof. Edvaldo Luiz Ranalli Prof. Dr. Vlamir Oliveira da Silva, Profa. Dra. Aline Evangelista de Souza Gabriel, Profa. Dra. Danielle Cristine Furtado Messias, Profa. Dra. Delsa Deise Macchetti Kanaan, Profa. Cristiane Celli Matheus dos Santos Pinto, Sergio Pereira de Mendonça, Fabiola Domenes de Sousa, Marina Janólio Ferreira, Amarildo Marques da Silva, Claudio de Paula Joaquim, Simone Andréia D’Alexandro Gomide, Maria Aparecida Santana e Andreia Cristina dos Santos Garcia;

Aos colegas e funcionários do Centro de Especialidades Odontológicas e da Prefeitura Municipal de Ribeirão Preto Aline Alessandra Manderley Oliveira, Prof. Dr. Amadeu Rodrigues Silva Júnior, Dra. Angela Rosalino Guelleri, Dra. Angela Mantovani, Dra. Ana Lucia Barilli, Carmem Célia Schiavoni, Dra. Célia Toscano, Dra. Flávia Neves Thomas, Dr. Francisco Pinto Filho, Geni Ferreira Lima, Dr. Hermano Magalhães Borges, Dr. Humberto Weffort, Dr. José Antonio Albuquerque, Luciene de Sousa Vieira, Marcio Roberto Luccas, Maria José Pezzuto, Raquel Rocco e Karina Mattos; 
Às colegas e funcionárias da Clínica de Atendimento à Pacientes Especiais da Prefeitura Municipal de Ribeirão Preto, Profa. Ana Paula Vieira, Benedita Rodrigues Viana, Fátima Aparecida Rizoli, Profa. Dra. Jaciara Miranda Gomes da Silva e Vilma Barcelos Otani, pela oportunidade de participar deste trabalho maravilhoso e iluminado e pela ajuda no transcorrer deste curso;

À cirurgiã-dentista do Departamento de Odontopediatria da Faculdade de odontologia da Universidade de São Paulo, Profa. Dra. Carolina Paes Torres Mantovani, pelo auxílio na realização do processo do Banco de Dentes e Comitê de Ética;

Ao colega de Doutorado, Prof. Marcos Versiani, pela convivência, companheirismo e por nos ajudar a tentar sempre buscar a excelência em tudo;

À mestranda, Graziela Bianchi Leoni, pela disponibilidade e presteza na sua ajuda na execução deste trabalho;

Ao mestrando, Luis Eduardo de Souza Flamini, pela solicitude e colaboração na execução deste trabalho;

À Associação Paulista de Ribeirão Preto (APCD), pela oportunidade de ministrar - Curso de Atualização em Endodontia nesta associação nestes vinte anos, sua gerente Angela Maria Garcia Sanches e seus funcionários, Maria Dalva Rodrigues de Lima, Magda da Silva, Valdeci Alves Ferreira, Felipe Dacanal, Marilza Carneiro, Rita de Cássia Balico, Sonia Aparecida Morandi e Neusa Nunes de Jesus, pelo suporte na realização do curso; 
À minha auxiliar e secretária, Adriana de Lima Teixeira, pelos vinte anos de convivência profissional, a quem credito grande parte das realizações profissionais alcançadas em minha atividade clínica particular;

À Maria Luzia Silva da Cruz, pelo carinho, atenção e suporte profissional;

À Coordenação de Aperfeiçoamento de Pessoal de Nível Superior (CAPES), pela concessão da Bolsa do tipo Demanda Social;

Ao Departamento de Química da Faculdade de Filosofia, Ciências e Letras de Ribeirão Preto (FFCLRP) da Universidade de São Paulo, professores e funcionários, por toda contribuição e recursos nas análises dos resultados;

À Faculdade de Odontologia de Ribeirão Preto da Universidade de São Paulo, com profunda gratidão, pela oportunidade de ter realizado toda a minha formação profissional nesta instituição;

A todos aqueles de minha convivência que, direta ou indiretamente, colaboraram para a conclusão deste trabalho; 


\section{Abreviaturas}

$\begin{array}{lll}\text { CDTA } & - & \text { Ácido cicloxilendinitrilo tetra acético } \\ \text { CT } & - & \text { Comprimento de trabalho } \\ \text { DA } & - & \text { Diâmetro anatômico } \\ \text { EA } & - & \text { Ácido etidrínico } \\ \text { EDTA } & - & \text { Ácido etilenodiamino tetra acético } \\ \text { EDTAC } & - & \text { Ácido etilenodiamino tetra acético }+ \text { cetavlon } \\ \text { EDTA-T } & - & \text { Ácido etilenodiamino tetra acético }+ \text { tergentol } \\ \text { EGTA } & - & \text { Ácido etilenoglicol tetra acético } \\ \text { FAAS } & - & \text { Espectrometria de absorção atômica com chamas } \\ \text { HO }_{2} O_{2} & - & \text { Peróxido de hidrogênio } \\ \text { MEDR } & - & \text { Microscopia eletrônica de difração retrógada }\end{array}$




\begin{tabular}{|c|c|c|}
\hline MET & - & Microscopia eletrônica de transmissão \\
\hline MEV & - & Microscopia eletrônica de varredura \\
\hline $\mathrm{mg} / \mathrm{L}$ & - & Miligrama(s) por litro(s) \\
\hline $\mathrm{mL}$ & - & Mililitro(s) \\
\hline $\mathrm{mL} / \mathrm{min}$ & - & Mililitro(s) por minuto(s) \\
\hline $\mathbf{m m}$ & - & Milímetro(s) \\
\hline $\mathbf{m m}^{2}$ & - & Milímetro(s) quadrado(s) \\
\hline mol. L ${ }^{-1}$ & - & Mol por litros \\
\hline MTAD & - & Solução de doxiciclina + ácido acético + Tween 80 \\
\hline $\mathrm{NaOCl}$ & - & Hipoclorito de sódio \\
\hline NiTi & - & Níquel titânio \\
\hline $\mathrm{nm}$ & - & Nanômetro(s) \\
\hline $\mathrm{O}_{2}$ & - & Oxigênio \\
\hline PA & - & Ácido peracético \\
\hline pH & - & Potencial hidrogeniônico \\
\hline rpm & - & Rotações por minuto \\
\hline SAF & - & Self-adjusting file \\
\hline TC & - & Tempo de coagulação \\
\hline TS & - & Tempo de sangramento \\
\hline$x$ & - & Vezes \\
\hline$\mu \mathrm{L}$ & - & Microlitro(s) \\
\hline$\mu \mathrm{m}$ & - & Micrometro(s) \\
\hline$\mu \mathrm{S}$ & - & Micro Siemens \\
\hline ○ & - & Graus \\
\hline${ }^{\circ} \mathrm{C}$ & - & Graus Celsius \\
\hline$\%$ & - & Por cento \\
\hline${ }^{\circledR}$ & - & Marca registrada \\
\hline
\end{tabular}




\section{Lista de Figuras}

Figura 1. Espécimes preparados para a tomografia de feixe cônico a fim de serem selecionados

Figura 2. Estudo tomográfico para seleção dos elementos

Figura 3. Ressecção coronária com disco de Carburundum

Figura 4. Instrumentos rotatórios FlexMaster ${ }^{\circledR}$ utilizados no experimento (VDW, Suíça)

Figura 5. Instrumentos do sistema Self-adjusting file $\left(\mathrm{SAF}^{\circledR}\right)$

Figura 6. Sistema para coleta das amostras das soluções: a Dente adaptado ao tubo coletor; $b$ - Seringa adaptada ao dente para coleta das soluções

Figura 7. Tubos tipo Falcon identificados para receberem as 
Figura 9. Elemento coberto com camada de ouro preparado para a MEV

Figura 10. Aparelho para metalização dos corpos de prova Deskll 93 Denton Vacuum

Figura 11. Microscópio eletrônico de varredura Jeol JSM5410

Figura 12. Fluxograma da metodologia. a) Seleção dos 96 espécimes; b) Ressecção das coroas; c) Preparo com o sistema rotatório $\mathrm{VDW}^{\circledR}$; d) Preparo com sistema $\mathrm{SAF}^{\circledR}$; e) Irrigação com as 3 diferentes soluções; f) Sistema preparado para a coleta das soluções de irrigação final; g) Soluções colhidas e armazenadas para espectrometria; h) Espectrômetro; i) Secção dos elementos preparados sentido mésio-distal; j) Metalizador Desk II Denton Vacuum (Tóquio, Japão); k) Elementos metalizados para a MEV, I) Microscópio eletrônico de varredura Jeol JSM5410 (Jeol, Tóquio, Japão)

Figura 13. Fotomicrografias da dentina (1000X) do terço cervical de dentes instrumentados com o sistema rotatório com as diferentes soluções: a) Hipoclorito de sódio 1\%; b) EDTA 15\%; c) Quitosana 0,20\%

Figura 14. Fotomicrografias da dentina (1000X) do terço médio de dentes instrumentados com o sistema rotatório com as diferentes soluções: a) Hipoclorito de sódio 1\%; b) EDTA 15\%; c) Quitosana $0,20 \%$

Figura 15. Fotomicrografias da dentina (1000X) do terço apical de dentes instrumentados com o sistema rotatório com as diferentes soluções: a) Hipoclorito de sódio 1\%; b) EDTA 15\%; c) Quitosana $0,20 \%$

Figura 16. Fotomicrografias da dentina (1000X) do terço cervical de dentes instrumentados com o sistema SAF ${ }^{\circledR}$ com as diferentes soluções: a) Hipoclorito de sódio 1\%; b) EDTA 15\%; c) Quitosana $0,20 \%$

Figura 17. Fotomicrografias da dentina $(1000 \mathrm{X})$ do terço médio de dentes instrumentados com o sistema $\mathrm{SAF}^{\circledR}$ com as diferentes soluções: a) Hipoclorito de sódio 1\%; b) EDTA 15\%; c) Quitosana $0,20 \%$

Figura 18. Fotomicrografias da dentina (1000X) do terço apical de dentes instrumentados com o sistema $\mathrm{SAF}^{\circledR}$ com as diferentes soluções: a) Hipoclorito de sódio 1\%; b) EDTA 15\%; c) Quitosana $0,20 \%$ 


\section{Lista de Tabelas}

Tabela 1 - Valores da concentração de cálcio em mg/L

Tabela 2 - Teste de Dunn para comparação entre as soluções avaliadas em sua capacidade de remoção de íons cálcio

Tabela 3 - Moda dos escores por grupo por meio de avaliação de três examinadores para avaliação da microscopia eletrônica de varredura (MEV)

Tabela 4 - Valores usados para a comparação entre as técnicas utilizadas na sua capacidade de remoção da camada de smear 
Tabela 5 - Teste de Dunn para comparação das soluções avaliadas na sua capacidade de remoção da camada de smear

Tabela 6 - Valores da mediana, da soma de postos e do posto médio da comparação entre os terços estudados para avaliação da remoção camada de smear

Tabela 7 - Teste de Dunn para avaliação da interação entre as técnicas de instrumentação utilizadas e as soluções avaliadas na sua capacidade de remoção da camada de smear

Tabela 8 - Valores da mediana, da soma de postos e do posto médio dos resultados da interação entre as técnicas de instrumentação utilizadas e os terços estudados para avaliação da remoção camada de smear

Tabela 9 - Teste de Dunn da interação entre as soluções avaliadas e os terços estudados na remoção da camada de smear 
FERRAZ, J.A.B. Avaliação da limpeza das paredes em canais radiculares instrumentados pelas técnicas rotatória e self-adjusting file (SAF) associadas ao uso de diferentes quelantes, 2012, 149 p. Tese (Doutorado) - Faculdade de Odontologia de Ribeirão Preto, Universidade de São Paulo, Ribeirão Preto, 2012.

O presente trabalho avaliou, por microscopia eletrônica de varredura (MEV), a limpeza das paredes dos canais radiculares instrumentados pelas técnicas rotatória e Self-adjusting file $\left(\mathrm{SAF}^{\circledR}\right)$ com uso do $\mathrm{NaOCl}$ a $1 \%$ como solução irrigadora e o uso do EDTA a $15 \%$ e da Quitosana 0,20\% como soluções quelantes, e quantificou os íons cálcio removidos pelas diferentes soluções irrigadoras por meio de espectrometria de absorção atômica. Trinta dentes caninos inferiores humanos foram divididos em dois grupos $(n=15)$, de acordo com a técnica de instrumentação utilizada: A - instrumentos FlexMaster ${ }^{\circledR}$ usados na técnica Free Tip Preparation, assegurado alargamento mínimo de 200 , até o instrumento \# 60.02, irrigados com 1 $\mathrm{mL}$ de $\mathrm{NaOCl} 1 \%$ em cada troca de instrumento e $\mathrm{B}$ - sistema $\mathrm{SAF}^{\circledR}$, com prévio alargamento manual até o instrumento $\mathrm{K} \# 20$, aplicação da $S A F^{\circledR}$ por 4 minutos, com fluxo de irrigação pelo sistema VATEA de $5 \mathrm{~mL} / \mathrm{min}$. Os dentes foram divididos em três subgrupos conforme a irrigação final: G1-NaOCl 1\%, G2- EDTA 15\% e G3 Quitosana $0,20 \%$. Utilizou-se $5 \mathrm{~mL}$ de cada solução à $1 \mathrm{~mL} / \mathrm{min}$. A solução extravasada pelo forame foi coletada e submetida à análise espectrométrica. $O$ EDTA 15\% apresentou maior capacidade de remoção de íons cálcio do que a Quitosana a $0,20 \%(p<0,05)$ e o $\mathrm{NaOCl} 1 \%$ não removeu íons. Os espécimes foram analisados em MEV. As fotomicrografias obtidas foram avaliadas qualitativamente em relação à remoção da camada de smear observada. Não houve diferença entre as instrumentações rotatória e $\mathrm{SAF}^{\circledR}$ nos terços dos canais avaliados. Analisadas as interações entre as técnicas utilizadas e aos terços do canal, o EDTA 15\% apresentou melhores resultados que a Quitosana $0,20 \%(p<0,05)$, sendo ambas as soluções melhores que o $\mathrm{NaOCl} 1 \%$. Conclui-se que as soluções quelantes testadas foram capazes de remover íons cálcio das paredes dos canais radiculares - com superioridade do EDTA $15 \%$ sobre a Quitosana $0,20 \%$, e o $\mathrm{NaOCl}$ a $1 \%$ não apresentou essa capacidade - e removeram a camada de smear das paredes dos canais radiculares com superioridade do EDTA 15\%, sem interferência das técnicas de instrumentação avaliadas - rotatória e $S A F^{\circledR}$.

Descritores: Agentes quelantes, EDTA, Quitosana, preparo rotatório, Self-adjusting file $\left(\mathrm{SAF}^{\circledR}\right)$, camada de smear, Microscopia Eletrônica de Varredura, Espectrometria de absorção atômica. 



\section{ABSTRACT}

FERRAZ, J.A.B. Evaluation of the cleanness of root canals walls instrumented with rotary and the self-adjusting file (SAF) techniques associated with different chelators, 2012, 149 p. Tese (Doutorado) - Faculdade de Odontologia de Ribeirão Preto, Universidade de São Paulo, Ribeirão Preto, 2012.

The present study evaluated, by scanning electron microscopy (SEM), the cleanness of the root canal walls instrumented by rotary and the self-adjusting file $\left(\mathrm{SAF}^{\circledR}\right)$ techniques using $1 \% \mathrm{NaOCl}$ as an irrigating solution and 15\% EDTA, $0.20 \%$ Chitosan as chelator solutions, and quantified the calcium ions removed by the different irrigants with atomic absorption spectrometry. Thirty human mandibular canine teeth were divided into 2 groups $(n=15)$ according to the instrumentation technique used: A- FlexMaster ${ }^{\circledR}$ instruments used with the Free tip Preparation, assuring a minimal enlargement of $200 \mu \mathrm{m}$, up to a \#60 .02 instrument, irrigated with $1 \mathrm{~mL}$ of $1 \% \mathrm{NaOCl}$ between each instrument; and $\mathrm{B}-\mathrm{SAF}^{\circledR}$ system, with previous enlargement to a type K \#20 manual instrument, application of SAF during 4 minutes, with VATEA irrigation system at a flow of $5 \mathrm{~mL} / \mathrm{min}$. The teeth were divided into three subgroups according to the final irrigation protocol: G1- $1 \% \mathrm{NaOCl}, \mathrm{G} 2-15 \%$ EDTA and G3- $0.20 \%$ Chitosan. Five $\mathrm{mL}$ of solution were used at $1 \mathrm{~mL} / \mathrm{min}$. The solution extruded thru the foramen was collected and submitted to spectrometric analysis. $15 \%$ EDTA showed higher calcium ion removal capacity then $0.20 \%$ Chitosan $(p<0.05)$ and the $1 \% \mathrm{NaOCl}$ did not remove ions. The specimens were evaluated by means of SEM. The photomicrographs obtained were qualitatively evaluated in terms of smear layer removal. There was no significant difference between the rotary and $\mathrm{SAF}^{\circledR}$ instrumentation systems in the evaluated canal thirds. The interaction techniques used and canals thirds showed that the 15\% EDTA revealed better results than the $0.02 \%$ Chitosan $(p<0.05)$, and both were better than $1 \% \mathrm{NaOCl}$. It can be concluded that the tested chelating solutions removed calcium ions from the root canals walls - with better results for $15 \%$ EDTA than $0.20 \%$ Chitosan; $1 \%$ $\mathrm{NaOCl}$ did not present this capacity - and removed the smear layer form the root canal walls with better results for $15 \%$ EDTA, with no difference between the evaluated techniques - rotary and $\mathrm{SAF}^{\circledR}$.

Keywords: Chelating agents, EDTA, Chitosan, rotary preparations, self-adjusting file $\left(\mathrm{SAF}^{\circledR}\right)$, scanning electron microscopy, atomic absorption spectrometry. 



\section{Sumário}

\section{Resumo}

Abstract

Introdução

Revista da Literatura

Proposição

77

Materiais e Métodos

81

Resultados

97

Discussão

Conclusões

Bibliografia

Anexos 

Introdução 
O preparo biomecânico dos canais radiculares constitui um ato que deve promover a microcirurgia das paredes do canal e que tem por objetivo remover a pré-dentina e a dentina, contaminadas ou não, em quantidade que varie de 150 a $200 \mu \mathrm{m}$. Assim, no diâmetro cirúrgico do canal radicular, deve haver parede isenta de microrganismos e de biofilme, o que significa a presença de um espaço sanificado, com a preservação da integridade e localização do forame (SPANÓ et al., 2009).

A limpeza do sistema de canais radiculares ocorre por meio da ação mecânica dos instrumentos endodônticos associada às propriedades físico-químicas das soluções irrigadoras e dos medicamentos, que tem por objetivo eliminar agentes agressores e irritantes como os microrganismos, seus produtos e restos de tecido pulpar, degradados ou não (HÜLSMANN et al., 2003).

Durante o processo de instrumentação dos canais radiculares, há a deposição de restos de tecido dentinário nas paredes destes canais, o que contribui para a formação de uma estrutura amorfa aderida a elas denominada de camada de smear, independentemente do tipo de instrumento utilizado ou da técnica estabelecida (McCOMB; SMITH, 1975; VIOLICH; CHANDLER, 2010). Os resíduos remanescentes na luz dos canais radiculares após o preparo biomecânico, ou em áreas em que não houve a ação das soluções químicas e dos instrumentos, são denominados de dèbris (McCOMB; SMITH, 1975; HÜLSMANN et al. 2003). A morfologia da camada de smear depende do tipo de instrumento que agiu sobre as paredes dentinárias, da pressão exercida pelo operador e da solução irrigadora utilizada (GWINNETT, 1984) e tem espessura variável de 1 a 2 um (MADER et al., 1984). 
Numerosas soluções irrigantes são recomendadas para uso clínico (DAKIN, 1915; BARRET, 1917; WALKER, 1936; GROSSMAN; MEIMAM, 1941; GROSSMAN, 1943; NYGAARD-ØSTBY, 1957; STEWART et al.; 1969; McCOMB e SMITH, 1975; BERUTTI et al. 1997; ESTRELA et al., 2007), sendo o hipoclorito de sódio (NaOCl), em diferentes concentrações, amplamente recomendado e, atualmente é a solução irrigadora preferida no tratamento dos canais radiculares, devido às suas propriedades químicas de dissolução dos tecidos pulpares ou remanescentes necróticos, controle da infecção dos canais radiculares, clareação, transformação de aminas em cloraminas e desodorização (WALKER, 1936; McCOMB; SMITH, 1975; YAMADA et al. 1983; CZONSTKOWSKY et al. 1990; GUERISOLI et al., 2002; VILLEGAS et al., 2002; TORABNEJAD et al., 2002; HÜLSMANN et al., 2003; TORABNEJAD et al., 2003; MARENDING et al.; 2007), embora não remova das paredes dos canais radiculares o material inorgânico, a camada de smear (McCOMB; SMITH, 1975; GWINNET, 1984; MADER et al., 1984; DAUTELMORAZIN et al., 1994).

$\mathrm{O} \mathrm{NaOCl}$, nas concentrações recomendadas para uso, apresenta citoxicidade de moderada à severa quando é extruído através do forame radicular (KOULAOZIDOU et al., 1999), motivo pelo qual se recomenda irrigação dos canais radiculares sem pressão, ao invés de com pressão positiva (METZGER et al.; 2010a). Tem capacidade de penetrar no interior dos túbulos dentinários e promover a limpeza e a desinfecção dos sistemas de canais radiculares (ZUOLO et al., 1987; BUCK et al., 2001; MARQUES et al., 2006, MAl et al., 2010; MELLO et al. 2010; ZOU et al., 2010; KAYA et al. 2011).

Para remover a camada de smear das paredes dos canais radiculares e, consequentemente, aumentar as chances de sucesso da terapia endodôntica, 
utilizam-se soluções quelantes e desmineralizadoras, tais como EDTA, CDTA, EGTA, MTAD, ácido cítrico, ácido málico, ácido acético, ácido lático, vinagre de maçã (LOEL, 1975; McCOMB; SMITH, 1975; PÉCORA et al.; 1993 SCELZA et al., 2000; SOUSA-NETO et al., 2002; TORABNEJAD et al., 2003; HÜLSMANN et al., 2003; ESTRELA et al., 2007; SPANÓ et al., 2009; MJÖR, 2009) e a quitosana (GUIBAL et al., 2000; RHAZI et al., 2002; SILVA, P.V. 2011). O agente quelante ou desmineralizador deve ser aplicado sobre a dentina radicular, o que promoverá a remoção da camada de smear e do smear plug, aumentando sua permeabilidade (GOLDBERG; ABRAMOVICH, 1977; SCELZA et al., 2000; ÇALT; SERPER, 2002; HÜLSMAN et al., 2003; KOKKAS et al., 2004; PEREZ; ROUQUEIROL-POURCEL, 2005; PEREZ-HEREDIA et al., 2006; BAUMGARTNER et al., 2007).

O EDTA foi o primeiro agente quelante utilizado na Endodontia com a finalidade de facilitar a instrumentação de canais atrésicos. É um sal de um ácido fraco (NYGAARD-ØSTBY, 1957). Para melhorar seu desempenho, o autor preconizou a adição de um tensoativo catiônico (Cetavlon), recebendo esta mistura resultante o nome de EDTAC (VON DER FEHR; NYGAARD-OSTBY, 1963).

A ação dos agentes quelantes e a sua eficiência dependem de muitos fatores, tais como: tempo de aplicação, pH, concentração da solução, temperatura e da quantidade da solução disponível (GOLDBERG; SPIELBERG, 1982; ÇALT; SERPER, 2002; HÜLSMAN et al., 2003).

Pesquisas têm sido desenvolvidas no intuito de se buscar uma solução irrigadora de fácil acesso, de simples uso e de baixo custo, com a capacidade de remover a camada de smear das paredes dos canais radiculares (ESTRELA et al., 2007). A quitosana, um oligossacarídeo que possui propriedades funcionais múltiplas, tem atraído interesse por suas propriedades biológicas (XIA et al. 2011). 
Este polímero apresenta biocompatibilidade, biodegradação, atoxidade, atividade antimicrobiana e baixa imunogenicidade (PILLAl et al.2009; KONG et al., 2010) e capacidade quelante (GUIBAL et al., 2000; SILVA, P.V., 2011)

O desenvolvimento da liga de níquel-titânio ( $\mathrm{NiTi}$ ), na segunda metade do século XX, favoreceu o desenvolvimento de novos instrumentos endodônticos com mais flexibilidade e com diferentes conicidades, possibilitando a utilização dos sistemas rotatórios (WALIA et al. 1988; THOMPSON; DUMMER, 1997b; PÉCORA et al., 2002).

A aplicação do NiTi na Endodontia foi um acontecimento revolucionário incorporando uma série de mudanças conceituais no preparo do sistema de canais radiculares (WALIA et al., 1988; PÉCORA et al., 2002; BUCHANAN, 2000; BUCHANAN, 2001). Apresentam estes sistemas a capacidade de preparar o canal radicular com pouco ou nenhum transporte do seu longo eixo axial (THOMPSON; DUMMER, 1997a; THOMPSON; DUMMER, 1997b; BUCHANAN, 2000; PÉCORA et al. 2002) e extrema flexibilidade (WALIA et al., 1988). Tais instrumentos são passíveis de fratura por fadiga cíclica após uso (GAMBARINI, 2001). Segundo BARBIZAM et al.(2002) estes instrumentos têm dificuldades em tocar, uniforme e regularmente, as paredes dos canais radiculares, principalmente daqueles achatados, dificultando sua limpeza, motivo pelo qual é o uso alternado de soluções irrigadoras, EDTA e NaOCl, indicado quando da sua utilização (BUCK et al., 2001).

A complexidade anatômica dos canais radiculares dificulta a sua limpeza e desinfecção em virtude da não adaptação dos instrumentos endodônticos às paredes dos canais radiculares. Tanto os instrumentos de aço inoxidável como os instrumentos rotatórios confeccionados em NiTi mantêm sua forma cônica e mesmo com as diferentes conicidades (tapers) continuam sem conseguir atingir todas as 
paredes dos canais radiculares eficiente e regularmente (BUCHANAN, 2000; BUCHANAN, 2001, BARBIZAM et al., 2002).

Um novo instrumento endodôntico foi pesquisado e já está em uso, recebendo o nome de Self-adjusting file $\left(\mathrm{SAF}^{\circledR}\right)$ (METZGER et al., 2010a). Tem um desenho inovador, apresenta-se como um tubo cilíndrico de níquel titânio, oco, vazado lateralmente, com aspecto de tela, compressível, com sua superfície abrasiva (METZGER et al., 2010a, HOF et al. 2010; METZGER et al. 2010b; METZGER et al. 2011; ADGÜZEL, 2011; VERSIANI et al., 2011). Por sua compressibilidade, age comprimido contra as paredes dentinárias, tocando-as de maneira mais uniforme e sobre elas faz pressão, provocando o alargamento do canal radicular (HOF et al., 2010; VERSIANI et al. 2011). Este sistema é dotado de fluxo interno de irrigação, que percorre o longo eixo do instrumento e também sai pelas suas aberturas laterais (METZGER et al. 2011).

Faz-se necessário aprofundar o estudo sobre a ação de substâncias químicas utilizadas como soluções irrigadoras dos canais radiculares no que se relaciona às suas capacidades de remover a camada de smear; tentar esclarecer como essas soluções agem e identificar quais os princípios ativos que atuam sobre o cálcio das paredes dos canais radiculares, interagindo com os sistemas de preparo dos canais radiculares, visando à melhoria da terapia endodôntica com a obtenção de melhores índices de sucesso. 
Revista da Literatura 
Para facilitar ao leitor, este capítulo foi dividido, ao final com dois subitens: A Quitosana e o Sistema Self-adjusting file.

A busca do melhor modo de se promover a limpeza e desinfecção dos canais radiculares tem motivado muitas pesquisas na área da Endodontia.

O hipoclorito de sódio a 0,5 \% associado ao ácido bórico, para redução de seu pH, foi proposto por DAKIN (1915) para a aplicação sobre feridas. Em 1917, BARRET sugere o uso desta solução em bolsas periodontais e abscessos de origem endodôntica, via canal radicular e WALKER (1936) propôs o uso do $\mathrm{NaOCl}$ a 5,0\% como irrigante dos canais radiculares, por acreditar que soluções mais concentradas seriam mais eficientes na neutralização de conteúdos sépticos presentes nos canais.

GROSSMAN; MEIMAN (1941) afirmaram que o hipoclorito de sódio a 5\% (soda clorada) tinha grande eficiência na dissolução pulpar. Em 1943 GROSSMAN preconiza o uso do $\mathrm{NaOCl}$ a $5 \%$ alternado com o peróxido de hidrogênio $\left(\mathrm{H}_{2} \mathrm{O}_{2}\right)$, o que gera uma reação de efervescência liberando $\mathrm{O}_{2}$ e forçando os dèbris para fora dos canais radiculares.

NYGAARD-ØSTBY (1957) sugeriu o uso do EDTA a 15\%, no pH 7,3, para a ampliação de canais atresiados como alternativa ao uso dos ácidos fortes utilizados até então. Dentre as evidentes vantagens da solução, é ressaltada a sua segurança por não agir sobre metais e, portanto, não afetar os instrumentos endodônticos. Nesse mesmo trabalho, o autor sugere a adição à solução em foco de um composto de amônio quaternário para potencializar seu efeito bactericida. Observou ter o EDTA uma ação autolimitante e que, no pH avaliado, não tem ação irritante aos tecidos periapicais. Concluiu o autor que o EDTA seria um possível substituto dos ácidos fortes utilizados até então para a ampliação química de canais atresiados. 
VON DER FEHR; ØSTBY (1963) estudaram a capacidade do EDTAC e do ácido sulfúrico a $50 \%$ de desmineralizar dentina humana, utilizando microrradiografias para determinar a extensão da descalcificação. Os resultados obtidos no experimento mostraram que o EDTAC, após 5 minutos no interior do canal radicular, promoveu desmineralização até a profundidade de $30 \mu \mathrm{m}$ das paredes. Semelhante resultado foi encontrado para o ácido sulfúrico a $50 \%$, com o mesmo tempo de aplicação. Porém, quando as soluções testadas foram deixadas pelo período superior a 40 horas no interior do canal radicular, os resultados foram diferentes. Enquanto o EDTAC produziu uma zona de desmineralização com profundidade igual a $50 \mu \mathrm{m}$, essa ação atingiu até $500 \mu \mathrm{m}$ nos canais submetidos ao ácido sulfúrico. Os autores concluíram que a ação do EDTAC possui caráter autolimitante e que era melhor utilizá-lo como solução auxiliar da instrumentação de canais radiculares ao invés do ácido sulfúrico.

FLASCHKA (1967), em seu livro sobre titulometria por complexação utilizando o EDTA, afirmou que este agente é bastante útil na determinação da quantidade de cálcio em uma solução. Os fatores determinantes para a escolha de um bom quelante neste tipo de análise, segundo o autor, são a característica estequiométrica, a rapidez na ligação, a estabilidade do complexo, a simplicidade da reação, a facilidade na detecção do ponto de viragem e a ausência de precipitado.

STEWART et al. (1969) propuseram uma preparação em forma de creme, contendo EDTA e peróxido de uréia em uma base de polietilenoglicol de alto peso molecular (Carbowax). Esse produto ficou conhecido comercialmente com o nome de RC-Prep ${ }^{\circledR}$ e seria um auxiliar no preparo biomecânico do canal radicular. Nesse estudo, demonstraram que o RC-Prep ${ }^{\circledR}$, combinado com o hipoclorito de sódio a 5,0\% foi capaz de aumentar a permeabilidade dentinária. 
SCHILDER (1974) ressaltou que o preparo do canal radicular, antecedendo a sua obturação, é um passo essencial no tratamento endodôntico, mas ressalta o paradoxo em que os conceitos para o preparo dos canais radiculares ainda têm fundamentos empíricos, ignorando a biologia e a física necessárias para o sucesso endodôntico.

McCOMB; SMITH (1975), em um estudo pioneiro, observaram sob microscopia eletrônica de varredura (MEV) o efeito de diversas soluções irrigadoras utilizadas no tratamento endodôntico sobre as paredes dentinárias do canal radicular e, pela primeira vez, observaram a formação de uma camada amorfa (smear) aderida a estas como resultado do preparo biomecânico. Concluíram que o EDTAC foi capaz de remover a camada de smear do canal radicular, tornando as paredes dentinárias próprias para receber o material obturador. A limpeza obtida com a aplicação do EDTAC mostrou-se proporcional ao tempo em que este foi deixado no interior do canal radicular.

LOEL (1975) propôs o uso do ácido cítrico a 50\%, alternado com hipoclorito de sódio, durante a instrumentação de canais radiculares. Concluiu o autor que o ácido cítrico a $50 \%$ é um agente eficiente para a remoção de tecido vital e que seu uso condiciona a dentina para a recepção do material obturador.

Acreditando na necessidade de aumentar a permeabilidade da dentina radicular, de modo a facilitar a ação dos medicamentos, GOLDBERG; ABRAMOVICH (1977) realizaram um estudo utilizando o EDTAC na remoção da camada de smear e do de smear plug formados durante a instrumentação dos canais radiculares. Neste experimento, os autores utilizaram soro fisiológico como solução irrigadora na fase de instrumentação dos canais radiculares. Em seguida, fraturaram longitudinalmente os dentes no sentido vestíbulo-lingual e aplicaram duas 
gotas de EDTAC, em intervalo de 15 minutos, em somente uma das metades. Com o auxílio de MEV, relataram que a metade do dente que não recebeu o tratamento com EDTAC encontrava-se coberta por uma massa amorfa ou granular, e os túbulos dentinários estavam parcialmente ou totalmente obstruídos por este material (smear). As metades tratadas com EDTAC mostravam-se livres desta massa amorfa, com os túbulos dentinários expostos e aumentados em diâmetro. Os autores concluíram que o uso do EDTAC traz benefícios à terapia endodôntica, pois auxilia na limpeza e desinfecção do canal radicular, facilita a ação das soluções irrigadoras e drogas devido ao aumento da permeabilidade radicular e, finalmente, condiciona as paredes dentinárias do canal de modo a promover maior adesão ao cimento obturador.

RAM (1980) estudou a eficiência de três preparações com propriedades quelantes (solução de EDTA a 15\%, RC-Prep ${ }^{\circledR}$ e Salvisol), na limpeza do canal radicular por meio de MEV. Para tanto, utilizou dentes caninos recém-extraídos, clivados longitudinalmente, sendo uma das metades mantida como controle e a outra submetida à ação dos agentes quelantes testados. Fotomicrografias foram obtidas dos três terços radiculares e analisadas. O autor relatou que, embora os agentes quelantes tenham sido eficientes nas porções média e cervical do canal, a porção apical apresentava-se sempre com restos de fibras colágenas e camada de smear. Assim, concluiu que os métodos de preparo radicular são ineficientes na limpeza do canal radicular e o EDTA foi o mais eficiente na remoção da camada de smear dos canais instrumentados.

GOLDBERG; SPIELBERG (1982) estudaram o efeito do tempo sobre a ação do EDTAC aplicado em paredes dentinárias do canal radicular. Após clivarem as raízes de dentes anteriores humanos, uma gota de EDTAC foi colocada em uma das 
metades obtidas, variando-se o tempo de aplicação em 5, 15 ou 30 minutos. Os espécimes foram observados por meio de MEV. As fotomicrografias obtidas mostraram uma camada de smear cobrindo as paredes dentinárias e entrada dos túbulos no grupo controle. Os espécimes tratados com 5 minutos de exposição ao EDTAC mostram paredes dentinárias livres da camada de smear, sendo que descalcificação mais severa pôde ser observada na dentina tratada por 15 ou 30 minutos. Os autores concluíram que a ação desmineralizante do EDTAC é crescente até 15 minutos, após os quais a ação autolimitante do EDTA não causa maiores mudanças na morfologia dentinária. Recomendaram, portanto, deixar o agente quelante agindo por cerca de 15 minutos no interior do canal radicular.

GOLDMAN et al. (1982) usaram o EDTAC e sua associação com hipoclorito de sódio a $5,25 \%$ durante a instrumentação de canais radiculares. As fotomicrografias obtidas pela MEV mostraram paredes dentinárias radiculares livres da camada de smear e dèbris, quando a instrumentação foi realizada associando-se - $\mathrm{NaOCl}$ ao EDTA, o que não ocorreu quando as soluções foram usadas separadamente. Os autores concluíram que a combinação de EDTAC seguido de hipoclorito para a irrigação final apresentou os melhores resultados para remoção da camada de smear. É interessante notar que, neste trabalho, pela primeira vez, sugeriu-se o uso alternado de soluções irrigadoras com o intuito declarado de remover a camada de smear e os dèbris dos canais radiculares.

YAMADA et al. (1983), com base no trabalho de GOLDMAN et al. (1982), obtiveram resultados semelhantes quando avaliaram a eficiência na instrumentação dos canais radiculares utilizando hipoclorito de sódio sozinho ou combinado com o EDTA a $17 \%$. Os autores, por meio de observação com MEV, constataram que o hipoclorito de sódio a 5,25\% era ineficiente para a remoção da camada de smear, 
enquanto o EDTA a 17\% removeu esta camada, porém persistiam dèbris aderidos às paredes do canal. Concluíram que os melhores resultados para remoção de dèbris e da camada de smear foram obtidos quando a instrumentação foi realizada com hipoclorito de sódio a 5,25\%, com irrigação final com $10 \mathrm{~mL}$ de EDTA a $17 \%$ e o mesmo volume de $\mathrm{NaOCl}$ a $5,25 \%$.

GWINNETT (1984), em suas considerações sobre a morfologia da camada de smear, descreveu que suas características dependem do tipo de instrumento que agiu sobre a superfície dentinária, da pressão exercida pelo operador e da solução irrigadora utilizada. Esta camada, segundo o autor, não se apresentou continuamente aderida em toda a superfície, mas em regiões descontínuas, algumas vezes firmemente aderidas, outras de maneira solta. A alteração provocada pela ação dos instrumentos sobre a dentina foi superficial, atingindo a espessura de 5 $\mu \mathrm{m}$, frequentemente com obliteração dos túbulos dentinários.

MADER et al. (1984) realizaram a mensuração da espessura da camada de smear recobrindo as paredes dentinárias do canal radicular após a instrumentação endodôntica, bem como o smear plug nos túbulos dentinários. Os autores instrumentaram canais distais de cinco molares humanos, utilizando como solução irrigadora o hipoclorito de sódio a 5,0\%, e, em seguida, processaram os espécimes para observação com MEV. Foram obtidas fotomicrografias perpendiculares ao canal radicular e de perfil, onde foi constatada uma espessura de 1 a $2 \mu \mathrm{m}$ para a camada de smear. O tampão de smear apresentou espessuras mais variáveis, chegando a $40 \mu \mathrm{m}$ no interior dos túbulos dentinários.

ZUOLO et al. (1987) analisaram a ação do EDTA e suas associações com tensoativos sobre a permeabilidade da dentina radicular. Os autores utilizaram soluções de EDTA, EDTAC, EDTA-T e EDTA + cloreto de cetilpiridino no preparo 
biomecânico dos canais radiculares de incisivos centrais superiores humanos. Utilizaram o método histoquímico para quantificar a permeabilidade dentinária, juntamente com a análise morfométrica. Os resultados mostraram maior infiltração de íons cobre nos dentes tratados com EDTAC. Os terços cervical e médio da raiz apresentaram índices de permeabilidade semelhantes, enquanto o terço apical mostrou os menores valores.

WALIA et al. (1988) estudaram a viabilidade de se manufaturar instrumentos em Nitinol e avaliaram sua flexibilidade e propriedades torcionais, comparando instrumentos convencionais (aço inox) com os de Nitinol \#15. Observaram ter os instrumentos de Nitinol duas ou três vezes mais elasticidade em flexão e torção, bem como maior resistência à fratura torcional, comparado aos instrumentos de aço inoxidável.

CZONSTKOWSKY et al. (1990), em uma revisão da literatura, concluíram que a remoção da camada de smear apresenta mais benefícios do que riscos. Recomendaram os autores o uso alternado de hipoclorito de sódio e EDTA durante o preparo biomecânico dos canais radiculares.

PÉCORA et al. (1993) estudaram o efeito das soluções de Dakin e de EDTA, isoladas, alternadas e misturadas, sobre a permeabilidade da dentina radicular de dentes humanos. Por meio do método de penetração de íons cobre na dentina radicular, esses autores puderam quantificar as alterações de permeabilidade do tecido. Os resultados do experimento indicaram aumento significante da permeabilidade dentinária, quando a solução de Dakin foi utilizada alternadamente com o EDTA ou a este misturada, durante o preparo biomecânico dos canais radiculares. Os autores concluíram que o $\mathrm{NaOCl}$, associado ao EDTA, promoveu aumento da permeabilidade dentinária radicular. 
GARBEROGLIO; BECCE (1994) analisaram o efeito de seis irrigantes na camada de smear criada pela instrumentação in vitro de 53 raízes. As soluções irrigantes avaliadas foram: hipoclorito de sódio a $1 \%$, hipoclorito de sódio a $5 \%$, uma combinação de ácido fosfórico a $24 \%$ e ácido cítrico a 10\%, EDTA a 0,2\% EDTA $17 \%$ e EDTA $3 \%$. Os dentes, após preparo e irrigação, foram avaliados por MEV para verificar a presença ou ausência da camada de smear. As duas soluções de hipoclorito não removeram a camada de smear. A solução de EDTA 0,2\% foi mais eficiente que o hipoclorito, mas não removeu totalmente a camada de smear, especialmente na entrada dos canalículos dentinários. As outras três soluções removeram a camada de smear efetivamente, mas sem diferenças estatísticas significantes entre elas $(p>0,05)$. A solução de EDTA a $3 \%$ foi tão efetiva quanto o ácido fosfórico, o ácido cítrico e o EDTA a 17\%, mas o EDTA não mostrou o significante efeito desmineralizante dentinário como a solução ácida.

DAUTEL-MORAZIN et al. (1994) analisaram a ultraestrutura da camada de smear, utilizando a microscopia eletrônica de difração retrógrada (backscattered electron image) - MEDR. Quinze dentes humanos tiveram seus canais radiculares instrumentados com soro fisiológico, solução de Dakin ou sem o uso de qualquer tipo de solução auxiliar. A camada de smear observada apresentou-se de constituição irregular, com áreas apresentando grandes quantidades de material inorgânico intercaladas com regiões mais carentes dele. O hipoclorito de sódio produziu camada de smear mais uniforme e de maior conteúdo inorgânico.

SEN et al. (1995) relataram que durante a instrumentação endodôntica há formação de uma camada composta de dentina, restos de tecido pulpar e processos odontoblásticos, além de microrganismos. Esta camada, denominada camada de smear, tem aparência amorfa, irregular e granular sob o microscópio eletrônico de 
varredura. Os autores complementaram que a camada de smear atuou como uma barreira física e interferiu na aderência e penetração de cimentos nos túbulos dentinários, afetando a eficiência da vedação da obturação do canal radicular.

THOMPSON; DUMMER (1997a e 1997b) estudaram a habilidade dos sistemas de $\mathrm{NiTi}$, usando os instrumentos $\mathrm{McXim}^{\circledR}$ em canais simulados com ângulos e curvaturas diferentes. Em um primeiro estudo, descrevem a eficácia dos instrumento em NiTi diminuindo: termos de tempo de preparo, falhas de instrumentação, obstruções dos canais, perda do comprimento de trabalho e ampliando a forma tridimensional do canal. Os autores concluíram que os instrumentos de NiTi preparam os canais rapidamente, com pequena deformação, sem obstruções e com mínima alteração de comprimento de trabalho e com características tridimensionais ótimas depois de preparados. Na segunda parte do trabalho, concluíram que os instrumentos de NiTi produziram mínimo transporte apical e as formas obtidas foram satisfatórias.

BERUTTI et al. (1997) analisaram a capacidade de algumas soluções irrigadoras de penetrar nos túbulos dentinários. Os autores utilizaram 24 incisivos centrais superiores, que foram esterilizados e, posteriormente, incubados com Streptococcus faecallis por 20 dias. A instrumentação dos dentes foi realizada em ambiente asséptico, irrigando-se os canais radiculares entre cada instrumento com hipoclorito de sódio a $5,25 \%$ e EDTA a $10 \%$. Na metade dos dentes, além das soluções irrigadoras citadas, também foi utilizado um detergente aniônico (Triton$X^{\circledR}$ ). Os dentes foram descalcificados e analisados por meio de microscopia óptica, onde se observou a presença de bactérias nos túbulos dentinários, em diferentes profundidades. No grupo onde não foi utilizado o tensoativo, havia a presença maciça de bactérias na profundidade de $300 \mu \mathrm{m}$; enquanto no grupo onde o 
tensoativo foi utilizado, havia uma camada livre de bactérias a partir da luz do canal, que se estendeu por $130 \mu \mathrm{m}$. Abaixo dessa zona livre de bactérias, havia contaminação. Os autores concluíram que o tensoativo auxilia a penetração do hipoclorito de sódio no interior dos túbulos dentinários.

KOULAOUZIDOU et al. (1999) estudaram a ação citotóxica do NaOCl e EDTA em diversas concentrações e potenciais hidrogeniônicos. Os autores utilizaram culturas de células submetidas às diferentes soluções irrigadoras e avaliaram, quantitativamente, a viabilidade celular após diferentes períodos de tempo. Os resultados indicaram grande porcentagem de células mortas nos meios tratados com hipoclorito de sódio e EDTA, independentemente do pH destas soluções, fato este que levou os pesquisadores a concluírem que ambas as soluções são citotóxicas nas concentrações utilizadas rotineiramente na endodontia.

ECONOMIDES et al. (1999) avaliaram in vitro os efeitos da camada de smear sobre a infiltração apical de dentes tratados endodonticamente. Utilizaram 104 dentes humanos unirradiculares, que receberam instrumentação até $1 \mathrm{~mm}$ aquém do ápice anatômico e irrigação com hipoclorito de sódio a 1\%. Metade dos dentes recebeu irrigação final com EDTA para remoção da camada de smear, sendo que, na outra metade, a camada foi mantida. Os dentes foram então obturados com gutapercha e um cimento à base de óxido de zinco e eugenol (Roth $811^{\circledR}$ ) ou à base de resina $\left(\mathrm{AH} 26^{\circledR}\right)$. A infiltração apical foi avaliada por meio de um método eletroquímico e os resultados indicaram redução da microinfiltração apical quando a camada de smear foi removida e o cimento resinoso foi utilizado.

SCELZA et al. (2000) estudaram a eficiência da irrigação final na Endodontia. Os autores instrumentaram trinta dentes, utilizando hipoclorito de sódio a 1\%, e realizaram a irrigação final com ácido cítrico, EDTA-T ou peróxido de hidrogênio. Os 
autores avaliaram, quantitativamente, a remoção da camada de smear. Os resultados indicaram ação semelhante a do ácido cítrico e do EDTA-T, sendo mais eficientes do que o peróxido de hidrogênio na remoção da camada de smear das paredes dentinárias.

BUCHANAN (2000) introduziu a variação da conicidade (taper) dos instrumentos para um preparo do canal radicular ergonômico e previsível, o que introduz um novo conceito no desenho dos instrumentos. $O$ autor relatou que a variabilidade de conicidades é a chave para um alargamento cervical ideal e modelagem de todo o canal. A facilidade e simplicidade do uso dos instrumentos de conicidades variáveis foi descrito e as melhoras de limpeza e obturação discutidas em relação a instrumentos de conicidade única.

BUCHANAN (2001) ressaltou não haver necessidade de remover a dentina excessivamente para um preparo de canal radicular efetivo. Salientou que as limas $\mathrm{NITi} \mathrm{GT}{ }^{\circledR}$ permitem um preparo seguro e estandardizado, variando a conicidade usada com o diâmetro original do canal a ser preparado, sendo o grande desafio abandonar as formas de preparo tradicionais. Os instrumentos $G T^{\circledR \circledast}$, segundo 0 autor, devem ser usados com toque suave e sem movimentos de vaivém, com velocidade abaixo de 300 rpm. Ressaltou também que estes instrumentos sejam descartados após 5 usos, pois são sujeitos a fadiga e separação, sendo que em casos de uma demanda grande do instrumento o uso único deve ser indicado.

A penetração de algumas soluções irrigadoras no interior dos túbulos dentinários foi avaliada por BUCK et al. (2001), que utilizaram hipoclorito de sódio a $5,25 \%$, EDTA a $0,2 \%$ e clorexidina a $0,12 \%$ no seu experimento. Os canais radiculares de doze dentes anteriores foram esterilizados e contaminados com Enterococcus faecalis por 12 horas, recebendo em seguida, por 1 minuto, as 
soluções testadas. Usando uma broca, os autores recolheram raspas de dentina, a partir da superfície externa da raiz, em profundidades de 0,5 e 1,0 mm, incubandoas em meio de cultura. Os resultados mostraram maior ação do hipoclorito de sódio, seguido pelo EDTA e clorexidina, com resultados semelhantes. Os autores concluíram que, embora o $\mathrm{NaOCl}$ seja capaz de eliminar bactérias dentro dos túbulos dentinários, maiores tempos de exposição à solução irrigadora são necessários para a desinfecção completa do canal radicular.

GAMBARINI (2001) investigou a resistência à fadiga cíclica de instrumentos de níquel titânio usados clinicamente, associados a um motor de alto torque tradicional e a um novo motor de baixo torque. Os instrumentos após uso clínico foram usados em canais simulados de aço inoxidável, girando livremente a 350 rpm, até o momento de fratura. Os resultados demonstraram que o uso de um motor de baixo torque reduz a fratura dos instrumentos rotatórios por fadiga cíclica.

SOUSA-NETO et al. (2002) estudaram os efeitos do EDTA, EGTA e CDTA sobre a adesividade dentinária e microinfiltração apical. Os resultados do experimento demonstraram não haver correspondência entre a remoção da camada de smear e a microinfiltração apical. Os autores concluíram que o cimento Sealer $26^{\circledR}$ e a solução de EDTA apresentaram os melhores resultados para os testes de adesividade e infiltração marginal apical.

ÇALT; SERPER (2002) avaliaram os efeitos do tempo de aplicação de EDTA sobre a dentina radicular. Os autores prepararam seis dentes unirradiculares, efetuando o preparo biomecânico com hipoclorito de sódio a 5\%. Em seguida, os terços coronário e apical das raízes foram descartados, e o terço médio foi fragmentado no seu longo eixo, expondo o canal radicular. Os espécimes foram então irrigados com EDTA a $17 \%$ por 1 ou 10 minutos, seguida de irrigação final 
com $\mathrm{NaOCl}$ a $5 \%$. Ao MEV, os canais de ambos os grupos mostraram-se livres da camada de smear, porém o grupo cuja irrigação foi feita com EDTA por 10 minutos apresentou-se com maior descalcificação, principalmente na dentina peritubular. Os autores sugeriram que o EDTA deve ser utilizado por apenas 1 minuto, principalmente em dentes jovens, onde a possibilidade de descalcificação extrema é maior.

PÉCORA et al. (2002), com objetivo de reduzir o índice de fratura de instrumentos de níquel titânio utilizados com sistemas mecanizados, preconizaram o uso da técnica Free Tip Preparation. Essa técnica tem como princípio o preparo do canal radicular de forma que a ponta do instrumento não toque as paredes dentinárias na maioria das vezes, servindo apenas como guia e diminuindo, assim, a possibilidade de fratura.

VILLEGAS et al. (2002) utilizaram quatro regimes distintos de irrigação para verificar sua influência sobre a obturação de canais acessórios. Sessenta e quatro pré-molares humanos foram instrumentados sem qualquer solução irrigadora, com água destilada, com hipoclorito de sódio a $6 \%$ ou $\mathrm{NaOCl}$ a $6 \%$ associado ao EDTA a $15 \%$. Os canais radiculares foram obturados, utilizando-se o System $B^{\circledR}$ associado ao sistema Obtura $\|^{\circledR}$. Os dentes foram diafanizados e a penetração do material obturador foi mensurada nos canais acessórios. Os maiores valores de penetração de material obturador foram observados nos dentes irrigados com $\mathrm{NaOCl}$ ou este associado ao EDTA. Os autores concluíram que o uso de EDTA teve pouco efeito sobre a obturação de canais acessórios.

GUERISOLI et al. (2002) avaliaram a capacidade de diferentes soluções irrigadoras, quando energizadas pelo ultrassom, na remoção da camada de smear. Os autores realizaram o preparo biomecânico dos grupos I a III, utilizando como 
soluções irrigadoras a água destilada, o hipoclorito de sódio e esta solução associada ao EDTAC a $15 \%$. No grupo IV, os canais foram irrigados apenas com $\mathrm{NaOCI}$ e EDTAC. Uma lima ISO 15, energizada pelo ultrassom, foi utilizada em todos os espécimes, com movimentos de limagem de pequena amplitude. Os dentes foram cisalhados e observados por meio de MEV, onde foi constatada a permanência da camada de smear nos canais irrigados com água destilada ou hipoclorito de sódio e a remoção desta nos canais onde houve a associação com EDTAC. Os autores concluíram que o uso de hipoclorito de sódio associado ao EDTAC, sob agitação ultrassônica, é capaz de remover a camada de smear, enquanto que as outras soluções testadas deixam mais resíduos aderidos às paredes do canal radicular.

BARBIZAM et al. (2002) avaliaram a efetividade das técnicas de instrumentação manual e rotatória para limpeza de canais achatados, através de análise morfométrica, por meio de microscópio óptico acoplado a computador, avaliando a área do canal com presença de dèbris. Observaram ser a técnica manual mais eficiente na limpeza dos canais com achatamento do que a rotatória, apesar de nenhuma delas limpar completamente o canal radicular.

NIU et al. (2002) estudaram a erosão causada pelo EDTA em dentina radicular humana. Os autores utilizaram diversas combinações de $\mathrm{NaOCl}$ a $6 \%$ e EDTA a $17 \%$ durante a instrumentação de canais de dentes unirradiculares, observando por meio de MEV as alterações estruturais sofridas pela dentina peri e intertubular. As fotomicrografias obtidas revelaram padrões de descalcificação distintos para os grupos experimentais testados, o que levou os autores a concluírem que a aplicação de hipoclorito de sódio a 6\%, após o uso de EDTA, 
causou destruição mais acentuada da matriz inorgânica do que os outros tratamentos, porém também foi mais eficiente na remoção de dèbris.

TORABINEJAD et al. (2002) fizeram uma revisão bibliográfica com ênfase nas implicações clínicas da camada de smear na Endodontia. Segundo os autores, está bem estabelecido que a instrumentação do canal radicular promove a formação da camada de smear, a qual recobre as superfícies das paredes dentinárias. Observaram que há vários métodos utilizados para sua remoção, no entanto, a manutenção ou não dessa camada ainda gerava bastante discussão científica.

HÜLSMANN et al. (2003) realizaram uma revisão da literatura sobre as substâncias quelantes utilizadas na Odontologia, bem como o emprego e função dos quelantes na Endodontia. Verificaram que as soluções quelantes apresentam capacidade de desmineralizar a dentina, facilitando a ação dos instrumentos em canais atrésicos, reduzem a microdureza, aumentam a permeabilidade dentinária, facilitando a ação da medicação intracanal e removem a camada de smear.

MENEZES et al. (2003) avaliaram a limpeza de canais radiculares instrumentados e irrigados com hipoclorito de sódio a 2,5\%, gluconato de clorexidina a 2,0\% e soro fisiológico. A associação dessas soluções com o EDTA também foi estudada. Para tanto, cinquenta dentes unirradiculares humanos foram instrumentados com as soluções testadas e clivados no sentido de seu longo eixo para observação por meio de MEV. Exceto para o grupo em que a clorexidina foi utilizada durante a instrumentação, a irrigação com EDTA diminuiu significantemente a quantidade da camada de smear observada. Os autores concluíram que se faz necessária a utilização do EDTA a fim de promover melhor limpeza das paredes dos canais radiculares. 
TORABINEJAD et al. (2003) avaliaram, por meio da MEV, a capacidade de limpeza do $M T A D^{\circledR}$, uma substância composta de isômero de tetraciclina, ácido e detergente, como um irrigante final na superfície dos canais radiculares. Quarenta e oito dentes humanos unirradiculares receberam, após a biomecânica, $5 \mathrm{~mL}$ de uma das seguintes soluções: água destilada, hipoclorito de sódio $5,25 \%$, EDTA $17 \%$ e $M T A D^{\circledR}$. A quantidade de smear layer, assim como o grau de erosão sobre a superfície dos três terços do canal radicular foi avaliado. Os resultados mostraram que $M T A D^{\circledR}$ foi eficiente na remoção da camada de smear, não alterando a estrutura dos túbulos dentinários.

SLUTZKY-GOLGBERG et al. (2004) estudaram o efeito do hipoclorito de sódio sobre a microdureza da dentina radicular. Quarenta e duas raízes de incisivos bovinos foram distribuídas em 6 grupos, variando-se a concentração da solução irrigante ( $\mathrm{NaOCl}$ 2,5 e 6\%) e o período de irrigação (5, 10 e 20 minutos). No grupo controle utilizou-se solução salina. As raízes foram cortadas transversalmente obtendo-se assim, discos de dentina, os quais foram lixados, polidos e levados a um aparelho de microdureza Vickers. As mensurações foram realizadas a $500 \mu \mathrm{m}, 1000$ $\mu \mathrm{m}$ e $1500 \mu \mathrm{m}$ da luz do canal radicular. Os resultados apontaram diminuição da microdureza em todas as distâncias analisadas para ambas concentrações. No entanto, o $\mathrm{NaOCl} 6 \%$ a $500 \mu \mathrm{m}$ promoveu uma redução significantemente maior que a $2,5 \%$.

KOKKAS et al. (2004) avaliaram, por meio da MEV, o efeito da camada de smear na capacidade de penetração de três cimentos endodônticos através dos túbulos dentinários. Após o preparo químico-mecânico de 64 dentes unirradiculares, os espécimes foram distribuídos em dois grupos: GA- a camada de smear permaneceu intacta; GB- remoção completa da camada de smear. Duas raízes de 
cada grupo foram utilizadas como controle. Os grupos foram redistribuídos de acordo com o cimento obturador a ser utilizado: AH Plus ${ }^{\circledR}$, Apexit $^{\circledR}$ e Roth $811^{\circledR}$. Os resultados revelaram que a camada de smear agiu como um selante dos túbulos dentinários, impedindo a penetração dos cimentos, enquanto que sua remoção permitiu a penetração de todos os cimentos numa profundidade variável.

A eficiência do EDTA a $8 \%$ na remoção da camada de smear do canal radicular foi avaliada por PEREZ; ROQUEYROL-POURCEL (2005), que observaram as paredes dentinárias por meio de MEV. A análise das fotomicrografias revelou paredes limpas e túbulos dentinários abertos nos grupos onde foram utilizadas soluções quelantes. O EDTA a $8 \%$, utilizado por 1 minuto no interior do canal radicular, foi capaz de remover a camada de smear; enquanto a utilização por 3 minutos mostrou ação semelhante ao EDTA a 15\% usado por 1 minuto. Os autores concluíram que a utilização do EDTA a $8 \%$ por 1 minuto pode limpar as paredes do canal radicular com menor erosão dentinária.

MARQUES et al. (2006) verificaram a capacidade de remoção da camada de smear e de íons cálcio da dentina radicular após irrigação com 3 diferentes soluções quelantes. Dezesseis dentes caninos foram instrumentados manualmente pela técnica Step Back. A cada troca de lima utilizou-se $1 \mathrm{~mL}$ de solução quelante conforme os grupos: G1- EDTAC 17\%; G2- CDTA 17\%; G3- EGTA 17\%. Ao final do preparo biomecânico foram coletados $8 \mathrm{~mL}$ de cada solução, os quais foram levados ao espectrofotômetro de absorção atômica para análise da quantidade de íons cálcio presente. As raízes foram seccionadas longitudinalmente e preparadas para avaliação em MEV. Os autores observaram que o EDTAC e CDTA removeram a camada de smear e íons cálcio da dentina de forma mais eficiente que a solução de EGTA. Em relação à limpeza, não houve diferença entre os terços analisados. 
Ainda no intuito de se chegar a uma solução alternativa capaz de remover a camada de smear, NAAMAN et al. (2007) realizaram um estudo in vitro avaliando a eficiência da capacidade de eliminação da camada de smear e de dèbris da solução de hipoclorito de sódio a 5,25\%, isolado e associado ao ácido cítrico e ao EDTA e associados ao ultrassom, após a remoção do hidróxido de cálcio do canal radicular. Os autores concluíram que a simples utilização do ácido cítrico é eficiente na remoção dos dèbris e da camada de smear das paredes do canal, sendo menos eficiente do que o EDTA. Eles também concluíram que a aplicação de hidróxido de cálcio dificulta a remoção dos dèbris e da camada de smear.

BAUMGARTNER et al. (2007), comparando a eficiência antimicrobiana do protocolo de irrigação, utilizando $\mathrm{NaOCl}$ a $1,3 \%$ associado ao $\mathrm{MTAD}^{\circledR}$ versus irrigação com $\mathrm{NaOCl}$ a $5,25 \%$ associado à EDTA a $17 \%$, constataram que a irrigação alternada com hipoclorito de sódio e EDTA era capaz de produzir canais radiculares livres de unidades formadoras de colônia, enquanto a associação entre $\mathrm{NaOCl}$ e $\mathrm{MTAD}^{\circledR}$ não conseguia produzir canais assépticos em cerca de $50 \%$ das amostras testadas. Desta forma, concluíram que a irrigação alternada utilizando $\mathrm{NaOCl}$ e EDTA é mais eficiente na descontaminação e canais radiculares.

ESTRELA et al. (2007) pesquisaram, por meio da MEV, a capacidade de limpeza das paredes dentinárias após irrigação com diferentes soluções. Foram avaliadas as soluções de clorexidina, vinagre de maçã e hipoclorito de sódio associados ou não ao EDTA. Os autores verificaram que a combinação de todas as soluções com EDTA aumentou significantemente a capacidade de remoção da camada de smear, e que o melhor resultado foi obtido com a associação com o vinagre de maçã. 
MARENDING et al. (2007) investigaram o efeito do hipoclorito de sódio em diferentes concentrações sobre a dentina radicular humana e observaram que a exposição ao $\mathrm{NaOCl}$ a $5 \%$ aumentou a permeabilidade da dentina intertubular e uma deterioração da matriz de dentina concentração-dependente ao NaOCl. Observaram também que o hipoclorito de sódio, em todas concentrações testadas deixou os componentes inorgânicos da dentina intactos. Concluíram os autores que o efeito do hipoclorito de sódio nas propriedades mecânicas da dentina é concentraçãodependente dissolvendo seus componentes orgânicos.

CARVALHO et al. (2008) avaliaram, por meio da MEV, a capacidade de limpeza de diferentes soluções utilizadas para irrigação e observaram uma grande quantidade de túbulos dentinários abertos naqueles grupos onde atuaram juntos o hipoclorito e o EDTA e que, em todos os grupos, a limpeza obtida no terço cervical foi melhor que a dos terços apical e médio.

KHEDMAT; SHOKOUHINEJAD (2008) compararam, por meio da MEV, a eficácia da SmearClear ${ }^{\circledR}$ na remoção da camada de smear, comparando-o ao $\mathrm{NaOCl}$ a $5,25 \%$, o EDTA a $17 \%$ e o ácido cítrico a $10 \% \%$. Os resultados demonstraram não haver diferença entre o SmearClear ${ }^{\circledR}$ e o EDTA a $17 \%$ nos três terços radiculares avaliados e o ácido cítrico apresentou, significativamente, uma menor ação no terço apical. Concluíram os autores que o protocolo usado neste estudo não foi eficiente em remover completamente a camada de smear, principalmente no terço apical, e que a adição de um surfactante ao EDTA no SmearClear $^{\circledR}$ não resultou em uma melhor remoção da camada de smear comparado ao EDTA sozinho.

MJÖR (2009) realizou um trabalho sobre a permeabilidade dentinária, para um entendimento das reações pulpares e da tecnologia adesiva, ressaltou a importância desta permeabilidade em suportar a fisiologia pulpar e dar padrões de 
resposta do complexo dentino-pulpar e comentou sobre a camada de smear, falando de sua formação e dificuldade de remoção.

LOTTANTI et al. (2009) estudaram os efeitos do EDTA, ácido etidrínico (EA) e ácido peracético (PA) na dentina humana e a remoção da camada de smear, associados ao hipoclorito de sódio como irrigantes após o preparo químicomecânico; por meio de MEV, espectrometria e dispersão reversa. Concluíram os autores que os agentes descalcificantes estudados foram capazes de remover ou prevenir a camada de smear, mas erodiram a dentina diferencialmente.

SPANÒ et al. (2009) avaliaram a capacidade de remoção da camada de smear promovida pela ação de agentes quelantes e desmineralizantes e quantificaram a concentração de íons cálcio presentes nas soluções após a utilização. Quarenta e dois incisivos centrais superiores foram instrumentados e, a cada troca de instrumento, os espécimes receberam $2 \mathrm{~mL}$ de $\mathrm{NaOCl} 1 \%$. Posteriormente, os dentes foram distribuídos em 7 grupos $(n=6)$, conforme a irrigação final estabelecida: G1- EDTA 15\%; G2 - ácido cítrico 10\%; G3- citrato de sódio 10\%; G4- vinagre de maçã; G5 - ácido acético 5\%; G6 - ácido málico 5\%; G7sem irrigação final (controle). Durante a irrigação, as soluções foram simultaneamente coletadas, após extravasamento apical, e encaminhadas à análise espectrométrica. Os autores verificaram que o EDTA $15 \%$ e o ácido cítrico 10\% removeram a camada de smear de forma semelhante entre si. As demais soluções não foram eficientes para esta finalidade. A maior quantidade de íons cálcio removidos foi observada no grupo do EDTA $15 \%$, seguido do ácido cítrico $10 \%$. citrato de sódio $10 \%$ apresentou as menores quantidades do íon.

MAI et al. (2010) avaliaram por meio de MET o possível efeito erosivo do $\mathrm{NaOCI} 5,25 \%$, associado ao EDTA $17 \%$, nas paredes dentinárias, concluindo ser a 
aparente agressividade do EDTA $17 \%$ em provocar erosão nas paredes dos canais radiculares, na verdade, atribuída ao uso prolongado do $\mathrm{NaOCl}$ a $5,25 \%$, podendo fragilizar os dentes tratados endodonticamente.

MELLO et al. (2010) compararam, por meio da MEV, a capacidade de remoção da camada de smear após utilização de duas técnicas de irrigação com EDTA 17\%. Sessenta dentes humanos unirradiculares foram instrumentados e distribuídos conforme o protocolo de irrigação: G1- irrigação contínua com $5 \mathrm{~mL}$ EDTA $17 \%$, por 3 minutos; G2- irrigação inicial de $1 \mathrm{~mL}$ de EDTA $17 \%$ por 6 segundos, seguida da inundação do canal com EDTA 17\%, por 2 minutos e meio, mais irrigação final com $4 \mathrm{~mL}$ da mesma solução, por 24 segundos. Os autores verificaram que o grupo com irrigação contínua apresentou maior superfície livre da camada de smear quando comparado ao outro grupo. Conclui-se que a irrigação contínua de $5 \mathrm{~mL}$ de EDTA $17 \%$ por 3 minutos pode remover de forma eficiente a camada de smear.

ZOU et al. (2010) relataram que o hipoclorito de sódio é o mais comum irrigante usado em endodontia mundialmente e afirmam que sua capacidade de penetrar nos túbulos dentinários é relacionada a tempo de exposição, concentração e temperatura. Trinta dentes superiores anteriores humanos foram instrumentados com o sistema ProTaper ${ }^{\circledR}$, seccionados e removidos seus terços coronários e apicais. Os blocos preparados foram tratados com hipoclorito a $1 \%, 2 \%, 4 \%$ e $6 \%$ por 2, 5 e 20 minutos, em temperaturas de $20^{\circ} \mathrm{C}, 37^{\circ} \mathrm{C}$ e $45^{\circ} \mathrm{C}$ respectivamente. Os resultados foram medidos pela mancha de clareamento formada através de microscópio de luz com aumentos de 20 e 40 vezes. Os autores concluíram que a concentração, o tempo e a temperatura têm influência sobre a capacidade da 
penetração do hipoclorito na dentina, sendo que a temperatura é o fator que afeta menos esta capacidade.

VIOLICH; CHANDLER (2010) realizaram, por meio de 408 trabalhos divulgados no PubMed, uma revisão literária, focando a relevância da camada de smear para a Endodontia. Os autores afirmaram que a remoção da camada de smear reforça a desinfecção do canal radicular e que, dentre os métodos atuais empregados para essa finalidade (química, ultrassom e técnicas utilizando laser), nenhum é totalmente eficaz. A maioria dos trabalhos recomenda o uso do EDTA alternado com hipoclorito de sódio para a limpeza do canal.

MICHETTI et al. (2010), em um estudo comparativo entre a tomografia de feixe cônico comparada a estudos histológicos de dentes humanos, afirmaram que a tomografia pode fornecer aos dentistas imagens de alta qualidade em 3 dimensões das estruturas dentais em função de sua resolução espacial. Ao comparar as reconstruções dos sistemas de canais em 3D com as secções histológicas, verificaram a fidelidade das reconstruções. Os autores afirmaram haver uma correlação muito forte entre a tomografia de feixe cônico com o estudo histológico dos dentes, sendo a tomografia um meio muito interessante, fácil de ser realizado e uma ferramenta não invasiva para ser usada.

ZHANG et al. (2010) avaliaram, por meio de MEV e MET, a capacidade de remoção da porção orgânica da dentina e o grau de erosão nas paredes dos canais radiculares após o uso de $\mathrm{NaOCI}$ seguido de EDTA. Dentina em pó foi imersa em $\mathrm{NaOCl} 5,25 \%$ ou $1,3 \%$ em diferentes tempos $(10,20,30,60,120,180$ e 240 minutos), seguido de irrigação com EDTA 17\% por 2 minutos. Antes e após o uso do EDTA $17 \%$, a dentina em pó foi examinada por meio da espectroscopia para verificação da perda de componentes orgânicos e inorgânicos. Os resultados 
mostraram que o uso de $\mathrm{NaOCl} 5,25 \%$ ocasionou maiores alterações na estrutura colágena, independentemente da irrigação posterior com EDTA 17\%. A erosão das paredes dentinárias foi observada apenas no grupo do $\mathrm{NaOCl} 5,25 \%$ seguido de EDTA 17\%. A erosão estendeu-se 10-15 micrometros abaixo da superfície da dentina após o uso de $\mathrm{NaOCl} 5,25 \%$ por 20 minutos. Os autores concluíram que o efeito destrutivo superficial do $\mathrm{NaOCl}$ é irreversível e independe do uso posterior de EDTA.

CRUZ FILHO et al. (2011) avaliaram o efeito de diferentes soluções quelantes na microdureza da dentina mais superficial do canal radicular. Trinta incisivos centrais superiores humanos foram extraídos e as raízes foram cortadas longitudinalmente em direção mesio-distal para expor toda a extensão do canal. Os dentes foram divididos em sete grupos de acordo com a irrigação final: EDTA 15\%, ácido cítrico $10 \%$, ácido málico $5 \%$, acido acético $5 \%$, vinagre de maçã, citrato de sódio $10 \%$ e um grupo controle sem irrigação. Um volume estandardizado de $50 \mu \mathrm{L}$ de cada solução quelante foi usada por 5 minutos. A microdureza da dentina foi medida, os dados foram analisados por meio de análise de variância e comparação múltipla de Tukey-Kramer com um nível de significância de $5 \%$. Os resultados demonstraram que o EDTA e o ácido cítrico tiveram os melhores efeitos, causando forte diminuição na microdureza da dentina, sem diferença estatística significante entre elas $(p>0.05)$. Ambos quelantes diferiram significativamente das outras soluções $(p<0.0001)$. O citrato de sódio e a água deionizada foram similares ( $p>0.05)$ e não afetaram a microdureza da dentina. Vinagre de maçã, ácido acético e ácido málico foram similares entre si $(p>0.05)$ e apresentaram resultados intermediários. Concluíram os autores que, à exceção do citrato de sódio, todas as 
soluções quelantes reduziram a microdureza da camada mais superficial da dentina da luz do canal, sendo o EDTA e o ácido cítrico os mais eficientes.

\section{A Quitosana}

A Quitosana é um polímero policatiônico natural (ONSØYEN; SKAUGRUD, 1990), que pode ser produzida a partir de resíduos da casca de caranguejos por processos que não prejudicam o meio ambiente (PETER, 1995) e que apresenta propriedades próprias aos polissacarídeos naturais, oferecendo inúmeras possibilidades de aplicação nas áreas de tecnologia, química, medicina e agricultura (SENEL et al., 2000a; JEON et al., 2000).

Estudando o mecanismo de quelação da Quitosana, BLAIR; HO (1981) e FOCHER et al. (1986), sustentaram a teoria de que dois ou mais grupos amino da cadeia de Quitosana ligam-se ao mesmo íon metálico (modelo da ponte). BLAIR; HO (1981) avaliaram a adsorção e difusão de íons cobre e de um corante, utilizando membranas de Quitosana contendo diferentes quantidades de íons cobre quelatados. Os resultados indicaram que, aumentando o teor de cobre sobre a membrana,diminui-se a taxa de difusão de íons através da membrana.

Diferentemente, DOMARD (1987) e PIRON; DOMARD (1998) defenderam a teoria de que apenas um grupo amino da estrutura da Quitosana é envolvido na ligação entre a substância e o metal. PIRON; DOMARD (1998) avaliaram, por meio da espectrofotometria, o mecanismo de interação que ocorre entre o quelante e íons de urânio. Os resultados mostraram que a saturação do polímero por íons de urânio ocorreu na proporção de 2:1, devido às propriedades intrínsecas da Quitosana. Os 
autores observaram a formação de um único tipo de complexo, caracterizado por ligações coordenadas dos grupos amino da Quitosana com íons urânio.

ONSØYEN; SKAUGRUD (1990) relataram que a Quitosana é um polímero policatiônico natural com várias aplicações como: tratamento de águas residuais para a remoção de metais pesados e isótopos de rádio; tratamento de águas para recuperação de metais valiosos; purificação de água potável; liberação controlada de metais essenciais para o crescimento de plantas e na melhora do sabor de alimentos cozidos e requentados na indústria alimentícia, por meio da quelação de ferro. Os autores salientaram que as interações dos metais com a Quitosana são complexas, apresentando processos simultâneos de adsorção, troca iônica e quelação. Por fim, chamaram a atenção para fato de que o grau de polimerização, a desacetilação e a distribuição dos grupos acetil na cadeia do polímero é de importância crucial para definir as características de interação entre a Quitosana e metal.

KLOKKEVOLD et al. (1991) avaliaram o efeito hemostático da Quitosana em ferimentos de coelhos, por meio dos tempos de sangramento (TS) e de coagulação (TC) sendo estes verificados em três momentos: no pré-operatório, no pósoperatório e antes do sacrifício dos animais. Os resultados revelaram que as incisões que receberam o composto com Quitosana apresentaram uma hemostasia $32 \%$ maior que o grupo controle.

MUZZARELLI et al. (1994) verificaram o efeito da Quitosana modificada em defeitos ósseos confeccionados cirurgicamente em côndilos femurais de ovelhas e tratados com e sem a Quitosana. Os resultados mostraram, que no período de 40 dias após a cirurgia, o grupo que recebeu o tratamento com a Quitosana respondeu 
diferentemente do grupo controle. Os autores concluíram que a Quitosana tem um forte potencial osteoindutor.

PETER (1995), revisando a literatura sobre as propriedades dos polissacarídeos naturais Quitina e Quitosana, ressaltaram que as características proeminentes das propriedades químicas e mecânicas desses materiais oferecem inúmeras aplicações, ainda pouco exploradas nas áreas da tecnologia, química, medicina e agricultura. Vários tipos de géis, membranas e fibras, incluindo materiais policatiônicos e solúveis em água, podem ser formados. Os autores enfatizaram, por fim, que a produção de Quitina e Quitosana, a partir de resíduos da casca de caranguejo, não são prejudiciais ao meio ambiente.

GUIBAL et al. (2000) avaliaram o mecanismo de quelação de molibdênio pela Quitosana e os possíveis fatores que interferem nesse processo. Concluíram que a interação entre o quelante e a substância era caracterizado pela "ancoragem" dos íons molibidênio nos grupos amino da Quitosana, sendo que associado a esse processo ocorria o mecanismo de troca iônica. Também verificaram que vários grupos amino podem também reagir com o mesmo grupo de molibidênio. O tipo de interação depende do íon metálico, de sua estrutura química e do pH da solução.

SENEL et al. (2000a) relataram que a quitosana é um polissacarídeo natural que tem atraído grande atenção dos pesquisadores no âmbito odontológico devido às suas propriedades de biocompatibilidade, biodegradabilidade, bioadesão e atoxidade diante do organismo humano.

SENEL et al. (2000b) avaliaram, in vitro, a atividade antifúngica da Quitosana associada ou não à clorexidina, assim como o tempo de liberação dessas substância na cavidade oral. Foram preparados géis e membranas de Quitosana com concentrações de 1 e $2 \%$ contendo clorexidina 0,1 ou $0,2 \%$. Os resultados 
evidenciaram que a liberação prolongada foi observada nas formulações em membrana e a maior atividade antifúngica foi obtida com gel de Quitosana $2 \%$ contendo clorexidina $0,1 \%$.

JEON et al. (2000) afirmaram que a Quitosana possui várias propriedades funcionais, as quais têm atraído grande interesse de pesquisadores, visto suas atividades biológicas e potenciais aplicações nas indústrias alimentar, farmacêutica, agrícola e ambiental. Muitos artigos científicos destacam a Quitosana como uma fonte potencial de materiais bioativos, sendo utilizados nas áreas farmacêutica e médica (efeito antibacteriano, agente antitumor, carreador para drogas, acelerador de cicatrização de feridas), na biotecnologia (carreador para enzimas e células, resina para cromatografia, matéria para membranas), no meio ambiente (tratamento de água), na agricultura (preparação de sementes, ativador de células de plantas, atividade antimicrobiana para patógenos de plantas), e no setor de cosméticos e alimentação (acelerador de absorção de ferro e cálcio, fonte de fibras).

RHAZI et al. (2002) avaliaram, por meio de diferentes técnicas, a influência da natureza do íon metálico no processo de quelação com a Quitosana. Os resultados mostraram que o polímero apresentou seletividade de acordo com o íon metálico na seguinte sequência de afinidade: $\mathrm{Cu}, \mathrm{Hg}, \mathrm{Zn}, \mathrm{Cd}, \mathrm{Ni}, \mathrm{Co}, \mathrm{Ca}, \mathrm{Eu}, \mathrm{Nd}$, Pr. Os autores salientaram que a seletividade parece não apresentar relação com o tamanho e dureza dos íons considerados, independentemente da forma de apresentação da Quitosana (filme, pó ou solução). Os estudiosos observaram que em função da capacidade quelante seletiva da Quitosana, a mesma pode ser utilizada como agente despoluente na recuperação de íons metálicos.

PARK et al. (2003) avaliaram, por meio de análise histológica, o comportamento da Quitosana no tratamento de defeitos intraósseos. Os defeitos 
foram confeccionados bilateralmente na maxila e mandíbula de cães e a Quitosana induziu a regeneração periodontal no tratamento de defeitos intraósseos com inibição apical da migração do epitélio juncional e aumento nas quantidades neoformadas de osso e cemento.

AKNCBAY et al. (2007) avaliaram o desempenho da Quitosana em gel 1\% e em uso associado ao metronidazol $15 \%$ para o tratamento coadjuvante da periodontite crônica, adotando parâmetros clínicos como: profundidade de sondagem, recessão gengival, índice de placa e sangramento gengival. Concluíram que a Quitosana isoladamente, bem como associada ao metronidazol, foi eficiente no tratamento coadjuvante da periodontite crônica.

PARK et al. (2008) avaliaram o efeito de diferentes materiais utilizados no enxerto de defeitos ósseos confeccionados em calvária de 75 ratos. Observaram que todos os grupos experimentais apresentaram maior formação óssea em relação ao controle. Concluíram os autores que defeitos intraósseos tratados com partículas de dentina em associação à Quitosana podem mediar um excelente efeito de neoformação óssea.

WU et al. (2008), pesquisando as propriedades biológicas de uma membrana complexa, composta de ácido hialurônico, colágeno e Quitosana. observaram ser a membrana capaz de induzir crescimento de fibroblastos sob sua superfície, promover alterações morfológicas das plaquetas durante a coagulação e apresentar efeito antimicrobiano contra Escherichia coli e Staphylococcus aureus. Os autores concluíram que a membrana apresentou propriedades efetivas de coagulação e compatibilidade celular, mostrando-se eficiente como agente antibacteriano.

BOYNUEĞRI et al. (2009) pesquisaram o tratamento da periodontite crônica tratada por meio da Quitosana isolada ou associada a uma membrana colágena ou 
a uma matriz óssea. Após os procedimentos periodontais básicos, medidas clínicas e radiográficas foram registrados no início do estudo e nos períodos de 3 e 6 meses após a cirurgia. Clinicamente, os autores não observaram diferenças entre os grupos, mas os dados radiográficos revelaram que todos os grupos apresentaram neoformação óssea com exceção do grupo controle. Concluíram que o gel de Quitosana, utilizado isoladamente ou em associação à matriz óssea desmineralizada ou à membrana colágena, foi eficiente como auxiliar para a regeneração óssea.

PILLAl et al. (2009) relataram que a Quitina e Quitosana são biopolímeros, apresentando imensas possibilidades de modificações mecânicas e químicas para formarem novas propriedades, funções e aplicações, especialmente na área biomédica, mas a utilização da Quitina tem sido restrita por sua insolubilidade e intratabilidade. Ressaltaram ainda que a Quitina é um material efetivo para suturas, essencialmente por sua biocompatibilidade, biodegradabilidade e atoxidade, juntamente com sua atividade antimicrobiana e baixa resposta imunológica, pontos que realçam imensas possibilidades para futuros desenvolvimentos. Esta revisão de literatura discutiu as várias maneiras reportadas de solucionar os problemas relacionadas à Quitina e Quitosana sob o ponto de vista químico e estrutural destes polímeros.

BALLAL et al. (2010) avaliaram, in vitro, o tempo de liberação de íons cálcio e as alterações de $\mathrm{pH}$ provocadas por medicações à base de hidróxido de cálcio com diferentes veículos. Após a biomecânica, os canais radiculares dos espécimes foram preenchidos com pasta de hidróxido de cálcio preparada com os seguintes veículos: G1- propilenoglicol; G2- polietilenoglicol 6000; G3- Quitosana; e G4- goma. Os dentes foram armazenados em frascos de vidro de forma a permitir que apenas o terço apical ficasse imerso em água destilada. Decorridos 30 dias, a solução do 
frasco foi coletada e analisada por meio de espectrofotômetro ultravioleta. Os resultados mostraram que a formulação com Quitosana apresentou a maior liberação de íons cálcio em comparação às demais. Os autores chamaram a atenção para o fato de a Quitosana apresentar-se como um veículo promissor à pasta de hidróxido de cálcio utilizada como medicação intracanal.

KONG et al. (2010) estudaram as propriedades da Quitosana e seu modo de ação por meio de revista de literatura, ressaltando a sua alta biodegradabilidade, sua atoxicidade e, principalmente, suas propriedades antimicrobianas. A inibição da mediação da Quitosana é afetada por vários fatores podendo ser classificados em 4 grupos: intrínseco, meio ambiente, microrganismos e apresentação. A sua ação antimicrobiana é ressaltada e salientaram que muitos estudos futuros sobre tal material devem ser considerados.

XIA et al. (2011), estudando por meio de revista de literatura as atividades da Quitosana e dos seus oligossacarídeos, ressaltaram que suas propriedades multifuncionais têm atraído especial interesse devido a suas atividades biológicas e aplicação potencial em alimentação, saúde, farmácia, agricultura, indústria e meio ambiente. Os autores salientam que muitos pesquisas focam a Quitosana como um material bioativo, mas a mesma também apresenta propriedades biológicas e propriedades físico-químicas. Devido a tais propriedades novas idéias de pesquisas surgirão e novas potencialidades de uso poderão ser descobertas.

SILVA (2011) avaliou a capacidade de limpeza do canal radicular por meio de agentes quelantes e desmineralizantes em um estudo, ex vivo, por meio de MEV e espectrometria dos compostos nos terços médio e apical dos canais radiculares. As soluções na irrigação avaliadas após o preparo dos canais com instrumentos rotatórios foram: EDTA 15\%, Quitosana 0,20\%, ácido cítrico 10\%, ácido acético 1\% 
e um grupo controle que não recebeu irrigação final. Utilizou-se $5 \mathrm{~mL}$ de soluções por 3 minutos. Após percorrer todo o canal, a solução extravasada via forame apical foi coletada e encaminhada para análise espectrométrica. Os espécimes foram seccionados longitudinalmente e encaminhados para MEV, tendo as fotomicrografias obtido avaliação por 3 examinadores que atribuíram escores a elas. Após análise estatística, observou-se que o EDTA 10\%, a Quitosana 0,20\% e o ácido cítrico removeram smear layer de maneira semelhante entre si, diferentemente do ácido acético $1 \%(p<0,05)$ e o controle e sem diferenças para os terços. A maior concentração de íons cálcio foi observada no EDTA 15\% e na Quitosana 0,20\% sem diferença entre si. Concluiu-se que as soluções de EDTA 15\%, Quitosana 0,20\% e ácido cítrico $10 \%$ foram eficientes na remoção da camada de smear dos terços. As soluções de EDTA $15 \%$ e Quitosana $0,20 \%$ promoveram o maior efeito desmineralizante, seguidas pelo ácido cítrico $10 \%$ e ácido acético $1 \%$.

\section{O sistema Self-adjusting file}

METZGER et al. (2010 a) introduziram o sistema Self-adjusting file $\left(\mathrm{SAF}^{\circledR}\right)$, um instrumento de conceito inovador. O instrumento $\mathrm{SAF}^{\circledR}$ é um tubo cilíndrico em $\mathrm{NiTi}$, apresentado como uma fina grade que se adapta à secção transversal do canal radicular. Um único instrumento é usado em todo o procedimento e deve ser introduzido em um canal previamente preparado até um instrumento tipo K \#20, sendo acionado por um contra-ângulo vibratório em pequenos movimentos de vaivém. A pressão circunferencial resultante permite que a superfície abrasiva remova gradualmente uma camada fina e uniforme de tecido duro de toda a superfície do canal radicular, resultando em um canal de secção transversal similar, 
mas aumentado ou dilatado. O estreitamento dos canais curvos também é reduzido pela alta flexibilidade do instrumento e pela ausência de um corpo metálico rígido, sendo a forma original do canal respeitada, tanto em sua secção transversal quanto em sua longitudinidade. O sistema $\mathrm{SAF}^{\circledR}$ é operado com um fluxo constante de irrigação, que penetra em todo o comprimento do canal, e que é ativado pela vibração e substituído, constantemente, durante todo o procedimento. Ele tem alta resistência mecânica, não ocorrendo fratura e, quando ocorrem falhas mecânicas, estas são limitadas a pequenas partes da grade que compõe sua porção ativa. Segundo os autores, o sistema $\mathrm{SAF}^{\circledR}$ representa um novo passo à frente no desenvolvimento da endodontia que deve vir a superar os sistemas rotatórios atuais.

HOF et al. (2010) estudaram as propriedades mecânicas do instrumento do sistema $\operatorname{SAF}^{\circledR}$ e sua aplicação no uso nos canais radiculares sob irrigação abundante. Os autores observaram que, por sua compressão contra as paredes dos canais radiculares e sua abrasividade, ele permite a remoção de tecido duro da superfície dos canais radiculares e, sob as condições experimentais usadas, nenhuma falha mecânica foi observada até 29 minutos de uso contínuo no interior dos canais, sendo que a eficácia do instrumento é reduzida em $40 \%$ após 30 minutos de uso e não há extrusão de solução irrigante pela região apical. Concluíram que o instrumento do sistema $\operatorname{SAF}^{\circledR}$ é elasticamente compressível e remove eficientemente a dentina pelo seu método de uso recomendado com perda mínima de eficácia.

METZGER et al. (2010b) estudaram a capacidade de limpeza do sistema $\mathrm{SAF}^{\circledR}$ em termos de remoção de dèbris e smear layer associada ao EDTA a 17\%, ao hipoclorito de sódio a 3\% e em alternância de uso. Observaram os autores que este 
protocolo de uso resulta em um canal limpo e quase que totalmente livre da camada de smear em toda sua superfície, nos terços cervical, médio e apical.

PETERS et al. (2010), por meio de microtomografia, estudaram a superfície dos canais, relacionando capacidade de remoção de dentina ao tempo de uso do sistema $\mathrm{SAF}^{\circledR}$. Verificaram as mudanças volumétricas dos canais comparando valores pré e pós operatórios bem como as áreas não preparadas. Observaram que o volume do canal aumenta com o tempo de uso, bem como diminuem as áreas não preparadadas com o aumento do tempo. Concluíram que o tempo de uso para aplicação clínica dependerá do quanto de dentina se intenta remover e feito através de uma seleção do instrumento do sistema $\operatorname{SAF}^{\circledR}$ pelo calibre apical do canal.

SIQUEIRA JR et al. (2010) analisaram a capacidade de desinfecção com o preparo químico-mecânico usando os sistemas rotatório e SAF ${ }^{\circledR}$. Utilizaram canais ovais infectados. Os resultados demonstraram que a redução da população bacteriana foi significativa com o uso dos dois sistemas e que o preparo de canais ovais com o sistema $\mathrm{SAF}^{\circledR}$ foi significativamente mais efetivo do que o preparo rotatório em reduzir a contagem de microrganismos. Concluíram os autores que o sistema $S A F^{\circledR}$ foi significativamente mais eficiente que o sistema rotatório utilizando seringa/agulha na desinfecção de canais ovais in vitro.

METZGER et al.(2011) avaliaram a qualidade do preparo e obturação de canais tratados com os sistemas rotatório e $\mathrm{SAF}^{\circledR}$ por meio de microtomografia. Os autores analisaram as áreas dos canais não tocadas pelo preparo anterior e posteriormente e, depois de obturados os canais por condensação lateral e $\mathrm{AH} 26^{\circledR}$, foram escaneados novamente e a área não tocada pelo material obturador analisada. Os autores observaram que uma maior porcentagem de área não tocada pelo instrumento e pela obturação foi encontrada no grupo do rotatório. Concluíram 
que o sistema $S A F^{\circledR}$ permite uma melhor modelagem e limpeza, além de uma melhor adaptação da obturação que aquela promovida pelo rotatório.

ADIGÜZEL (2011) realizou uma revista da literatura sobre o desenho, parâmetros de uso e apresentação do sistema $\mathrm{SAF}^{\circledR}$, afirmando que o mesmo foi projetado para as restrições de uso dos instrumentos rotatórios por se adaptar à secção transversal do canal.

VERSIANI et al.(2011) compararam por meio de microtomografia o preparo do sistema $\mathrm{SAF}^{\circledR}$ em canais achatados com o sistema rotatório. Observaram que o sistema rotatório apresentou mais áreas não tocadas pelo instrumento. Concluíram os autores que o sistema $\mathrm{SAF}^{\circledR}$ proporciona um canal mais homogênea e circunferencialmente preparado e, no terço cervical, um aumento significativo. $O$ diâmetro do preparo com o sistema $\mathrm{SAF}^{\circledR}$ no terço apical era equivalente àqueles canais preparados com um instrumento rotatório \#40.02.

PETERS; PAQUÉ (2011) fizeram um estudo com microtomografia do preparo dos canais de molares superiores utilizando o sistema $\mathrm{SAF}^{\circledR}$, de acordo com o protocolo de uso do fabricante, comparando mudanças no volume dos canais, área de superfície e geometria seccional antes e depois de seu uso e também avaliaram o transporte do canal e a porção de canal não preparado. Os resultados demonstraram que, por meio do uso do sistema $S A F^{\circledR}$, os canais foram homogênea e circunferencialmente preparados com pequeno transporte.

SOLOMONOV (2011) em uma avaliação de oito meses de uso clínico com o sistema $\mathrm{SAF}^{\circledR}$, observou que a sua utilização é simples e previsível, podendo ser aplicado em muitas situações clínicas, mas recomendam aos usuários iniciantes uma curva de aprendizado, indo dos casos mais simples aos mais complexos gradativamente. 
DE-DEUS et al.(2011) estudaram a otimização da qualidade de debridamento

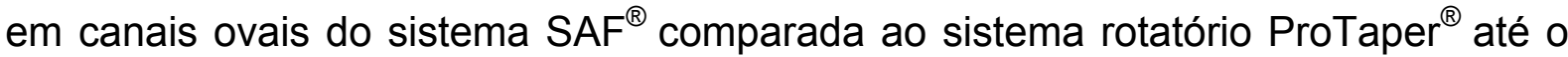
instrumento F2 por meio de a avaliação morfométrica, avaliando a porcentagem de remanescente pulpar nas paredes dos canais por área. Observaram que houve, significativamente, mais resíduos no sistema $\operatorname{ProTaper}^{\circledR}$ que no sistema $\mathrm{SAF}^{\circledR}$. Concluíram os autores que o protocolo de uso do sistema $\mathrm{SAF}^{\circledR}$ foi mais eficiente para o debridamento em canais ovais que o sistema ProTaper ${ }^{\circledR}$.

PAQUÉ; PETERS (2011) avaliaram por meio de microtomografia o preparo de canais ovais em raízes distais molares inferiores com o sistema $\mathrm{SAF}^{\circledR}$. Os canais foram modelados, reconstruídos tridimensionalmente e avaliados. Os resultados demonstraram que o volume e a superfície de área aumentaram significativamente e nenhum erro de preparo foi observado. A área não preparada do canal variou entre os canais individualmente, mas a área preparada foi significativamente maior comparada com sistema rotatório. O transporte do canal foi maior no terço coronário comparado ao apical. Os autores concluíram que o preparo com o sistema $\mathrm{SAF}^{\circledR}$ em canais longos e ovais foi efetivo e seguro e que, geralmente, a modelagem com este sistema foi mais completa quando comparada ao preparo rotatório.

ALVES et al. (2011) analisaram o efeito do tempo no uso do sistema SAF ${ }^{\circledR}$ com duas concentrações de hipoclorito de sódio diferentes (2,5 e 6 \%) em canais ovais contaminados. Não encontraram diferenças estatísticas significantes quando comparados os períodos de tempo de uso de 2, 4 e 6 minutos. Os resultados demonstraram que o uso do sistema $\mathrm{SAF}^{\circledR}$ por 6 minutos promoveu significativa redução tanto de contagem bacteriana quanto de culturas positivas. Concluíram os autores que o sistema $\mathrm{SAF}^{\circledR}$ promove uma redução bacteriana significativa mesmo depois de 2 minutos, de uso independente da concentração de hipoclorito, mas os 
resultados mais significativos foram obtidos após 6 minutos de uso com as duas concentrações testadas.

KAYA et al. (2011) estudaram, por meio da microscopia eletrônica de varredura, a erosão dentinária e a capacidade de remoção da camada de smear pelo sistema $\operatorname{SAF}^{\circledR}$, utilizando diferentes concentrações de hipoclorito de sódio $(1,3$, 2,6 e 5,25\%) associado ao EDTA a 1\%, por meio de microscopia eletrônica de varredura. Os resultados demonstraram não haver diferença estatística significante entre as diferentes concentrações e as diferentes regiões dos canais analisadas. As concentrações de 1,3\% e 2,6\% demonstraram padrão de erosão similar, já a 5,25\% encontrou-se um padrão severo de erosão. Os autores concluíram que, quando do uso do sistema $\mathrm{SAF}^{\circledR}$ com irrigação contínua e vibração, concentrações menores de hipoclorito e EDTA são recomendadas para uma remoção clínica eficiente da camada de smear mesmo no terço apical, evitando a erosão da dentina do canal.

Observa-se pela revista de literatura que a promoção de uma limpeza efetiva do sistema dos canais radiculares vem despertando o interesse dos pesquisadores. A melhor associação entre os instrumentos e as soluções para a remoção da camada de smear tem atraído atenção e estimulado a busca por novas alternativas que possam mostrar-se eficientes, aumentando o índice de sucesso das intervenções endodonticas. 
Proposição 
O objetivo do presente trabalho consiste em:

1 - Avaliar, por microscopia eletrônica de varredura (MEV), a limpeza das paredes dos canais radiculares instrumentados pelas técnicas rotatórias e Selfadjusting file $\left(\mathrm{SAF}^{\circledR}\right)$, com uso do $\mathrm{NaOCl}$ a $1 \%$ como solução irrigadora e o uso do EDTA a $15 \%$ e da Quitosana 0,20\% como soluções quelantes;

2 - Quantificar os íons cálcio removidos pelas diferentes soluções irrigadoras por meio de espectrometria de chama. 


\section{Materiais e Métodos}


Esse trabalho foi aprovado pelo Comitê de Ética em Pesquisa (CEP) da Faculdade de Odontologia de Ribeirão Preto da Universidade de São Paulo (FORPUSP) (CAAE nº 0058.0.138.000-11) (Anexo I) (Processo 2011.1.1127.58.9) (Anexo II). Foram utilizados 30 dentes caninos inferiores humanos cedidos pelo Banco de Dentes desta Instituição, que estavam armazenados em solução de timol a $0,1 \%$, em geladeira à temperatura de $9^{\circ} \mathrm{C}$ até o momento do experimento, quando então foram lavados em água corrente por 24 horas para a remoção de todos os traços da solução de timol, presente sobre a superfície dos mesmos.

Uma amostra inicial de 219 dentes (Figura 1) foi usada e, destes, foram selecionados os espécimes utilizados no trabalho após avaliação tridimensional, com uso do aparelho tomográfico de feixe cônico i-CAT (KAVO, USA) (Figura 2), Os critérios de inclusão utilizados foram: presença de canal radicular único, retilíneo, processo formativo completo (rizogênese e apicigênese) e ausência de calcificações em níveis coronários e radiculares.

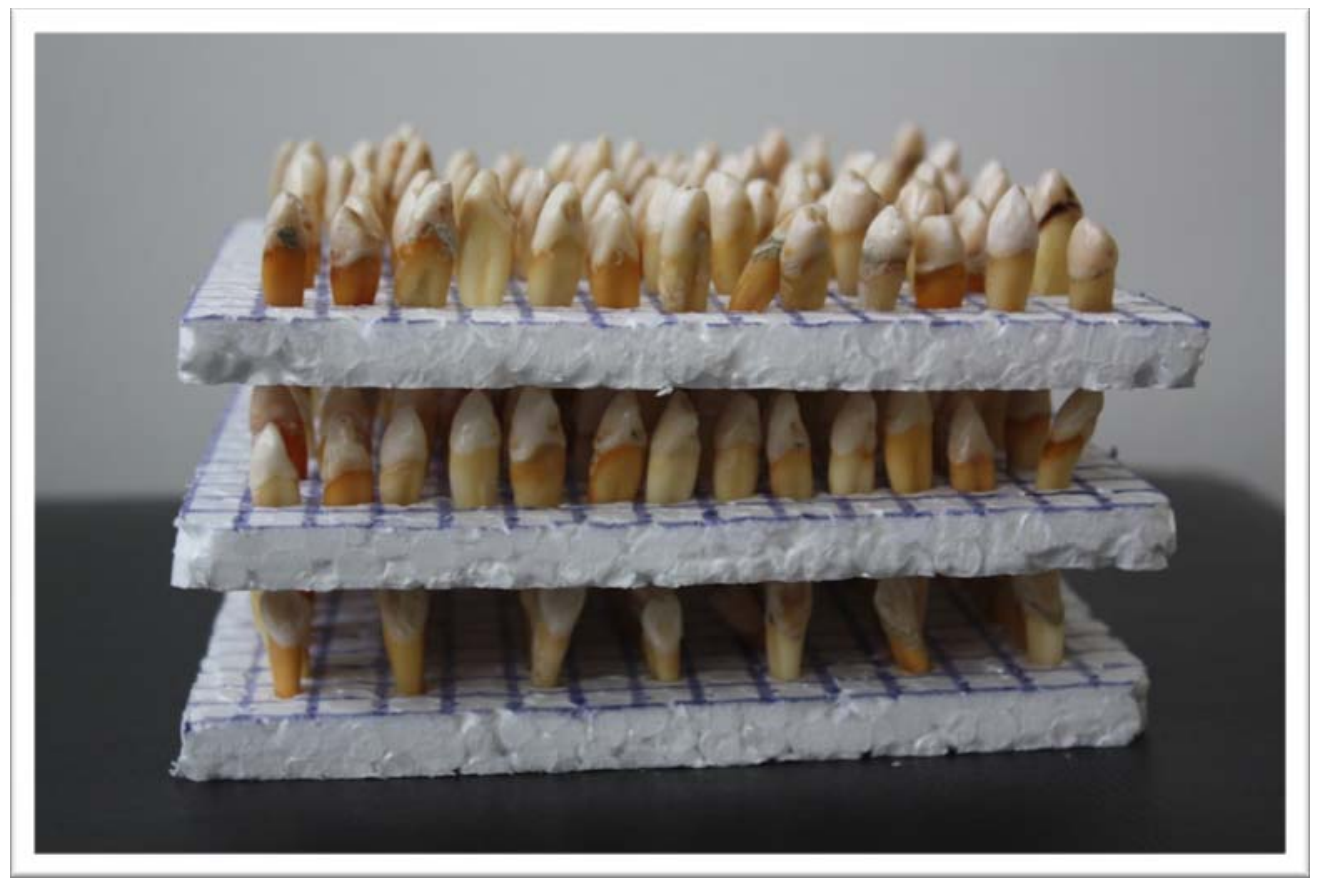

Figura 1. Espécimes preparados para tomografia de feixe cônico a fim de serem selecionados. 


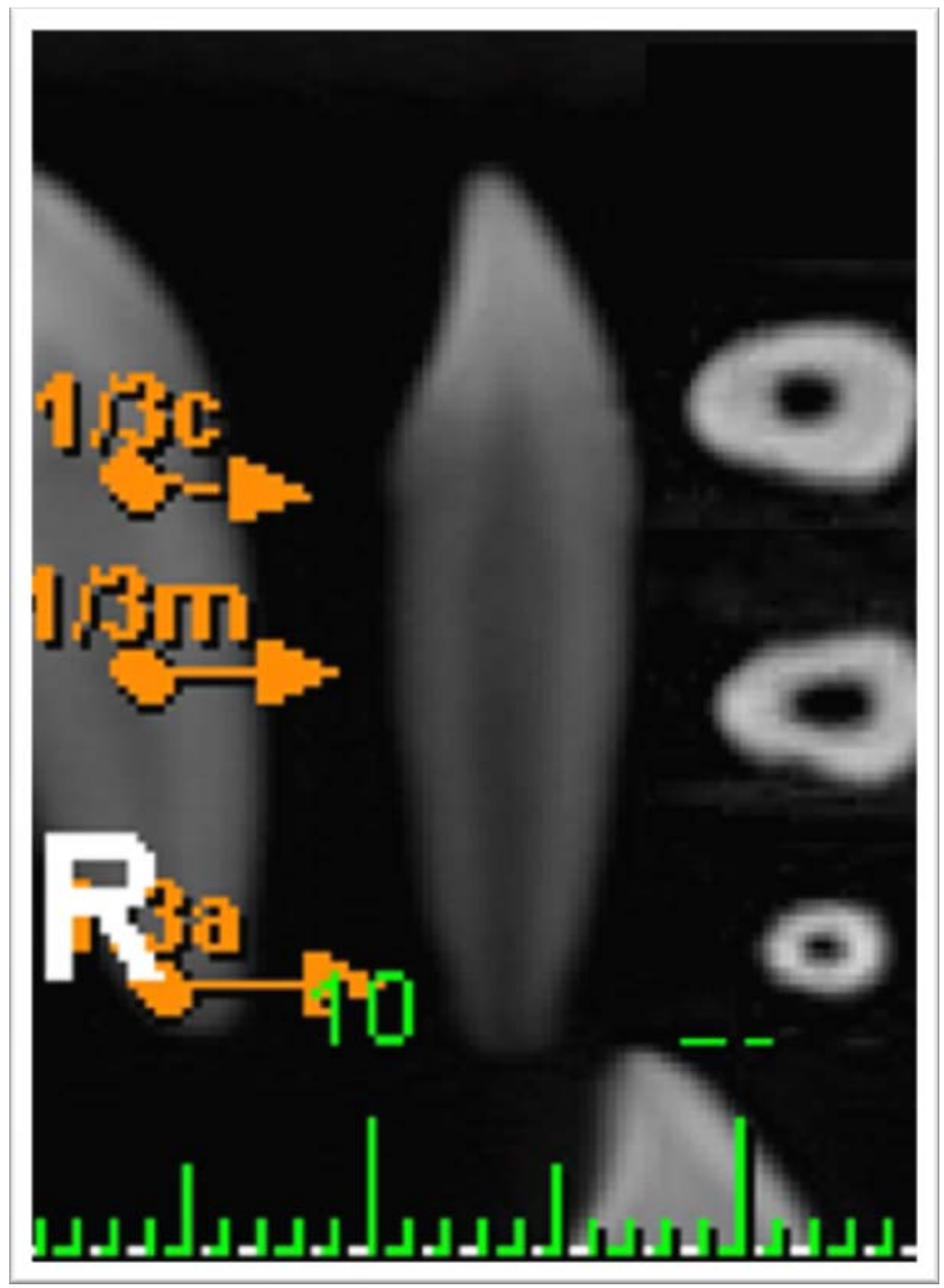

Figura 2. Estudo tomográfico para seleção dos elementos

\section{PREPARO DOS ESPÉCIMES}

Todos os elementos selecionados tiveram suas coroas seccionadas na altura da junção amelo-cementária, com disco de Carburundum (Dentorium, New York, NY, USA) acoplado a uma ponta reta e micromotor pneumático (Dabi Atlante, Ribeirão Preto, SP, Brasil) (Figura 3). 


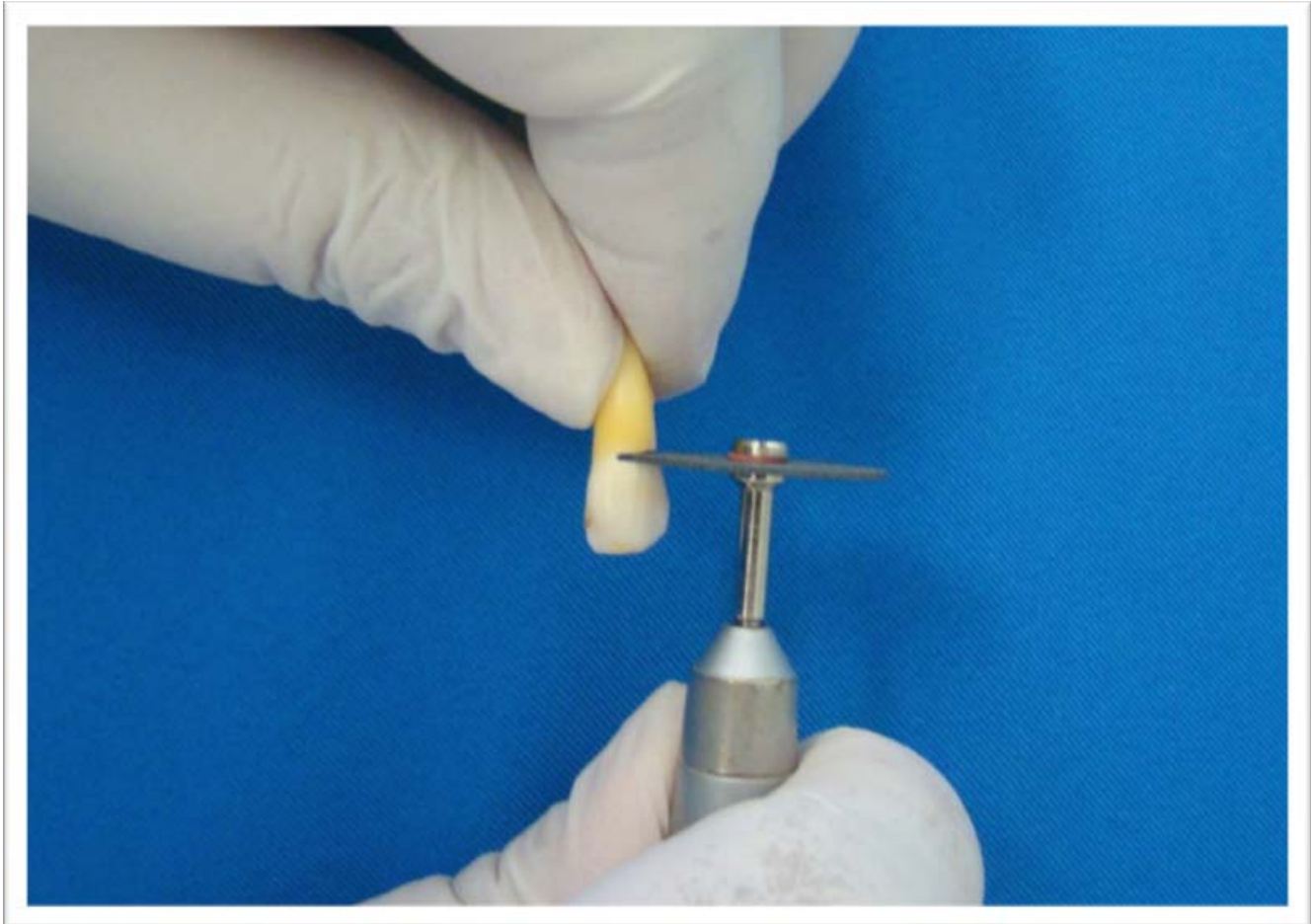

Figura 3. Ressecção coronária com disco de Carburundum

Após a ressecção coronária, foi feito preparo cervical com brocas La Axxess ${ }^{\circledR}$ (Sybronendo Corporation, West Collins, Orange, CA), acionadas por micromotor pneumático (Dabi Atlante, Ribeirão Preto, SP, Brasil), usadas em sequência ascendente de numeração de 1 a 3 ( $D_{0}=0,20 ; 0,35$ e 0,45, respectivamente).

Procedeu-se então à exploração dos canais radiculares com lima manual \#10 (Dentsply-Maillefer, Petrópolis, Rio de Janeiro, Brasil) para verificação de possíveis interferências anatômicas internas e remoção de eventual remanescente pulpar. Esse instrumento foi introduzido até a visualização de sua extremidade no forame apical e, desta medida, subtraiu-se $1 \mathrm{~mm}$ para a determinação do comprimento de trabalho $(\mathrm{CT})$.

Determinou-se o diâmetro anatômico (DA) no CT com instrumentos manuais do tipo K (Dentsply-Maillefer, Petrópolis, Rio de Janeiro, Brasil), mediante a escolha daquele que se adaptasse adequadamente no comprimento estabelecido. Os 
valores referentes ao CT e DA de cada espécime foram anotados individualmente (Anexo III).

Os dentes foram divididos em dois grupos, em função dos diferentes preparos biomecânicos que receberiam. O primeiro grupo $(n=15)$ foi preparado por meio do sistema FlexMaster ${ }^{\circledR}$ (VDW, Suíça) (Figura 4), acoplados ao motor elétrico X-Smart ${ }^{\circledR}$ (Dentsply-Maileffer, Suíça) pela técnica Free Tip Preparation (PÉCORA et al., 2002). Para este preparo, seguiu-se a ordem crescente dos instrumentos do DA determinado até o instrumento \#60.02, assegurando-se de ter havido a remoção de pelo menos $200 \mu \mathrm{m}$ de estrutura dentinária do terço apical, uma vez que o maior DA determinado foi correspondente a uma lima tipo $\mathrm{K} \# 40$.

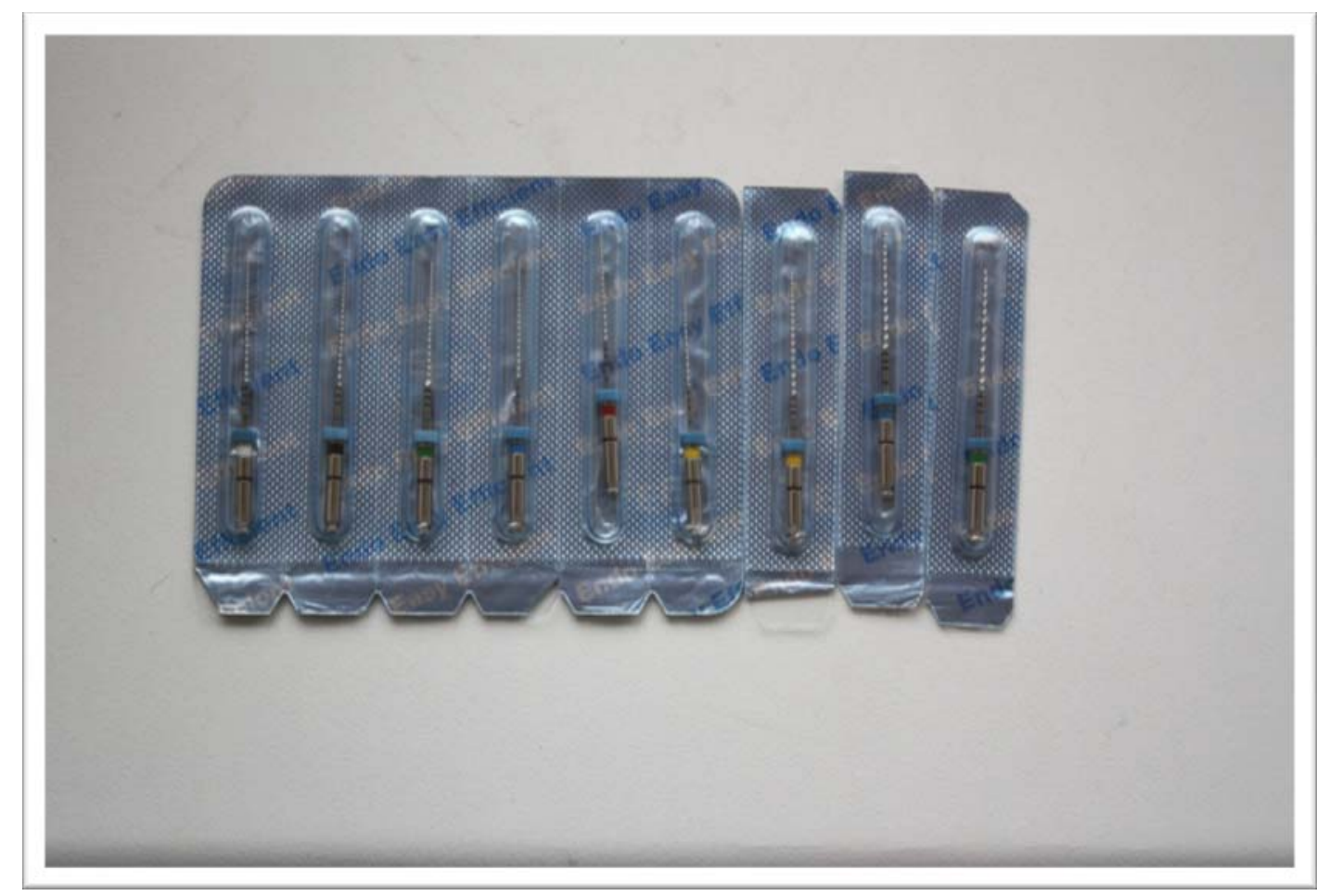

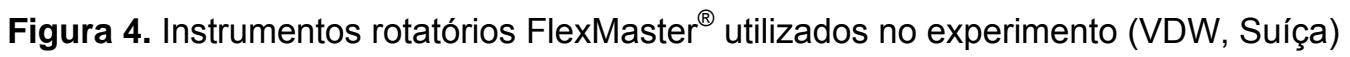


Durante a etapa de preparação dos elementos com o sistema rotatório, procedeu-se à irrigação/aspiração/inundação com $1 \mathrm{~mL}$ de $\mathrm{NaOCl} 1 \%$ entre a troca de cada instrumento e, ao final, mais uma irrigação com o mesmo volume.

A solução irrigadora foi introduzida no interior do canal radicular por meio de cânula de $21 \mathrm{~mm}$ de comprimento e gauge 29 (Nav Tip, Ultradent Products Inc., South Jordan, USA).

O segundo grupo $(n=15)$ foi preparado com o sistema Self-Adjusting File $\left(\mathrm{SAF}^{\circledR}\right)($ ReDentNOVA, Ra`anana, Israel) (Figura 5) de 1,5 mm, de acordo com as especificações do fabricante. Para a realização dessa técnica, utilizou-se o contraângulo recomendado pelo fabricante, $\mathrm{RDT}^{\circledR}$ (ReDentNOVA, Ra`anana, Israel), que promove movimento de vaivém de pequena amplitude $(0,4 \mathrm{~mm})$, acoplado a um motor elétrico (Nouvag, Samstag, Switzerland), ajustado na velocidade de 5000 rpm. O instrumento do sistema $\mathrm{SAF}^{\circledR}$ foi adaptado ao contra- -ângulo RDT3 ${ }^{\circledR}$ acoplado a uma bomba peristáltica VATEC (ReDentNOVA, Ra`ananá, Israel) para promover fluxo constante da solução irrigadora de $\mathrm{NaOCl} 1 \%$ de $5 \mathrm{~mL} / \mathrm{min}$, pelo tempo de 4 minutos.

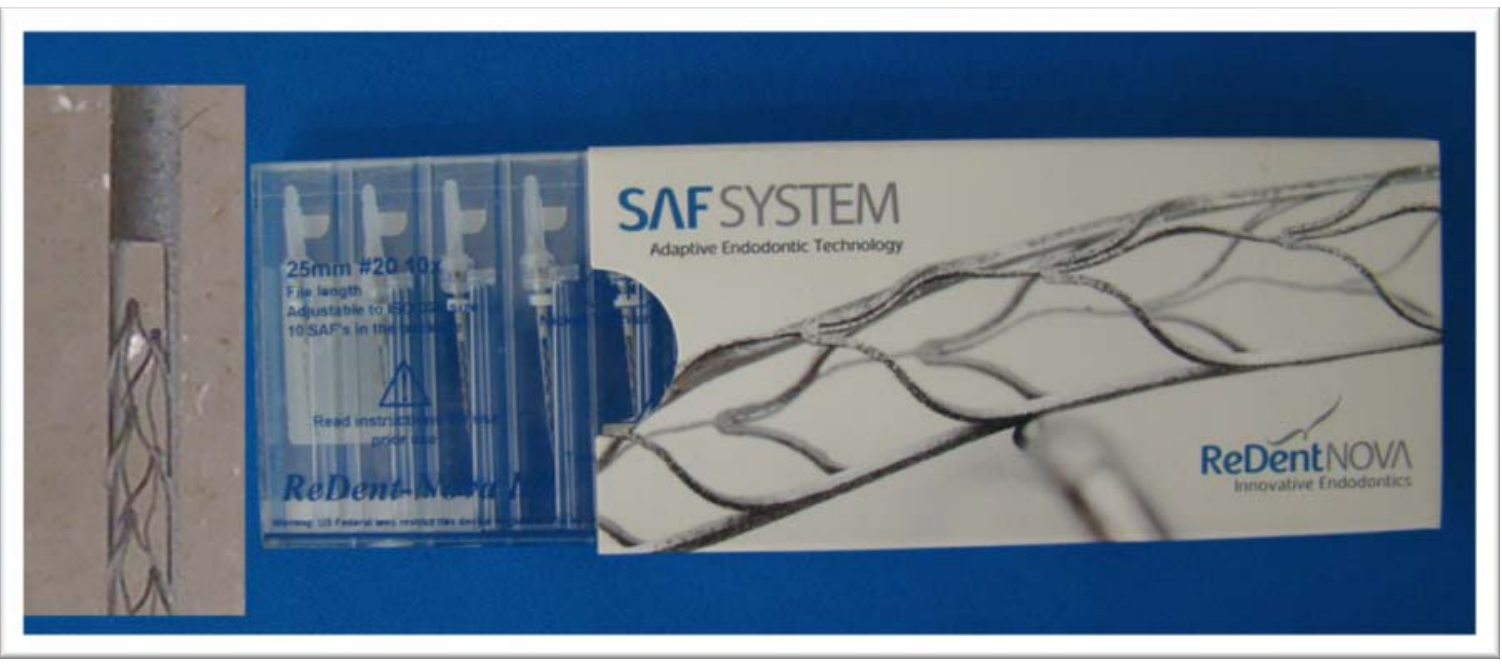

Figura 5. Instrumentos do sistema Self-adjusting file $\left(\mathrm{SAF}^{\circledR}\right)$ 
Após os preparos, todos os elementos foram secos por meio de aspiração por cânulas plásticas por 1 minuto (Ultradent Products Inc, South Jordan,USA).

\section{PREPARO DAS SOLUÇÕES UTILIZADAS}

As soluções utilizadas foram aviadas pelo Laboratório de Pesquisa em Endodontia da FORP-USP. As soluções e amostras foram preparadas com água purificada por meio de sistema de Osmose reversa com Luz Ultravioleta (Quimis, Diadema, SP, Brasil), com condutividade elétrica inferior a $1 \mu \mathrm{S}$.

\section{Hipoclorito de sódio a 1\%}

A solução de $\mathrm{NaOCl} 1,0 \%$ foi obtida por meio da diluição de solução com concentração inicial de $17,0 \%$.

\section{Ácido Etilenodiamino tetra acético Dissódico (EDTA 15\%)}

Em um béquer para $200 \mathrm{~mL}$, pesaram-se 17 gramas de EDTA (Merck KGaA, Darmstaldt, Germany) e adicionaram-se $100 \mathrm{~mL}$ de água destilada deionizada. A solução formada, com coloração branca, foi agitada por meio de agitador magnético e, em seguida, gotejou-se lentamente o hidróxido de sódio $5 \mathrm{~mol} . \mathrm{L}^{-1}$, até se obter pH de 7,25. Nesse momento, a solução esbranquiçada tornou-se límpida e transparente. $\mathrm{O}$ pH da solução foi aferido por meio de um pHmetro Analion. O EDTA, depois de aviado, foi colocado em recipiente plástico âmbar, dotado de batoque e tampa.

\section{Quitosana 0,20\%}

Em um béquer para $200 \mathrm{~mL}$, pesaram-se 0,2 gramas de quitosana (ACROS Organics, Geel, Belgium) e adicionaram-se $100 \mathrm{~mL}$ de ácido acético a $1 \%$. A mistura, que inicialmente é heterogênea, foi agitada por meio de agitador magnético 
por 2 horas, aproximadamente. Ao final, obteve-se uma mistura homogênea cristalina com $\mathrm{pH} 3,2$.

\section{DISTRIBUIÇÃO DOS GRUPOS}

Os elementos preparados com o sistema rotatório e com a SAF receberam irrigação final de $5 \mathrm{~mL}$ à velocidade constante de $1 \mathrm{~mL} / \mathrm{min}$, cronometrados, com as seguintes soluções: $\mathrm{NaOCI}$ 1\%, EDTA a 15\% e Quitosana a 0,20\%. Essas soluções, ao serem usadas, foram coletadas em um tubo do tipo Falcon, com capacidade para $15 \mathrm{~mL}$.

Para a coleta das soluções, perfurou-se a tampa do tubo do tipo Falcon de maneira a adaptar a porção cervical dos espécimes, de forma que os dentes fossem colocados nesse furo, com suas raízes para o lado interno do tubo. Um segundo furo foi feito na tampa onde se adaptou uma cânula aspiradora de baixa potência para direcionar a solução testada à região apical e induzir sua saída via forame caindo diretamente no tubo coletor (Figura 6a)

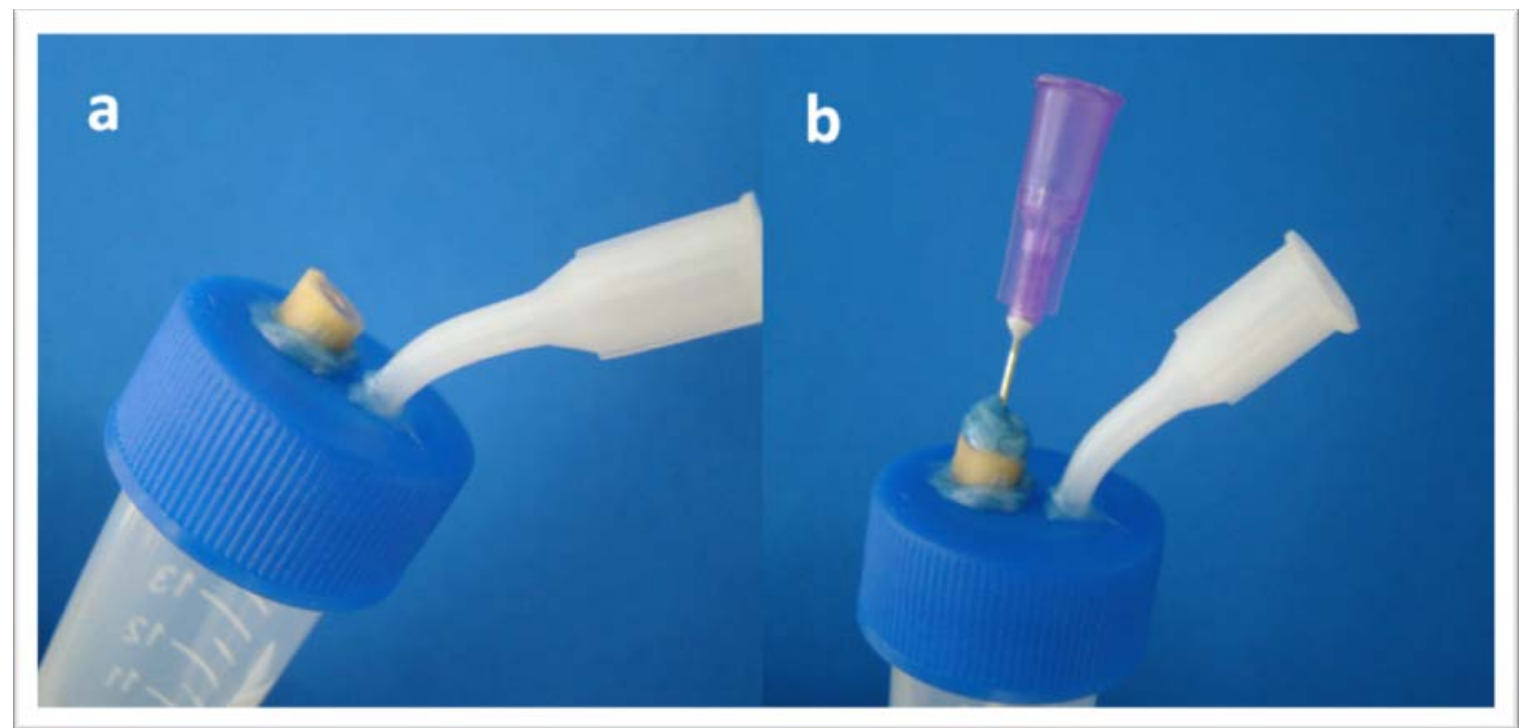

Figura 6. $\mathbf{a}$ - Dente adaptado ao tubo coletor; $\mathbf{b}$ - Seringa adaptada ao dente para coleta das soluções 
As soluções foram introduzidas no interior dos canais radiculares por meio de agulha de $0,45 \times 13 \mathrm{~mm}$ (BD, Franklin Lakes, NJ, USA - 26G 1/2), fixada na embocadura dos canais, individualmente, para cada espécime. A fixação das agulhas aos dentes foi feita com resina fotopolimerizável Top Dan Blue ${ }^{\circledR}$ (FGM/Dentscare, Joinvile, SC, Brasil), recobrindo todo o terço coronário para evitar possíveis refluxos da solução (Figura 5b).

Após as coletas das soluções, desacoplava-se a seringa com as soluções testadas e se acoplava uma nova seringa com $5 \mathrm{~mL}$ de água deionizada por um purificador tipo Milli-Q ${ }^{\circledR}$ Ultrapure Water Purification System (Millipore, Temecula, CA, USA), sendo esta colhida no mesmo tubo, removendo toda a solução do interior do canal radicular, ficando então, cada tubo, com volume final de $10 \mathrm{~mL}$ de solução recolhida a ser analisada.

Coletadas todas as amostras, a seringa de irrigação era desconectada da agulha adaptada ao elemento dental, a tampa plástica utilizada para fixação do dente era desacoplada do tubo tipo Falcon, que recebia uma nova tampa e era fechado, identificado e submetido à análise pela espectrometria de absorção atômica com chamas (Figura 7).

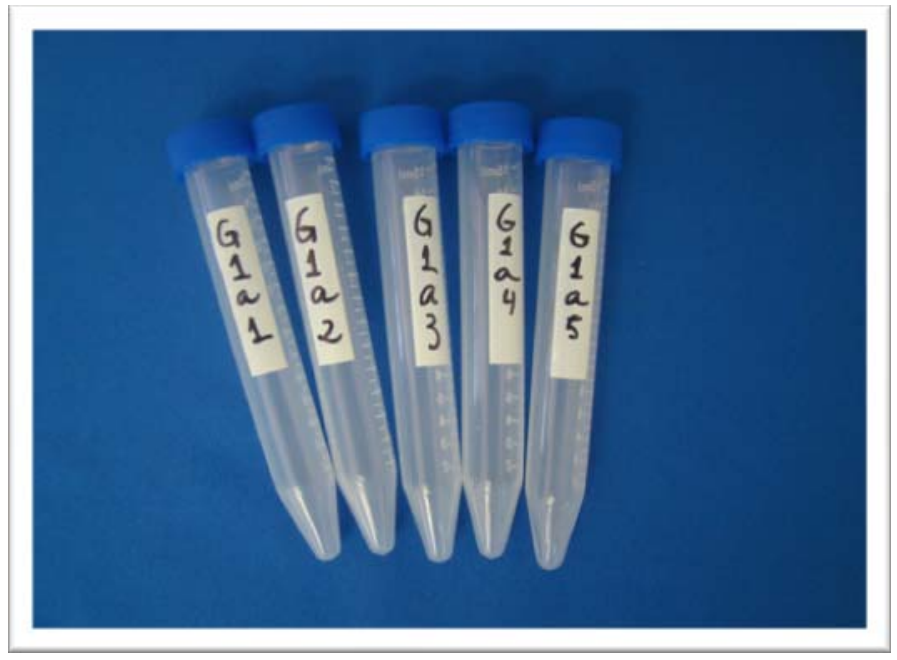

Figura 7. Tubos tipo Falcon identificados para receberem as soluções a serem analisadas 
ANÁLISE POR ESPECTROMETRIA DE ABSORÇÃO ATÔMICA COM CHAMAS (FAAS)

Para a determinação da concentração de íons cálcio removidos pelas diferentes soluções, utilizou-se um espectrômetro de absorção atômica com chama, modelo AAnalyst 800 (PerkinElmer, USA), da Faculdade de Química da Universidade de São Paulo, campus de Ribeirão Preto (Figura 8). Para medida dos sinais da absorbância, foram usadas lâmpadas de cátodo oco de cálcio PerkinElmer (Norwalk, EUA) e gás acetileno White Martins (SP, Brasil). O tempo de integração foi de 5 segundos. A vazão de acetileno, assim como a altura do queimador, foram ajustadas para se obter a melhor relação sinal/ruído.

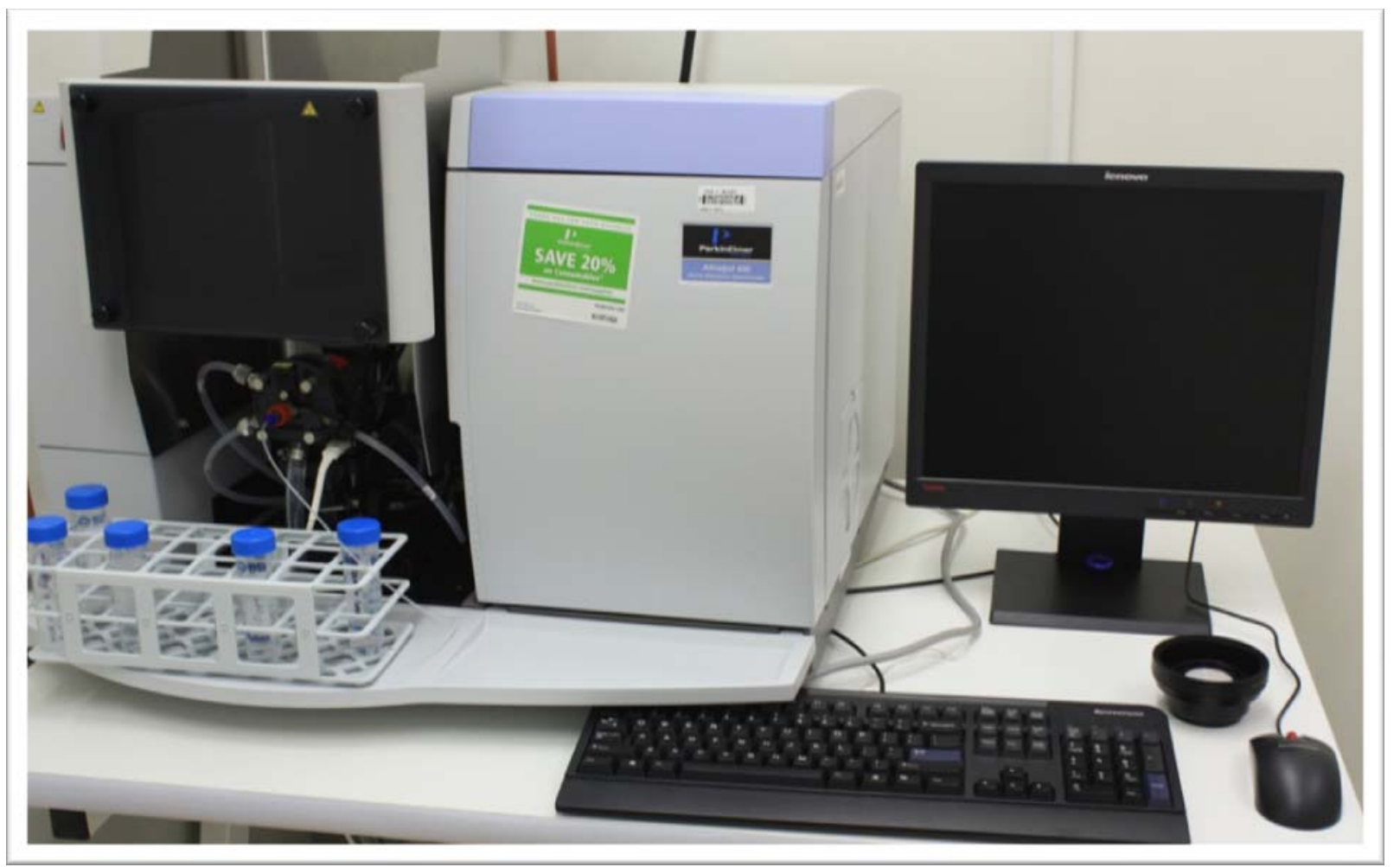

Figura 8. Espectrômetro de chama AAnalyst 800

Para o ajuste da curva de calibração do espectrômetro para íons cálcio, utilizou-se uma solução padrão de cálcio de concentração $1000 \mathrm{mg}$. L ${ }^{-1}$ (Ultra 
Scientific). As amostras das soluções a serem analisadas foram previamente diluídas em água deionizada para que as concentrações de cálcio se enquadrassem na curva de calibração supracitada. Na amostra da solução de quitosana, especificamente, a diluição foi realizada em solução de lantânio $0,1 \%$ (relação massa/volume), evitando assim a interferência da matriz polimérica da quitosana na quantificação de íons cálcio.

\section{ANÁLISE POR MICROSCOPIA ELETRÔNICA DE VARREDURA (MEV)}

$\mathrm{Na}$ sequência, os elementos foram seccionados, recebendo dois sulcos diametralmente opostos nas suas faces proximais, feitos com discos de Carburundum (Dentorium, New York, NY, USA), acoplados a motor pneumático em baixa rotação (Dabi-Atlante, Ribeirão Preto, SP, Brasil), com o cuidado para que os sulcos não atingissem o interior dos canais radiculares e, consequentemente, depositassem raspas de dentina sobre a superfície a ser analisada.

Os dentes foram então clivados utilizando-se de um cinzel bi-biselado. A porção que apresentasse menos irregularidades e com a melhor extensão do canal radicular a ser avaliado foi selecionada para ser submetida à microscopia eletrônica de varredura (MEV).

Os dentes seccionados foram submetidos à bateria ascendente de álcool etílico para sua desidratação $\left(50^{\circ}, 70^{\circ}, 80^{\circ}, 96^{\circ}\right.$ e absoluto), permanecendo 20 minutos em cada diferente concentração. Após desidratados, foram acondicionados em eppendorfs, com tampas abertas, e alocados em um desumidificador pelo período de 24 horas, a fim serem encaminhados para a realização da MEV. 
A realização da MEV exigiu que, primeiramente, fossem os elementos metalizados, recebendo cobertura ultrafina de material eletricamente condutor (30 $\mathrm{nm}$ ) e fixados com fita adesiva condutora de corrente elétrica em suportes metálicos, onde receberam uma tênue camada de ouro (Figura 9), por meio do aparelho Deskll Denton Vacuum (Tóquio, Japão) (Figura 10).

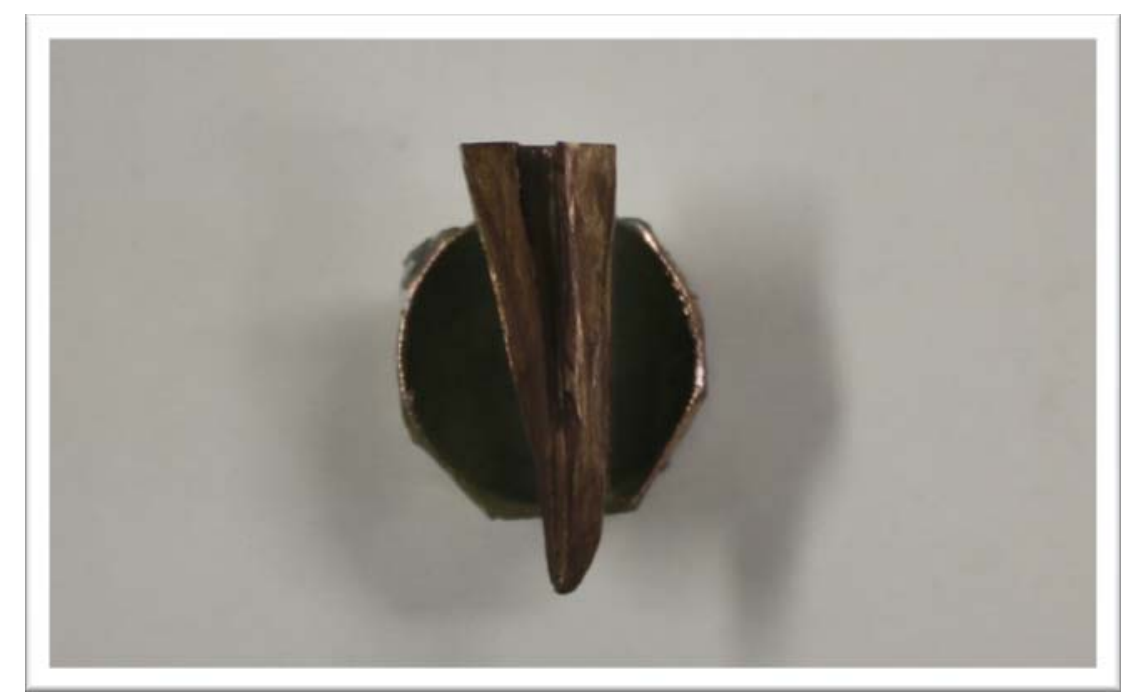

Figura 9. Elemento coberto com camada de ouro preparado para a MEV

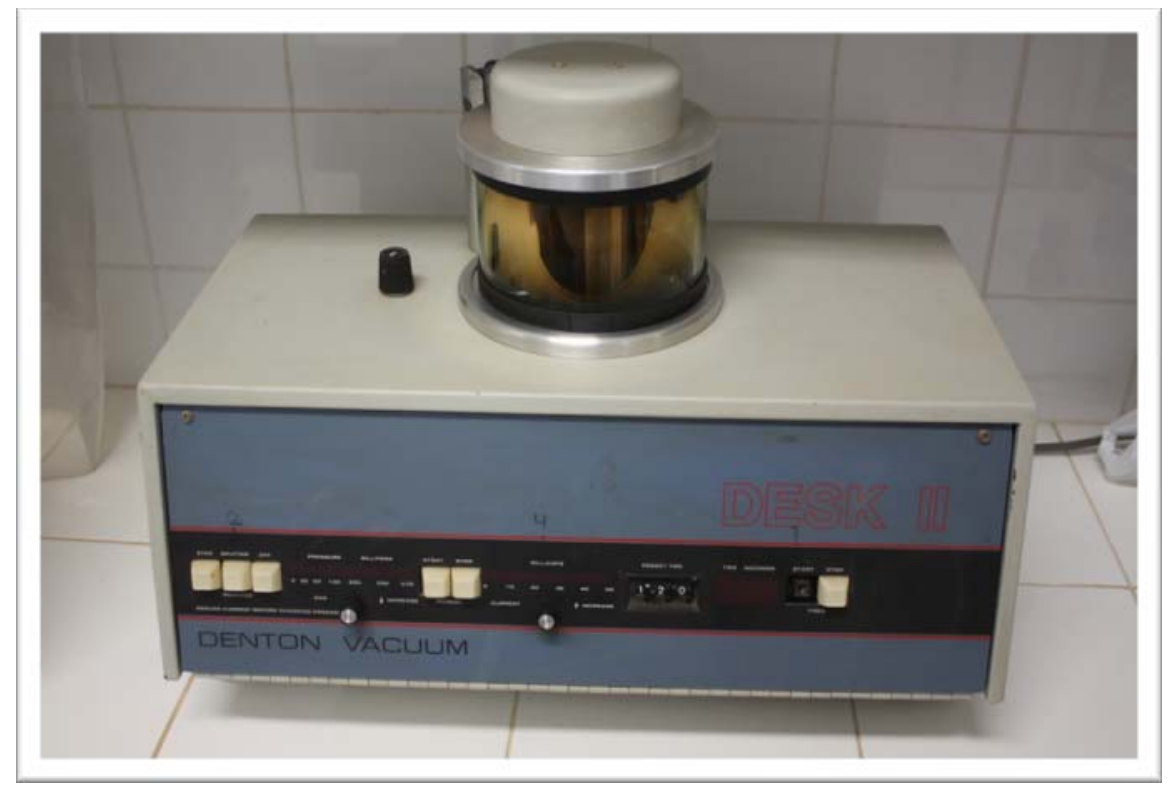

Figura 10. Aparelho para metalização dos corpos de prova Deskll Denton Vacuum 
O aparelho para a realização da MEV foi o Jeol JSM5410 (Jeol, Tóquio, Japão) (Figura 11). Cada elemento recebeu três fotomicrografias, sendo de 1000X o aumento, referentes aos três terços: cervical, médio e apical.

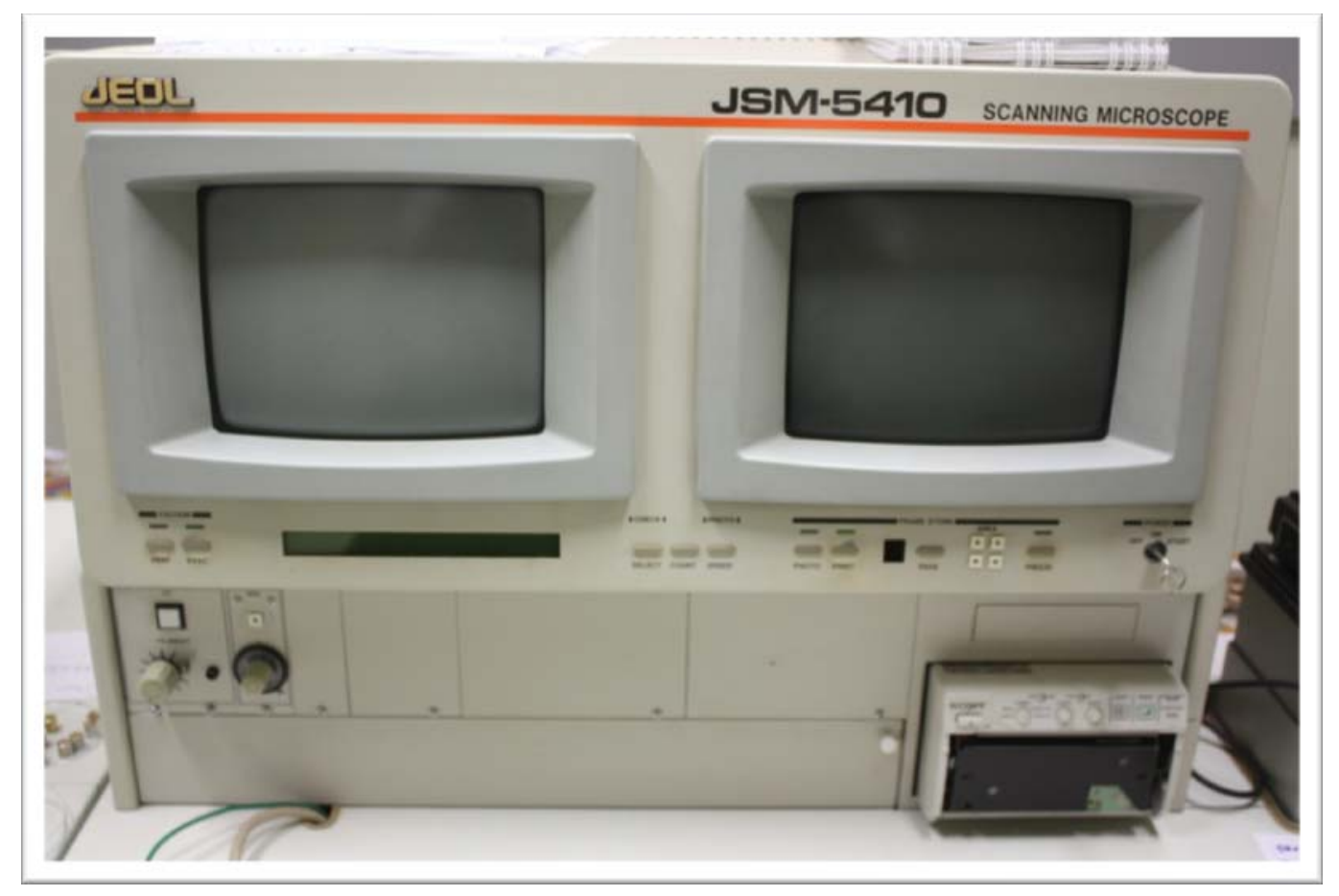

Figura 11. Microscópio eletrônico de varredura Jeol JSM5410

As fotomicrografias foram tabuladas sem identificação e submetidas à apreciação de 3 examinadores, previamente calibrados para a leitura e avaliação da limpeza. Os avaliadores, com a titulação mínima de mestres em Endodontia, atribuíram escores que variaram de 1 a 4 a cada fotomicrografia, conforme a quantidade de camada de smear observada nas parede dos canais radiculares.

Os escores em números absolutos, variando de acordo com a quantidade da camada de smear observada, foram: 1 (quantidade insignificante da camada de smear); 2 (pequena camada de smear e túbulos visíveis); 3 (camada de smear recobrindo a dentina e poucos túbulos visíveis); 4 (obliteração total dos túbulos dentinários pela camada de smear). 


\section{ANÁLISE ESTATÍSTICA}

Os resultados referentes à análise da quantidade de íons cálcio revelados pela espectrofotometria de absorção atômica com chamas, bem como os valores atribuídos à limpeza por meio de MEV, foram tabulados, montando-se assim um arquivo de dados e, posteriormente, submetidos à análise estatística.

A Figura 12 ilustra o fluxograma seguido na realização deste experimento. 


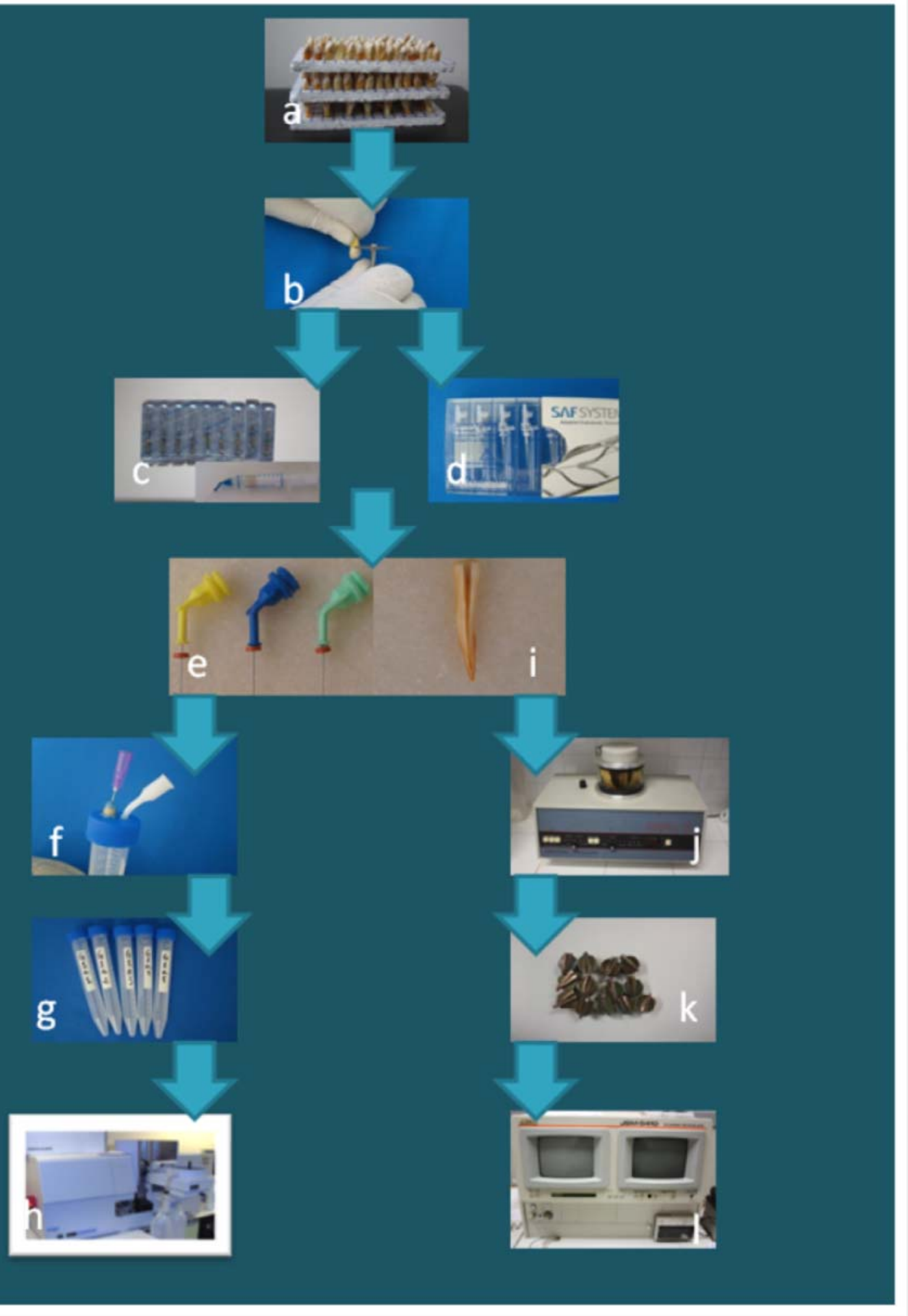

Figura 12. Fluxograma da metodologia. a) Seleção dos espécimes; b) Ressecção das coroas; c) Preparo com o sistema rotatório; d) Preparo com sistema SAF; e) Irrigação com as 3 diferentes soluções; f) Sistema preparado para a coleta das soluções de irrigação final; g) Soluções colhidas e armazenadas para espectrometria, h) Espectrômetro, i) Secção dos elementos preparados, j) Metalizador Desk II Denton Vacuum (Tóquio, Japão); k) Elementos metalizados para a MEV, I) Microscópio eletrônico de varredura Jeol JSM5410 (Jeol, Tóquio, Japão) 
Resultados 
Os resultados apresentados no presente estudo foram obtidos por meio da análise estatística dos dados provenientes de dois arquivos distintos, sendo um referente à quantidade de íons cálcio removida pelas soluções avaliadas e o outro aos escores atribuídos à limpeza dos terços cervical, médio e apical dos canais radiculares associada às diferentes técnicas de instrumentação e às soluções avaliadas. Dessa forma, visando facilitar a disposição e compreensão dos resultados, dividiu-se este capítulo em dois, como seguem:

\section{1 - ANÁLISE DAS CONCENTRAÇÕES ÍONS CÁLCIO REMOVIDOS PELAS SOLUÇÕES POR MEIO DE ESPECTROMETRIA}

O conjunto matemático segue um modelo composto por um fator de variação denominado soluções, formado por 3 grupos experimentais, sendo G1 (hipoclorito de sódio a 1\%), G2 (EDTA 15\%) e G3 (Quitosana 0,20\%).

Foram obtidos 30 dados provenientes da mensuração da concentração de cálcio, dados em miligramas por litro, após a irrigação final de 5 espécimes por grupo, associados às soluções e às diferentes técnicas de instrumentação estudadas $(5 \times 3 \times 2=30)$.

A Tabela 1 mostra os valores obtidos da concentração de cálcio por solução e por técnica estudada, valores expressos em $\mathrm{mg} / \mathrm{L}$. 
Tabela 1. Valores obtidos da concentração de cálcio em $\mathrm{mg} / \mathrm{L}$

\begin{tabular}{lccc}
\hline & Hipoclorito 1\% & EDTA 15\% & Quitosana 0,20\% \\
\hline Rotatório & n.detec & 63,7 & 21,0 \\
& n.detec & 70,4 & 20,3 \\
& n.detec & 93,0 & 40,1 \\
n.detec & 86,5 & 33,3 \\
& & 114,0 & 40,9 \\
n.detec & & \\
n.detec & 131,0 & 51,7 \\
& 0,64 & 99,4 & 35,8 \\
& n.detec & 76,2 & 27,7 \\
& n.detec & 88,2 & 34,0 \\
& & 75,4 & 23,0 \\
\hline
\end{tabular}

Legenda: $n$.detec - não detectável

Para análise estatística, foram comparados os dados da remoção de íons cálcio das soluções avaliadas em $\mathrm{mg} / \mathrm{L}$ obtidos pela espectrometria de absorção atômica de chamas (FAAS)

Diante da não normalidade da distribuição amostral, optou-se pelo teste de Kruskal-Wallis, por se tratar de amostras independentes.

Os resultados do teste $(\mathrm{KW}=26,29 ; \mathrm{p}<0,0001)$ demonstraram haver diferença estatística significante entre as três soluções. Para a determinação de quais soluções eram diferentes, em termos estatísticos, foi realizado o teste de Dunn cujos resultados são mostrados na Tabela 2.

Tabela 2. Valores da mediana, da soma de postos e do posto médio em cada grupo

\begin{tabular}{lccc}
\hline Grupos & Mediana* $^{*}$ & Soma de postos & Posto médio \\
\hline Hipoclorito & $0,00 \cdot$ & 55,00 & 5,50 \\
EDTA & $87,35 \cdot$ & 255,00 & 25,50 \\
Quitosana & 33,65 & 155,00 & 15,50 \\
\hline
\end{tabular}

* Símbolos diferentes indicam diferença estatística, $p<0,05$ 
Os resultados demonstraram haver diferença estatística significante entre a capacidade de remoção de íons cálcio do EDTA a 15\% comparado ao hipoclorito 1\% $(p<0,001)$; entre a Quitosana $0,20 \%$ e o hipoclorito $1 \%(p<0,01)$; entre o EDTA $15 \%$ e Quitosana 0,20\% (p<0,05).

Os resultados evidenciam que o hipoclorito de sódio a $1 \%$ não tem capacidade para quelar íons de cálcio e que o EDTA a 15\% apresenta maior capacidade de quelar íons de cálcio que a Quitosana 0,20\% ( $p<0,05)$.

\section{2 - ANÁLISE dA LIMPEZA DOS TERÇOS CERVICAL, MÉDIO E APICAL EM CANAIS RADICULARES PROMOVIDA POR DIFERENTES TÉCNICAS DE INSTRUMENTAÇÃO E SOLUÇÕES POR MEIO DE MEV}

O conjunto matemático segue um modelo composto por um fator de variação denominado soluções, formado por 3 grupos experimentais, sendo G1 (hipoclorito de sódio a 1\%), G2 (EDTA 15\%) e G3 (Quitosana 0,20\%); outro chamado técnicas de instrumentação, sendo estas a instrumentação pelo sistema rotatório e a instrumentação pelo sistema Self-adjusting file $\left(\mathrm{SAF}^{\circledR}\right)$; outro chamado terços correspondente aos terços cervical, médio e apical dos canais radiculares estudados.

Foram obtidas 30 micrografias para cada solução avaliada referentes às imagens representativas da limpeza do terço cervical $(n=10)$, médio $(n=10)$ e apical $(n=10)$, sendo uma metade para cada sistema de instrumentação: rotatória e Selfadjusting file $\left(\mathrm{SAF}^{\circledR}\right)$. Somaram-se, no total, 90 fotomicrografias de aumento de 1000x, avaliadas por 3 examinadores que atribuíram escores variando de 1 a 4 , conforme a quantidade da camada de smear observada. Assim, obtiveram-se 270 
dados de escores, sendo 135 referentes à técnica rotatória e 135 associados ao sistema $\mathrm{SAF}^{\circledR}$.

Os dados dos escores foram submetidos ao Coeficiente Kappa, que teve por objetivo analisar a confiabilidade da classificação das fotomicrografias feita pelos três examinadores. Esse teste descreve a intensidade de concordância entre examinadores e está baseado no número de respostas concordantes, ou seja, no número de casos cujo resultado seja concordante entre examinadores, além do que seria esperado, tão somente pelo acaso. Os valores obtidos pelo Kappa podem variar entre zero (ausência de concordância) e 1 (concordância perfeita). O valor encontrado neste experimento foi de $85 \%(I C=0,783-0928)$ que indica uma substancial concordância entre os examinadores, classificada como quase perfeita.

Para que os cálculos estatísticos fossem realizados, calculou-se a moda, ou seja, o valor que mais se repetia entre os três examinadores, o que gerou 90 dados com os quais se montou uma tabela com os resultados para cada terço estudado. Os escores atribuídos podem ser vistos na Tabela 3.

Tabela 3. Moda dos escores por grupo por meio de avaliação de três examinadores

\begin{tabular}{|c|c|c|c|c|c|c|}
\hline terços & Hipoclorito & $\begin{array}{c}\text { Rotatório } \\
\text { EDTA }\end{array}$ & Quitosana & Hipoclorito & $\begin{array}{l}\text { SAF } \\
\text { EDTA }\end{array}$ & Quitosana \\
\hline \multirow{5}{*}{ cervical } & 4 & 2 & 3 & 3 & 2 & 2 \\
\hline & 1 & 2 & 2 & 4 & 2 & 3 \\
\hline & 4 & 2 & 3 & 4 & 2 & 2 \\
\hline & 4 & 2 & 4 & 2 & 2 & 3 \\
\hline & 4 & 2 & 3 & 3 & 1 & 3 \\
\hline \multirow{5}{*}{ médio } & 4 & 4 & 2 & 3 & 2 & 2 \\
\hline & 1 & 2 & 2 & 4 & 1 & 3 \\
\hline & 3 & 2 & 3 & 3 & 1 & 3 \\
\hline & 3 & 2 & 4 & 3 & 1 & 2 \\
\hline & 4 & 1 & 2 & 4 & 2 & 2 \\
\hline \multirow{5}{*}{ apical } & 3 & 2 & 1 & 3 & 2 & 2 \\
\hline & 3 & 2 & 2 & 4 & 2 & 3 \\
\hline & 3 & 3 & 4 & 4 & 2 & 2 \\
\hline & 3 & 2 & 4 & 3 & 3 & 2 \\
\hline & 4 & 1 & 2 & 3 & 3 & 2 \\
\hline
\end{tabular}


Por se tratarem de escores, que são considerados pela estatística como variáveis subjetivas, optou-se pela realização do teste não-paramétrico para amostras independentes.

Para a análise estatística, foi feita a comparação entre as diferentes técnicas de instrumentação utilizadas, entre as soluções avaliadas, entre os terços estudados, da interação das técnicas utilizadas com as soluções avaliadas, da interação das técnicas utilizadas com os terços estudados e da interação das soluções avaliadas com os terços estudados.

\section{Comparação entre as técnicas utilizadas}

Optou-se pelo teste de Mann-Whitney, por se tratar de dois grupos a serem comparados.

Os resultados $(U=952 ; p>0,05)$ demonstraram não haver diferença estatística significante entre as duas técnicas na sua capacidade de remoção da camada de smear.

A Tabela 4 mostra os valores utilizados para a realização do teste.

Tabela 4. Valores do posto médio dos grupos e da soma de postos

\begin{tabular}{lcc}
\hline Técnicas & Média & Soma de postos \\
\hline Rotatório & 2,64 & 2108,00 \\
SAF & 2,53 & 1987,00 \\
\hline
\end{tabular}




\section{Comparação entre as soluções avaliadas}

Optou-se pelo teste de Kruskal-Wallis, por se tratar de 3 amostras independentes. Observa-se na Tabela 3 os resultados do teste de Kruskal-Wallis.

Os resultados deste teste $(K W=96,111 ; p<0,0001)$ demonstraram haver diferença estatística significante entre as três soluções. Para a determinação de quais soluções eram diferentes, em termos estatísticos, foi realizado o teste de Dunn cujos resultados são mostrados na Tabela 5 .

Tabela 5. Valores da mediana, da soma de postos e do posto médio em cada grupo.

\begin{tabular}{lccc}
\hline Grupos & Mediana $^{*}$ & Soma de postos & Posto médio \\
\hline Hipoclorito & $3,00 \bullet$ & 17217,00 & 191,29 \\
EDTA & $2,00 \cdot$ & 7407,50 & 82,31 \\
Quitosana & $2,50 \bullet$ & 11961,00 & 132,90 \\
\hline
\end{tabular}

* Símbolos diferentes indicam diferença estatística, $p<0,05$

Os resultados obtidos demonstraram, em relação à remoção da camada de smear, haver diferença estatística significante entre o EDTA $15 \%$ e o hipoclorito a $1 \%(p<0,0001)$; entre a Quitosana $0,20 \%$ e o hipoclorito a $1 \%(p<0,01)$; entre o EDTA e a Quitosana $(p<0,05)$, ou seja, o EDTA $15 \%$ promoveu maior remoção da camada de smear do que a Quitosana $0,20 \%$. O hipoclorito de sódio a $1 \%$ não removeu a camada de smear.

\section{Comparação entre os terços estudados}

O teste Kruskal-Wallis foi realizado para verificar a presença de diferença estatística entre os terços do canal radicular. Os resultados obtidos $(\mathrm{KW}=0,6154$; 
$p>0,05)$ demonstraram não haver diferença estatística significante entre os terços estudados, ou seja, para os três terços estudados, a limpeza promovida foi similar.

A Tabela 6 mostra os valores utilizados para a realização do teste.

Tabela 6. Valores da mediana, da soma de postos e do posto médio em cada grupo

\begin{tabular}{lccc}
\hline Terços & Mediana & Soma de postos & Posto médio \\
\hline Cervical & 2,50 & 1371,50 & 45,72 \\
Médio & 2,15 & 1284,50 & 42,82 \\
Apical & 2,85 & 1439,00 & 47,97 \\
\hline
\end{tabular}

\section{Interação entre as técnicas de instrumentação e as soluções}

\section{avaliadas}

Optou-se pelo teste de Kruskal-Wallis, por se tratar de seis amostras independentes.

Os resultados do teste $(\mathrm{KW}=100,43 ; \mathrm{p}<0,0001)$ demonstraram haver diferença estatística significante entre as técnicas de instrumentação e as soluções. Para a determinação de quais amostras eram diferentes, em termos estatísticos, foi realizado o teste de Dunn cujos resultados são mostrados na Tabela 7.

Tabela 7. Valores da mediana, da soma de postos e do posto médio em cada grupo

\begin{tabular}{lccc}
\hline \multicolumn{1}{c}{ Grupos } & Mediana* $^{*}$ & Soma de postos & Posto médio \\
\hline Rotatório/Hipoclorito & $4,00 \cdot$ & 8360,50 & 185,79 \\
Rotatório/EDTA & $2,00 \bullet$ & 3894,00 & 86,53 \\
Rotatório/Quitosana & $3,00 \cdot \bullet$ & 6647,00 & 147,71 \\
SAF/Hipoclorito & $3,00 \cdot$ & 8856,00 & 196,80 \\
SAF/EDTA & $2,00 \bullet$ & 3513,50 & 78,08 \\
SAF/Quitosana & $2,00 \bullet \bullet$ & 5314,00 & 118,09 \\
\hline
\end{tabular}

* Símbolos diferentes indicam diferença estatística, $p<0,05$ 
Os resultados obtidos demonstram, em relação à remoção da camada de smear, que a associação das técnicas de instrumentação rotatória e SAF $^{\circledR}$ ao EDTA $15 \%$ é superior à associação das técnicas rotatória e SAF a Quitosana $0,20 \%$ $(p<0,05)$; que a associação das técnicas rotatória e $\mathrm{SAF}^{\circledR}$ ao EDTA $15 \%$ é superior a associação das técnicas rotatória e $\operatorname{SAF}^{\circledR}$ ao hipoclorito $1 \%(\mathrm{p}<0,0001)$; que a associação das técnicas rotatória e $\operatorname{SAF}^{\circledR}$ a Quitosana $0,20 \%$ é superior à associação das técnicas rotatória e $\operatorname{SAF}^{\circledR}$ ao hipoclorito $1 \%(p<0,01)$.

\section{Interação das técnicas de instrumentação utilizadas e dos}

\section{terços estudados}

Optou-se pelo teste de Kruskal-Wallis por se tratar de amostras independentes. Os resultados do teste demonstraram que não havia diferença estatística significante $(K W=0,9668 ; p>0,05)$ entre a interação das técnicas de instrumentação rotatória e $\operatorname{SAF}^{\circledR}$ e os terços no que diz respeito à remoção da camada de smear.

A Tabela 8 mostra os valores utilizados para a realização do teste.

Tabela 8. Valores da mediana, da soma de postos e do posto médio em cada grupo

\begin{tabular}{lccc}
\hline Técnica/Terço & Mediana & Soma de postos & Posto médio \\
\hline Rotatório/cervical & 3,00 & 735,50 & 49,03 \\
Rotatório/médio & 2,00 & 682,00 & 45,47 \\
Rotatório/apical & 3.00 & 690,50 & 46,03 \\
SAF/cervical & 2,00 & 659,50 & 43,97 \\
SAF/médio & 2,00 & 614,50 & 40,97 \\
SAF/apical & 3,00 & 713,00 & 47,53 \\
\hline
\end{tabular}




\section{Interação entre as soluções avaliadas e os terços estudados}

Optou-se pelo teste de Kruskal-Wallis por se tratar de amostras independentes.

Os resultados do teste demonstraram que havia diferença estatística significante $(K W=35,199 ; p<0,0001)$ entre a interação das soluções e os terços. Para a determinação de quais amostras eram diferentes, em termos estatísticos, foi realizado o teste de Dunn cujos resultados são mostrados na Tabela 9.

Os resultados obtidos demonstram haver superioridade na ação do EDTA $15 \%$ nos três terços estudados sobre o hipoclorito a $1 \%(p<0,0001)$, da Quitosana $0,20 \%$ nos três terços estudados sobre o hipoclorito a $1 \%(p<0,01)$ e do EDTA $15 \%$ nos três terços estudados sobre a Quitosana 0,20\% $(p<0,05)$.

Tabela 9. Valores da mediana, da soma de postos e do posto médio em cada grupo

\begin{tabular}{lccc}
\hline Técnica/Terço & Mediana* $^{*}$ & Soma de postos & Posto médio \\
\hline Cervical/hipoclorito & $4,00 \bullet$ & 640,50 & 64,05 \\
Cervical/EDTA & $2,00 \cdot$ & 235,00 & 23,50 \\
Cervical/quitosana & $3,00 \bullet-$ & 519,50 & 51,95 \\
Médio/hipoclorito & $3,00 \bullet$ & 626,50 & 62,65 \\
Médio/EDTA & $2,00 \cdot$ & 243,50 & 24,35 \\
Médio/quitosana & $2,00 \cdot$ & 426,50 & 42,65 \\
Apical/hipoclorito & $3,00 \bullet$ & 657,50 & 65,75 \\
Apical/EDTA & $2,00 \bullet-$ & 350,50 & 35,05 \\
Apical/quitosana & $2,00 \bullet-$ & 395,50 & 39,55 \\
\hline
\end{tabular}

* Símbolos diferentes indicam diferença estatística, $p<0,05$

Pelos resultados obtidos observa-se que tanto na capacidade de remoção de íons cálcio quanto na capacidade de limpeza, ou seja, remoção da camada de smear, o EDTA 15\% apresentou um melhor comportamento que a Quitosana $0,20 \%$ e que ambas apresentaram melhores resultados que o hipoclorito de sódio a $1 \%$. 


\section{Resultado fotomicrográfico}

As Figuras $13,14,15,16,17$ e 18, a seguir, ilustram as imagens representativas dos resultados relacionadas às técnicas, soluções e terços radiculares. 


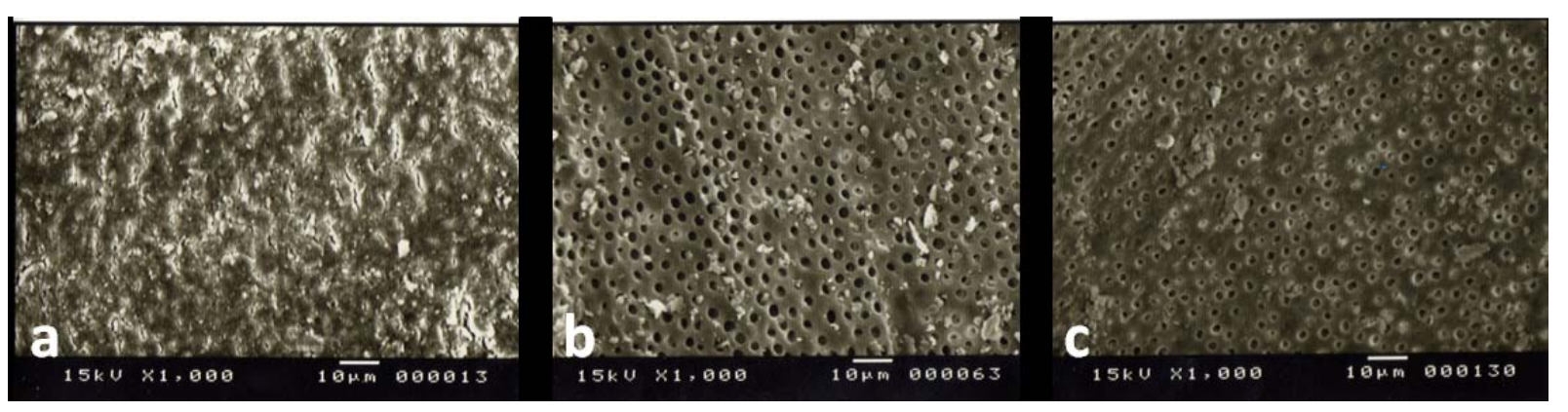

Figura 13. Fotomicrografias da superfície radicular interna (1000X) do terço cervical de dentes instrumentados com a técnica rotatória com as diferentes soluções: a) Hipoclorito de sódio 1\%; b) EDTA $15 \%$; c) Quitosana 0,20\%

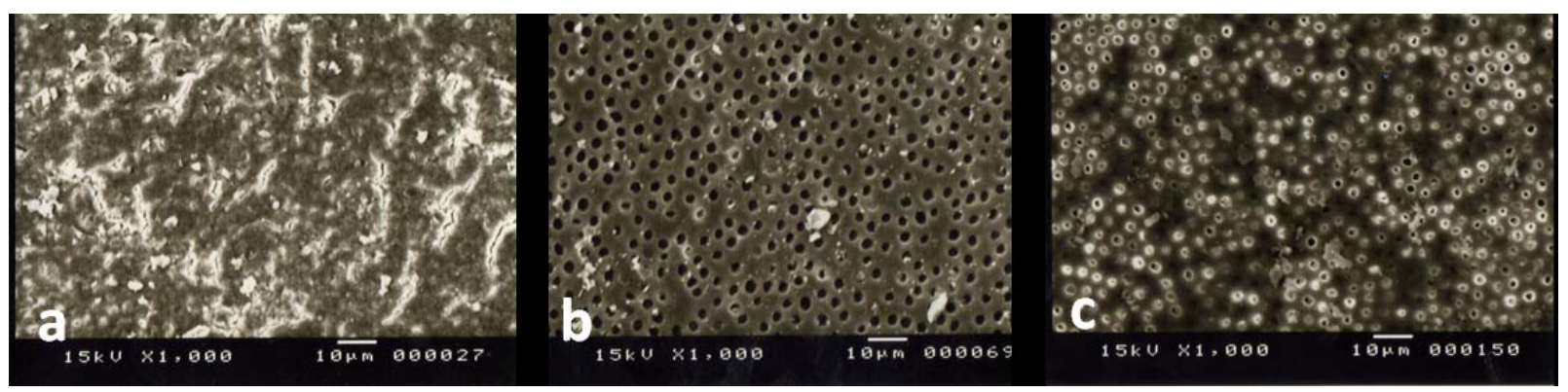

Figura 14. Fotomicrografias da superfície radicular interna (1000X) do terço médio de dentes instrumentados com a técnica rotatória com as diferentes soluções: a) Hipoclorito de sódio 1\%; b) EDTA 15\%; c) Quitosana 0,20\%

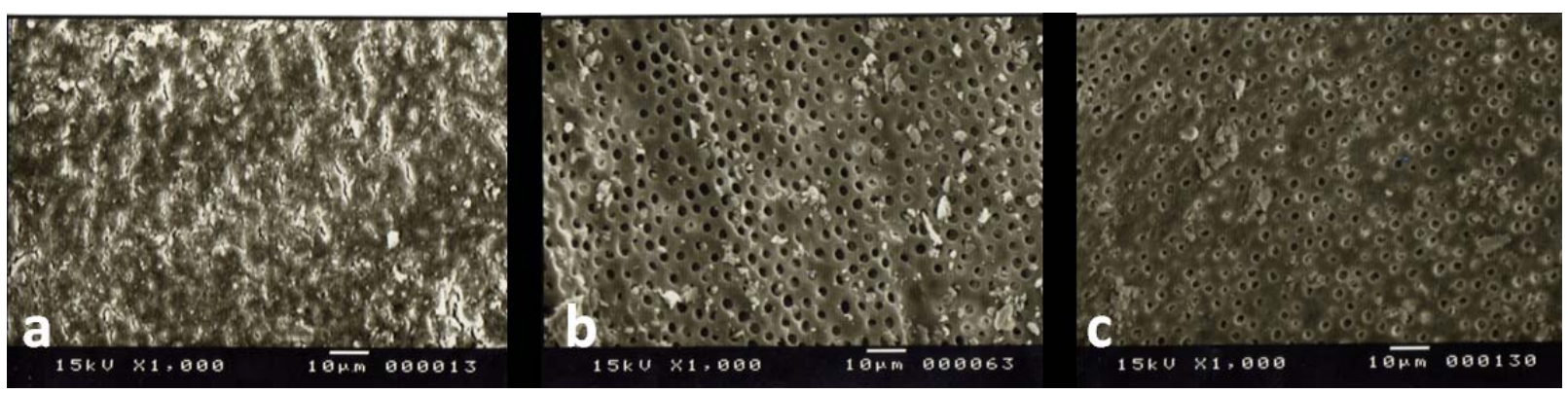

Figura 15. Fotomicrografias da superfície radicular interna (1000X) do terço apical de dentes instrumentados com a técnica rotatória com as diferentes soluções: a) Hipoclorito de sódio 1\%; b) EDTA $15 \%$; c) Quitosana 0,20\% 


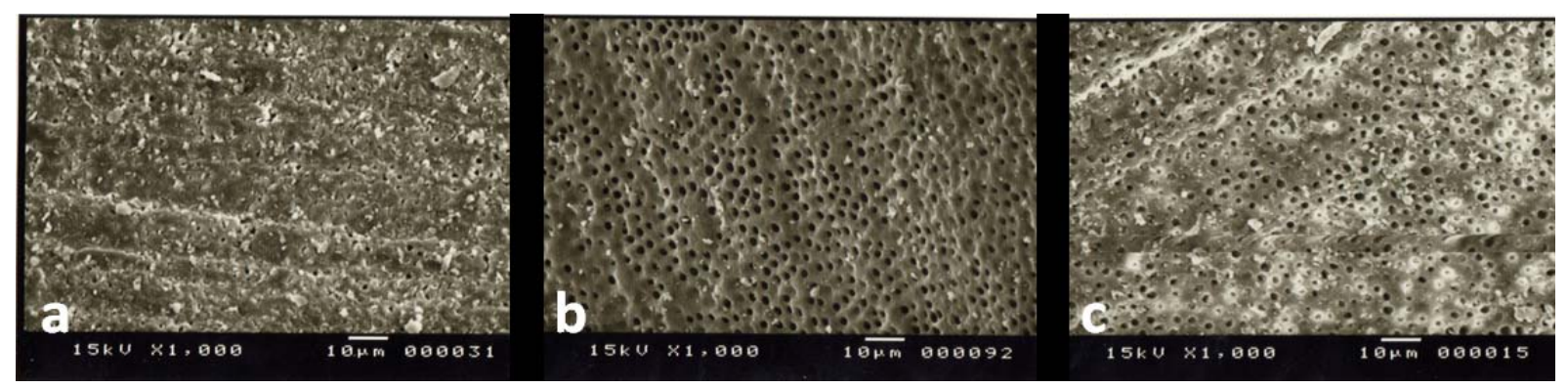

Figura 16. Fotomicrografias da superfície radicular interna (1000X) do terço cervical de dentes instrumentados com a SAF ${ }^{\circledR}$ com as diferentes soluções: a) Hipoclorito de sódio 1\%; b) EDTA $15 \%$; c) Quitosana 0,20\%
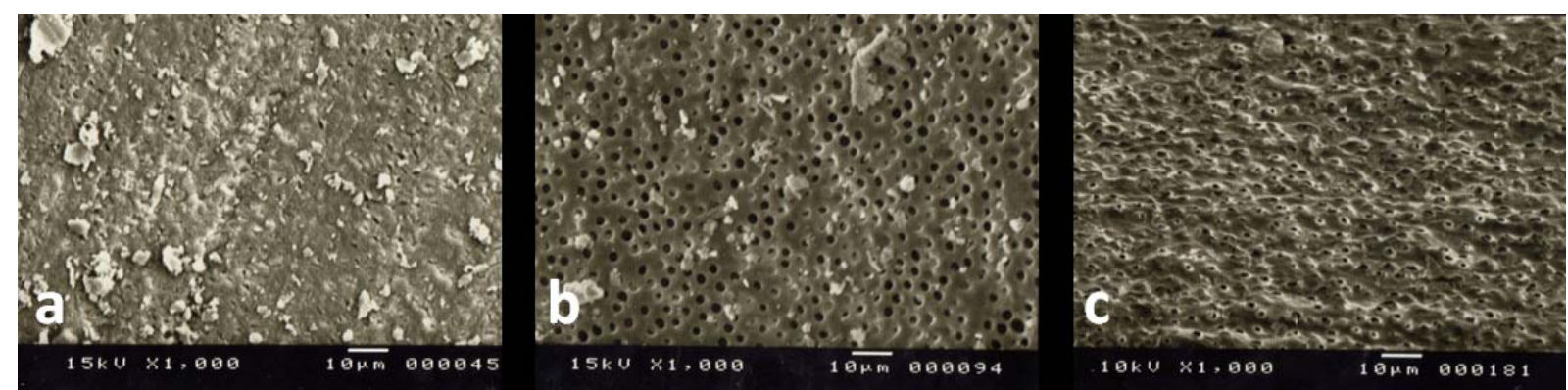

Figura 17 - Fotomicrografias da superfície radicular interna (1000X) do terço médio de dentes instrumentados com a SAF ${ }^{\circledR}$ com as diferentes soluções: a) Hipoclorito de sódio 1\%; b) EDTA $15 \%$; c) Quitosana 0,20\%
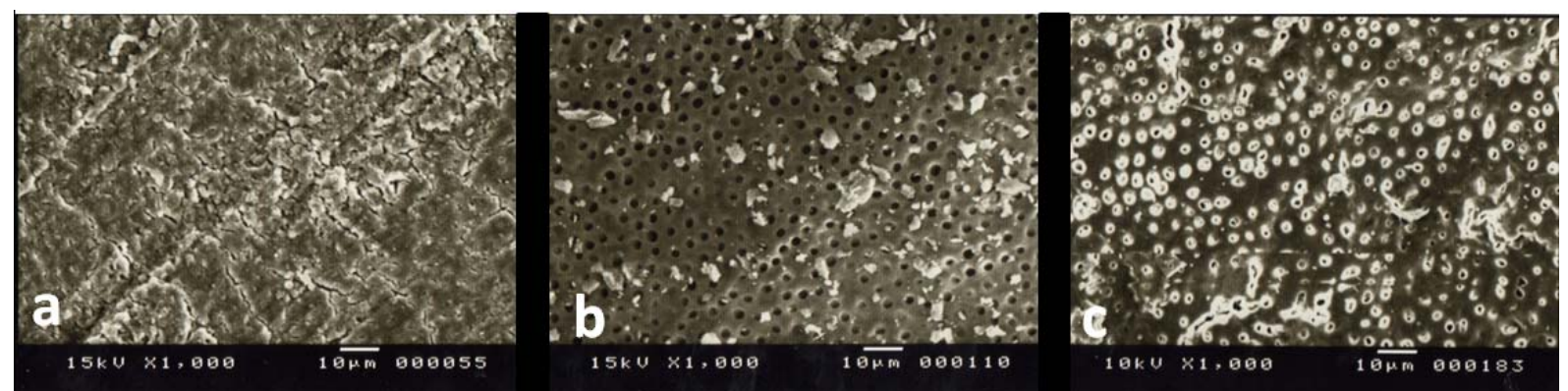

Figura 18 - Fotomicrografias da superfície radicular interna (1000X) do terço apical de dentes instrumentados com a SAF ${ }^{\circledR}$ com as diferentes soluções: a) Hipoclorito de sódio 1\%; b) EDTA 15\%; c) Quitosana 0,20\% 
Discussão 
O presente se desenvolveu a partir de duas avaliações distintas: a capacidade das soluções de NaOCI 1\%, EDTA 15\% e Quitosana 0,20\% de remover a camada de smear das paredes dos três terços de canais radiculares de caninos inferiores humanos quando utilizadas em associação com duas técnicas de instrumentação - a rotatória e a $S A F^{\circledR}$ - e a capacidade de remoção de íons cálcio promovida pelas soluções.

Para a avaliação da capacidade de remoção dos íons cálcio, utilizou-se a espectrometria de absorção atômica com chamas (FAAS) por ser um método que permite quantificar a concentração de íons presentes em uma solução e por ser o método eleito para tal finalidade em estudos das soluções de uso endodôntico (MARQUES et al., 2006; SPANÓ et al., 2009; SILVA, P.V., 2011).

A presença do cálcio na solução, após a irrigação, não provém exclusivamente da descalcificação da estrutura inorgânica da camada de smear, mas também da ação das soluções sobre o cálcio da matriz de hidroxiapatita da dentina, com consequente exposição do colágeno e redução da microdureza (SLUTZKY-GOLDBERG et al., 2004), interpretando-se assim que a maior concentração de íons cálcio removida aponta maior capacidade desmineralizadora e, consequentemente, maior capacidade de limpeza (SILVA, 2011.

Os resultados do presente trabalho evidenciaram a ineficiência do $\mathrm{NaOCl} 1 \%$ na remoção de íons cálcio, o que está de acordo com DAUTEL-MORAZIN et al.(1994), que demonstraram que essa solução não age sobre a matriz dentinária mineralizada, mas sim sobre a sua matriz orgânica. A superioridade do EDTA como solução quelante nos canais instrumentados encontrada no presente estudo está de acordo com achados da literatura (RAM, 1980; GOLDMAN et al., 1982; YAMADA et al., 1983; GARBEROGLIO; BECE, 1994; SCELZA et al., 2000; MENEZES et al., 
2003; PEREZ; ROQUEYROL-POURCEL, 2005; NAAMAN et al., 2007; CARVALHO et al., 2008; KHEDMAT; SHOKOUHINEJAD, 2008; LOTTANTI et al., 2009; SPANÓ et al., 2009).

Sobredita superioridade do EDTA é explicada pelo fato de ele reagir com um átomo metálico - como o cálcio, metal alcalino-terroso - e forma um complexo que o quela, formando um quelato de cálcio. Para que isso aconteça, é necessário que os grupamentos carboxílicos da molécula do EDTA liberem para o meio átomos de hidrogênio que competem com o átomo metálico. A este fenômeno dá-se o nome de ionização (HULSMANN et al., 2003).

A inclusão da Quitosana na presente pesquisa decorre da busca de novos materiais para uso endodôntico, de melhor eficiência e com menores efeitos indesejáveis. Seu uso para fins de quelação se deve ao fato de o EDTA apresentar potencial citotóxico (KOULAOUZIDOUL et al., 1999). Sua concentração tem aumentado muito nos rios e lagos do hemisfério norte (SPANÒ et al., 2009; SILVA, P.V., 2011) e, em decorrência da crescente preocupação com a saúde e o meio ambiente, tem-se buscado produtos alternativos, que possam ser de uso mais seguro. Assim, a Quitosana é testada como solução irrigadora, devido à sua biocompatibilidade, biodesintegração, atoxicidade (ONSØYEN; SKAUGRUD, 1990; MUZZARELLI et al. 1994; PETER, 1995; SENEL et al. 2000; JEON et al., 2000; PILLAl et al., 2009; BALLAL et al., 2010; KONG et al. 2010; XIA et al., 2010) e também à capacidade quelante (RHAZI et al., 2002; SILVA, P.V., 2011).

O uso da microscopia eletrônica de varredura (MEV), no presente trabalho, para avaliar a camada de smear se deve à sua ampla aceitação para esta finalidade, tendo sido o método por meio do qual se evidenciou a existência dessa camada pela primeira vez (McCOMB; SMITH, 1975) e permitiu que estudos sobre as 
características da camada de smear fossem realizados (GWINNETT, 1984; MADER et al. 1984; DAUTEL-MORAZIN et al. 1994). Inúmeros estudos sobre a camada de smear foram feitos por diversos pesquisadores, tais como: GOLDBERG; ABRAMOVICH, 1977; RAM, 1980; GOLDBERG; SPIELBERG, 1982; GOLDMAN et al. 1982; YAMADA et al. 1983; CZONSTKOWSKY et al., 1990; GARBEROGLIO; BECE, 1994; ECONOMIDES et al., 1999; SEN et al. 1995; NIU et al., 2002; TORABINEJAD et al., 2003; KOKKAS et al., 2004; PEREZ; ROQUEYROLPOURCEL, 2005; KHEDMAT; SHOKOUHINEJAD, 2008; LOTTANTI et al., 2009; METZGER et al., 2010b.

Os resultados de MEV obtidos nesse estudo permitiram observar que as duas técnicas de instrumentação utilizadas não interferiram na capacidade de remoção da camada de smear pelas soluções irrigadoras testadas, qualquer que fosse o terço radicular analisado, o que era de se esperar, já que a capacidade de quelação é uma característica da solução (HÜLSMANN et al., 2003) e não da técnica de instrumentação.

A interação do estudo das técnicas de instrumentação com as soluções irrigadoras testadas se deve ao fato de as diferentes técnicas possuírem cinemáticas diferentes dos instrumentos (METZGER et al., 2010a, HOF et al., 2010), o que, por hipótese, poderia gerar diferentes quantidades de smear, gerar calor de forma diferenciada e se valer de volumes desiguais de solução irrigadora, uma vez que a $\mathrm{SAF}^{\circledR}$ tem um fluxo constante de solução irrigadora durante seu uso e o rotatório recebe a irrigação alternada a cada troca de instrumento (METZGER et al., 2010a), fatores que poderiam interferir com a ação das soluções. No presente estudo, o volume de irrigação final de cada solução foi padronizado. 
Comparadas individualmente, o hipoclorito a $1 \%$ não apresenta capacidade de remover a camada de smear e as duas soluções quelantes utilizadas, sim, apresentando o EDTA a $15 \%$ um comportamento significativamente melhor que a Quitosana a $0,20 \%$, o que, como dito anteriormente, evidencia as capacidades quelantes das últimas e a ausência dessa qualidade na solução clorada, fatos descritos em pesquisas anteriores (GOLDMAN et al., 1982; YAMADA et al. 1983; GABEROGLIO; BECE, 1994, MENEZES et al., 2003, MARQUES et al., 2006, SPANO et al., 2009).

Deve-se ressaltar que, independentemente do sistema e instrumentos utilizados no preparo dos canais radiculares, a formação da camada de smear está presente. Ela é inerente ao ato operatório. Tal observação repete os achados de SEN et al.(1995), TORABNEJAD et al. (2002), e do presente experimento, pois o sistema rotatório e o $\mathrm{SAF}^{\circledR}$ apresentaram a camada de smear nas paredes dos canais radiculares, sem diferença estatística entre as técnicas.

Neste experimento, a superioridade do EDTA 15\% sobre a Quitosana 0,20\% se deu tanto na capacidade de remoção de íons cálcio, quanto na remoção da camada de smear. SILVA, P.V. (2011) observou que não havia diferença estatística significante entre o EDTA a $15 \%$ e a Quitosana a 0, 20\%, o que difere de nossos achados.

Há relação direta entre a quantidade de íons cálcio removida e a remoção da camada de smear, conforme observado em experimentos que utilizaram metodologia semelhante (MARQUES et al., 2006; SPANÓ et al., 2009 e SILVA, P.V., 2011), onde se nota que a maior capacidade de remoção implica em maior limpeza da mesma forma como ocorreu no presente estudo. 
Este trabalho abre perspectiva para novas investigações no que diz respeito à preconização da Quitosana como solução quelante para ser utilizada nos canais radiculares. Assim deve ser estudada a sua concentração ideal, seu tempo de ação e o volume a ser utilizado de forma a não promover grandes alterações na superfície da dentina. 
Conclusões 
120 | Conclusões 
Com base na metodologia empregada e nos resultados obtidos, é licito concluir que:

1- As soluções quelantes testadas - EDTA 15\% e Quitosana 0,20\% - foram capazes de remover íons cálcio do interior dos canais radiculares, com superioridade do primeiro sobre a segunda, e o $\mathrm{NaOCl} 1 \%$ não apresentou essa qualidade;

2- As soluções quelantes testadas - EDTA 15\% e Quitosana 0,20\% - foram capazes de remover a camada de smear das paredes dos canais radiculares, com superioridade do primeiro;

3- As técnicas de instrumentação dos canais radiculares avaliadas - sistemas rotatório e $\mathrm{SAF}^{\circledR}$ - não interferiram na remoção da camada de smear pelas soluções avaliadas. 
122 | Conclusões 
Bibliografia 
ADIGÜZEL, Ö. A literature review of Self Adjusting File. International Dental Restorative, v.1, n.1, p. 18-25, 2011.

AKNCBAY, H.; SENEL, S.; AY, Z.T. Application of chitosan gel in the treatment of chronic periodontitis. Journal of Biomedical Material Research, v. 80, n.2, p. 290296, 2007.

ALVES, F.R.F.; ALMEIDA, B.M.; NEVES, M.A.S.; RÔÇAS, I.N., SIQUEIRA JR, J.F. Time-dependent antibacterial effects of the self-adjusting file used with two sodium hypochlorite concentrations. Journal of Endodontics, v. 23, n. 4, p. 1451-1455, 2011.

BALLAL, N.V.; SHAVI, G.V.; KUMAR, R.; KUNDABALA, M.; SEETHARAMA, K. In vitro sustained release of calcium ions and $\mathrm{pH}$ maintenance from different vehicles containing calcium hydroxide. Journal of Endodontics, v.36, n.5, p.862-866, 2010.

BARBIZAM, J.V.B..; FARINIUK, L.F., MARCHESAN, M.A., PĖCORA, J.D.; SOUSANETO, M.D. Effectiveness of manual and rotary instrumentation techniques for cleaning flattened root canals. Journal of Endodontics, v. 28, n. 5, p. 365-366, 2002.

BARRET, M.T. The Dakin-Carrel antiseptic solution. Dental Cosmos, v. 59, n. 4, p. 446-448, 1917. 
BAUMGARTNER, J. C.; JOHAL, S.; MARSHALL, J. G. Comparison of the antimicrobial efficacy of $1.3 \% \mathrm{NaOCl} / \mathrm{BioP}$ ure MTAD to $5.25 \% \mathrm{NaOCl} / 15 \%$ EDTA for root canal irrigation. Journal of Endodontics, v. 33, n. 1, p. 48-51, 2007.

BERUTTI, E.; MARINI, R.; ANGERETTI, A. Penetration ability of different irrigants into dentinal tubules. Journal of Endodontics, v. 23, n. 12, p. 725-727, 1997.

BLAIR, H.S.; HO, T.C. Studies in the adsorption and diffusion of ions in chitosan. Journal of Chemical technology and Biotechnology, v.31, p. 6-10, 1981.

BOYNUEĞRI, D.; ÖZCAN, G.; SENEL, S.; UÇ, D.; URAZ, A.; ÖĞÜŞ, E.; ÇAKILCI, B.; KARADUMAN, B. Clinical and radiographic evaluations of chitosan gel in periodontal intraosseous defects: a pilot study. Journal Biomed Mater Res B Appl Biomater, v. 28, n.1, p. 17-19, 2009.

BUCHANAM, L.S. The standardized-taper root canal preparation - Part 1. Concepts for variability tapered shaping instruments International Endodontic Journal, v.33, n.6, p. 516-529, 2000.

BUCHANAM, L.S. The standardized-taper root canal preparation - Part 2. File selection and safe handpiece-driven file use. International Endodontic Journal, v.34, n.1, p. 63-71, 2001.

BUCK, R. A.; ELEAZER, P. D.; STAAT, R. H.; SCHEETZ J. P. Effectiveness of three endodontic irrigants at various tubular depths in human dentin. Journal of Endodontics, v. 27, n. 3, p. 206-208, 2001. 
ÇALT, S.; SERPER, A. Time dependent effects of EDTA on dentin structures. Journal of Endodontics, v. 28, n. 1, p. 17-19, 2002.

CARVALHO, A. S; CAMARGO, C. H; VALERA, M. C.; CAMARGO, S. E.; MANCINI, M. N. Smear layer removal by auxiliary chemical substances in biomechanical preparation: a scanning electron microscope study. Journal of Endodontics. v. 34, n. 11, p. 1396-400, 2008.

CRUZ FILHO, A.M.; SOUSA-NETO, M.D.; SAVIOLI, R.N.; SILVA, R.G.; VANSAN, L.P.; PÉCORA, J.D. Effect of chelating solutions on the microhardness of root canal lumen dentin. Journal of Endodontics, v. 37, n. 3, p. 358-362, 2011.

CZONSTKOWSKY, M.; WILSON, E.G.; HOLSTEIN, F.A. The smear layer in Endodontics. Dental Clinics of North America, v. 34, n. 1, p. 13-25, 1990.

DAKIN, H.D. On the use of certain antiseptic substances in treatment of infected wounds. British Medical Journal, v. 2, p. 318-320, 1915.

DAUTEL-MORAZIN, A.; VULCAIN, J. M.; BONNAURE-MALLET, M. An ultra structural study of the smear layer: comparative aspects using secondary electron image and backscattered electron image. Journal of Endodontics, v. 20, n. 11, p. 531-534, 1994. 
DE-DEUS, G.; SOUZA, E.M.; BARINO, B.; MAIA, J.; ZAMOLYI, R.Q.; REIS, C.; KFIR, A. The self-adjusting file optimizes debridement quality in oval-shaped root canals. Journal of Endodontics, v.37, n.5, p. 701-705, 2011.

DOMARD, A. $\mathrm{pH}$ and c.d. measurements on a fully deacetylated chitosan: application to Cull-polymer interactions. International Journal of Biological Macromolecules, v. 9, p. 98-104, 1987.

ECONOMIDES, N.; LIOLIOS, E.; KOLOKURIS, I.; BELTES, P. Long-term evaluation of the influence of smear layer removal on the sealing ability of different sealers. Journal of Endodontics, v. 25, n. 2, p. 123-125, 1999.

ESTRELA, C.; LOPES, H. P.; ELIAS, C. N.; LELES, C. R.; PÉCORA, J. D. Limpeza da superfície do canal radicular pelo vinagre de maçã, hipoclorito de sódio, clorexidina e EDTA.Revista da Associação Paulista de Cirurgiões-Dentistas, v. 61, n. 2, p. 117-122, 2007.

FLASCHKA, H.A. EDTA Titrations. 2 ed. London: Pergamon Press, 1967.

FOCHER, B.; MASSOLI, A.; TORRI, G.; GERVASINI, A.; MORAZZONI, F. High molecular weight chitosan 6-O-sulphate synthesis, ESR and NVR characterization. Makromoleculare Chemie, v.167, p. 2809-2820, 1986. 
GAMBARINI, G. Cyclic fatigue of nickel titanium rotary instruments after clinical use with low- and high- torque endodontics motors. Journal of Endodontics, v.27, n.12, p. 772-774, 2001.

GARBEROGLIO, R.; BECCE, C. Smear layer removal by root canal irrigants. Oral Surgery, Oral Medicine, Oral Pathology, Oral Radiology, and Endodontics, v. 78, n. 3, p. 359-367, 1994.

GOLDBERG, F.; ABRAMOVICH, A. Analysis of the effect of EDTAC on the dentinal walls of the root canal. Journal of Endodontics, v.3, n.3, p.101-105, 1977.

GOLDBERG, F.; SPIELBERG, C. The effect of EDTAC and the variation of its working time analyzed with scanning electron microscopy. Oral Surgery, Oral Medicine and Oral Pathology, v. 53, n.1, p. 74-77, 1982.

GOLDMAN, M. GOLDMAN, L. B.; CAVALERI, R.; BOGIS, J.; LIN, P. S. The efficacy of several endodontic irrigating solutions: a scanning electron microscopic study: Part 2. Journal of Endodontics, v. 8, n. 11, p. 487-492, 1982.

GROSSMAN, L.I.; MEIMAN, B.W. Solution of pulp tissue by chemical agents. Journal of the American Dental Association, v. 28, n. 2, p. 223-225, 1941.

GROSSMAN, L.I. Irrigation of root canals. Journal of the American Dental Association, v. 30, n.13, p. 1915-1917, 1943. 
GUERISOLI, D. M. Z.; MARCHESAN, M. A.; WALMSLEY, A. D.; LUMLEY, P. J.; PÉCORA, J. D. Evaluation of smear layer removal by EDTAC and sodium hypochlorite with ultrasonic agitation. International Endodontic Journal, v. 35, n. 5, p. 418-421, 2002.

GUIBAL, E.; MILOT, C.; ROUSSY, J. Influence of hydrolysis mechanisms on molybdate sorption isotherms using chitosan. Separation Science and Technology, v.35, p. $1020-1038,2000$.

GWINNETT, A. J. Smear layer: morphological considerations. Operative Dentistry (supplement), v. 3, p. 2-12, 1984.

HOF, R.; PEREVALOV, V.; ELTANANI, M.; ZARY, R.; METZGER, Z. The Selfadjusting file (SAF). Part 2: Mechanical analysis. Journal of Endodontics. v.36, n.4, p. $691-696,2010$.

HÜLSMANN, M.; HECKENDORFF, M.; LENNON, A. Chelating agents in root canal treatment: mode of action and indications for their use. International Endodontic Journal, v. 36, n. 12, p. 810-830, 2003.

JEON, Y.J.; SHADID, F.; KIN, S.K. Preparation of chitin and chitosan logomers and their applications in physiological functional foods. Food Reviews International, v. 16, n.2, p. 159-176, 2000. 
KAYA, S,; YI"GIT-ÖZER, S.; ADIGÜZEL, Ö. Evaluation of radicular dentin erosion and smear layer removal capacity of self-adjusting file using different concentrations of sodium hypochlorite as an initial irrigant. Oral Surgery Oral Medicine Oral Pathology Oral Radiology Endodontics, v.112, n.4. p. 524 -530, 2011.

KHEDMAT, S.; SHOKHOUHINEJAD, N. Comparison of the efficacy of three chelating agents in smear layer removal. Journal of Endodontics, v. 34, n. 5, p. 599-602, 2008.

KLOKKEVOLD, P.R.; LEW, D.S.;ELLIS, D.G., GERTOLAMI, C.N. Effect of chitosan on lingual hemostasis in rabbits. Journal of Maxillofacial Surgery, v. 49, n.8, p. 858-883, 1991.

KOKKAS, A. B.; BOUTSIOUKIS, A. CH.; VASSILIADIS, L. P.; STAVRIANIS, C. K. The influence of smear layer on dentinal tubule penetration depth by three different root canal sealers: an in vitro study. Journal of Endodontics, v. 30, n. 2, p. 100-102, 2004.

KONG, M.; CHEN, X.G.; XING, K.; PARK, H.J. Antimicrobial properties of chitosan and mode of action: A state of the art review. International Journal of Food Microbiology, v.144, n. 1, p. 51-63, 2010.

KOULAOUZIDOU, E. A.; MARGELOS, J.; BELTES, P.; KORTSARIS, A. H. Cytotoxic effects of different concentrations of neutral and alkaline EDTA solutions used as root canal irrigants. Journal of Endodontics, v. 25, n. 1, p. 21-23, 1999. 
LOEL, A. Use of acid cleanser in endodontic therapy. Journal of American Dental Association, v. 90, p. 145-151, 1975.

LOTTANTI, S., GAUTSCHI, B., SENER, B., ZEHNDER, M. Effects of ethylenediaminatetraacetic, etidronic and peracetic acid irrigation on human root dentine and the smear layer. International Endodontic Journal, v. 42, n. 4, p. 335-343, 2009.

MADER, C.L.; BAUMGARTNER, J.C.; PETERS, D.D. Scanning electron microscopic investigation of the smeared layer on root canal walls. Journal of Endodontics, v.10, n.10, p.477-483, 1984.

MAI, S.; KIM, Y. K.; AROLA, D.; GU, L. S.; KIM, J. R.; PASHLEY, D. H.; TAY, F. R. Differential aggressiveness of ethylenediaminetetraacetic acid in causing canal wall erosion in the presence of sodium hypochlorite. Journal of Dentistry, v. 38, n. 3, p. 201-206, 2010.

MARENDING, M.; LUDER, H.; BRUNNER, T. J.; KNECHT, S.; STARK, W. J.; ZEHNDER, M. Effect of sodium hypochlorite on human root dentine- mechanical, chemical and structural evaluation. International Endodontic Journal, v. 40, n. 10, p. 786-793, 2007.

MARQUES, A. A.; MARCHESAN, M. A.; SOUSA-FILHO, C. B.; SILVA-SOUSA, Y. T.; SOUSA-NETO, M. D.; CRUZ-FILHO, A. M. Smear layer removal and chelated calcium ion quantification of three irrigating solutions. Brazilian Dental Journal, v. 17, n. 4, p. 306-309, 2006. 
McCOMB, D., SMITH, D. C. A preliminary scanning microscopic study of root canals after endodontic procedures. Journal of Endodontics, v. 1, n. 7, p. 238242, 1975.

MELLO, I.; KAMMERER, B. A.; YOSHIMOTO, D.; MACEDO, M. C. S.; ANTONIAZZI, J. H. Influence of final rinse technique on ability of Ethylenediaminetetracetic Acid of removing smear layer. Journal of Endodontics, v. 36, n.3, p. 512-514, 2010.

MENEZES, A. C.; ZANET, C. G.; VALERA, M. C. Smear layer removal capacity of disinfectant solutions used with and without EDTA for the irrigation of canals: a SEM study. Pesquisa Odontológica Brasileira, v. 17, n. 4, p. 349-355, 2003.

METZGER, Z; TEPEROVICH, E; ZARY, R; COHEN, R; HOF, R. The Self-adjusting File (SAF). Part 1: Respecting the root canal anatomy - A new concept of endodontic files and its implementation. Journal of Endodontics. v. 36, n. 4, p. 679-690, 2010a.

METZGER, Z; TEPEROVICH, E; COHEN, R; ZARY, R; PAQUÉ, F; HÜLSMANN, M. The Self-adjusting file (SAF). Part 3: Removal of debris and smear layer - A scanning electron microscope study. Journal of Endodontics. v. 36, n. 4, p. 697702, 2010b.

METZGER, Z.; ZARY, R.; COHEN, R.; TEPEROVICH, E.; PAQUÉ, F. The quality of root canal preparation and root canal obturation in canals treated with rotary versus Self-adjusting file: A three-dimensional micro-computed tomographic study. Journal of Endodontics. v. 36, n. 9, p. 1569-1573, 2011. 
MICHETTI, J.; MARET, D.; MALLET, J.P.; DIEMER, F. Validation of cone beam computed tomography as a tool to explore root canal anatomy. Journal of Endodontics, v.36, n.7, p. 1187-1190, 2010.

MJÖR, I.A. Dentin permeability: The basis for understanding pulp reactions and adhesive technology. Brazilian Dental Journal, v.20, n.1, p.3-16, 2009.

MUZZARELLI, R.A.; MATTIOLI-BELMONTE, M.; TIETZ, C.; BIAGINI, R.; FERIOLI, G.; BRUNELLI, M.A.; GIARDINO, R.; ILARI, P.; BIAGINI, G. Stimulatory effect on bone formation exerted by a modified chitosan. Biomaterials, v. 15, n.13, p. 10751081, 1994.

NAAMAN, A.; KALOUSTIAN, H.; OUNSI, H. F.; ABBOUD, N. N. B; RICCI, C.; MEDIONI, E. A scanning electron microscopic evaluation of root canal wall cleanliness after calcium hydroxide removal using three irrigation regimens. The Journal of Contemporary Dental Practice, v. 8, n. 1, p. 2007.

NIU, W.; YOSHIOKA, T.; KOBAYASHI, C.; SUDA, H. A scanning electron microscopic study of dentinal erosion by final irrigation with EDTA and $\mathrm{NaOCl}$ solutions. International Endodontic Journal, v. 35, n. 11, p. 934-939, 2002.

NYGAARD- ØSTBY, B. Chelation in root canal therapy: ethylenediaminetetracetic acid for cleansing and widening of root canals. Odontologisk Tidskrift, v. 65, n. 2, p. 3-11, 1957. 
ONSØYEN, E.; SKAUGRUD, O. Metal recovery using chitosan. Journal of Chemical Technology and Biotechnology, v. 49, n. 4, p.395-404, 1990.

PAQUÉ, F.; PETERS, O.A. Micro-computed tomography evaluation of preparation of long oval root canals in mandibular molars with the self-adjusting file. Journal of Endodontics, v. 37, n. 4, p. 517-521, 2011.

PARK, J.S.; CHOI, S.H.; MOON, I.S.; CHO, K.S.; CHAI, J.K.;KIM, C. K. Eight week histological analysis on the effect of chitosan on created one-wall intrabony defects in beagle dogs. Journal of Clinical Periodontology, v. 30, n. 5, p. 443-453, 2003.

PARK, S.S.; KIM, S.G.; LIM, S.C.; ONG, J.L. Osteogenic activity of the mixture of chitosan and particulate dentin. Journal of Biomedical Material Research Applied, v. 87, n.3, p. $618-623,2008$.

PÉCORA, J. D.; SOUSA NETO, M. D.; SAQUY, P. C.; SILVA, R. G.; CRUZ FILHO, A. M. Effect Of Dakin's and EDTA solutions on dentin permeability of root canals. Brazilian Dental Journal, v. 4, n. 2, p. 79-84, 1993.

PÉCORA, J. D. ; CAPELLI, A. ; SEIXAS, F. H. ; MARCHESAN, M. A ; GUERISOLI, D. M. Z. Biomecânica Rotatória:Realidade ou Futuro. Revista da Associação Paulista de Cirurgiões Dentistas, São Paulo, v. 56, n. 3, p. 04-06, 2002.

PÉREZ-HEREDIA, M.; FERRER-LUQUE, C. M.; GONZÁLES-RODRÍGUEZ, M. P. The effectiveness of different acid irrigating solutions in root canal cleaning after hand and rotary instrumentation. Journal of Endodontics, v. 32, n. 10, p. 993-997, 2006. 
PEREZ, F.; ROUQUEYROL-POURCEL, N. Effect of a low-concentration EDTA solution on root canal walls: a scanning electron microscopic study. Oral Surgery, Oral Medicine, Oral Pathology, Oral Radiology, and Endodontics, v. 99, n.3, p. 383-387, 2005.

PETER, M.G. Applications and environmental aspects of chitin and chitosan. Journal of Macromolecular Science, v. 22, n.1, p. 33-40, 1995.

PETERS, O.A.; BOESSLER, C.; PAQUÉ, F. Root canal preparation with a novel nickel-titanium instrument evaluated with micro-computed tomography: canal surface preparation over time. Journal of Endodontics, v. 36, n. 6, p. 1068-1072, 2010.

PETERS, O.A.; PAQUÉ, F. Root canal preparation of maxillary molars with the Selfadjusting file: A micro-computed tomography study. Journal of Endodontics, v.37, n.1, p. 53-57, 2011.

PILLAI, C.K.S.; PAUL, W.; SHARMA, C.P. Chitin and chitosan polymers: Chemistry, solubility and fiber formation. Progress in Polymer Science, v. 34, n. 7, p. 641-678, 2009.

PIRON, E.; DOMARD, A. Interaction between chitosan and uranyl ions. Part 2. Mechanism of interaction. International Journal of Biological Macromolecules, v.22, n.1, p. 33-40, 1988. 
RAM, Z. Chelation in root canal therapy. Oral Surgery, Oral Medicine and Oral Pathology, v. 49, n. 1, p. 64-74, 1980.

RHAZI, M.; DESBRIERES, J.; TOLAIMATE, A.; RINAUDO, M.; VOTERRO, P.; ALAGUI, A.; MERAY, M.L. Influence of the nature of the metal ions on the complexation with chitosan. Application to the treatment of liquid wast. European Polymer Journal, v. 38, p. 1523-1530, 2002.

SCELZA, M. F.; ANTONIAZZI J. H.; SCELZA P. Efficacy of final irrigation - a scanning electron microscopic evaluation. Journal of Endodontics, v. 26, n. 6, p. 355-358, 2000.

SCHILDER, H. Cleaning and shaping the root canal. Dental Clinics of North America, v. 18, n. 2, p. 269-296, 1974.

SEN, B. H.; WESSELINK, P. R.; TÜRKÜN, M. The smear layer: a phenomenon in root canal therapy. International Endodontic Journal, v. 28, n.3, p. 141- 8, 1995.

SENEL, S.; KAS, H.S.; SQUIER, C.A. Application of chitosan in dental drug delivery and therapy. In: Muzzareli RAA, editor . Chitosan Per os: From Dietary Supplement to Drug Carrier. Italy: Atec, Grottammare, p. 241-256, 2000.

SENEL, S.; IKINCI, G.; KAS, S.; YOUSEFI-RAD; SARGON, M.F.; HINCAL, A.A. Chitosan films and hydrogels of chlorexidine gluconate for oral mucosal delivery. International Journal of Pharmacy, v.193, n. 2, p. 197-203, 2000. 
SILVA, P. V. Avaliação da capacidade de limpeza do canal radicular por meio de agentes quelantes e desmineralizantes; estudo, ex vivo, por meio de MEV e espectrometria dos compostos. 2011. Dissertação (Mestrado) - Faculdade de Odontologia de Ribeirão Preto, Universidade de São Paulo, Ribeirão Preto, 2011.

SIQUEIRA JR, J.F.; ALVES, F. R.F.; ALMEIDA, B.M.; OLIVEIRA, J.C.M.; RÔÇAS, I.N. Ability of chemomecanical preparation with either rotary instruments or Selfadjusting file to disinfect oval-shaped root canals. Journal of Endodontics, v. 36, n. 11, p. $1860-1865,2010$.

SLUTZKY- GOLDBERG, I.; MAREE, M.; LIBERMAN, R.; HELING, I. Effect of sodium hypochlorite on dentin microhardness. Journal of Endodontics, v. 30, n. 12, p. 880 $-882,2004$.

SOLOMONOV, M. Eight months of clinical experience with the Self-adjusting file system. Journal of Endodontics, v. 37, n. 6, p. 881-887, 2011.

SOUSA NETO, M. D.; PASSARINHO NETO, J. G.; CARVALHO JÚNIOR, J. R.; CRUZFILHO, A. M.; PÉCORA, J. D.; SAQUY, P. C. Evaluation of the effect of EDTA, EGTA and CDTA on dentin adhesiveness and microleakage with different root canal sealers. Brazilian Dental Journal, v. 13, n. 2, p. 123-128, 2002.

SPANÓ, J. C. E.; SILVA, R. G.; GUEDES, D. F. C.; SOUSA-NETO, M. D. ; ESTRELA, C.; PÉCORA, J. D. Atomic absorption spectrometry and scanning electron microscopy evaluation of concentration of calcium ions and smear layer removal with root canal chelators. Journal of Endodontics, v. 35, n. 5, p. 727-730, 2009. 
STEWART, G. G.; KAPSIMALAS, P.; RAPPAPORT, H. EDTA and urea peroxide for root canal preparation. Journal of the American Dental Association, v. 78, n. 2, p. 335- 338, 1969.

THOMPSON, S.A.; DUMMER, P.M. Shaping ability of Profile .04 taper series 29 rotary nickel-titanium instruments in simulated root canals: Part 1. International Endodontic Journal, v. 30, n. 1, p. 1-7, 1997a.

THOMPSON, S.A.; DUMMER, P.M. Shaping ability of Profile .04 taper series 29 rotary nickel-titanium instruments in simulated root canals: Part 2. International Endodontic Journal, v. 30, n. 1, p. 8-15, 1997b.

TORABINEJAD, M.; HANDYSIDES, R.; KHADEMI, A. A.; BAKLAND, L. K. Clinical implications of the smear layer in endodontics: a review. Oral Surgery, Oral Medicine, Oral Pathology, Oral Radiology, and Endodontics, v. 94, n. 6, p. 658666, 2002.

TORABINEJAD, M.; CHO, Y.; KHADEMI,; A. A.; BAKLAND, L. K.; SHABAHANG, S. The effect of various concentrations of sodium hypochlorite on the ability of MTAD to remove the smear layer. Journal of Endodontics, v. 29, n. 4, p. 233-239, 2003.

VERSIANI, M.A.; PÉCORA, J.D.; SOUSA-NETO, M.D. Flat-oval root canal preparation with Self-adjusting file instrument: A micro-computed tomography study. Journal of Endodontics. v.37, n.7, p. 1002-1007, 2011. 
VILLEGAS, J. C.; YOSHIOKA, T.; KOBAYASHI, C.; SUDA, H. Obturation of accessory canals after four different final irrigation regimes. Journal of Endodontics, v. 28, n. 7, p. 534-536, 2002.

VIOLICH, D. R.; CHANDLER, N. P. The smear layer in endodontics - a review. International Endodontic Journal, v. 43, n.1, p. 2 - 15, 2010.

VON DER FEHR, F.R.; ØSTBY, N.B. Effect of EDTAC and sulfuric acid on root canal dentine. Oral Surgery, v. 16, n. 2, p. 199-205, 1963.

WALIA, H., BRANTLEY, W.A.; GERSTEIN, H. An initial investigation of the bending and torsional properties of Nitinol root canal files. Journal of Endodontics, v. 14, n.7 , p. 346-351, 1988.

WALKER, A. A definite and dependable therapy for pulpless teeth. Journal of the American Dental Association, v. 23, n. 2, p. 1418-1425, 1936.

WU, Y.; HU, Y.; CAI, J.; MA, S.; WANG, X. Coagulation property of hyaluronic acidcollagen/chitosan complex film. Journal of Material Science Mater.Med., v. 19, n.12, p. 3621-3629, 2008.

XIA, W.; LIU, P.; ZHANG, J.; CHEN, J. Biological activities of chitosan and chitooligosaccharides. Food Hydrocolloids, v. 25, n. 2, p. 170-179, 2011. 
YAMADA, R.S.; ARMAS, A.; GOLDMAN, M. LIN, S.P. A scanning electron microscopic comparison of a high volume final flush with several irrigating solutions. Part 3. Journal of Endodontics, v. 9, n. 4, p.137-142, 1983.

ZHANG, K.; TAY, F. R.; KIM, Y. K.; MITCHELL, J. K.; CARRILHO, M.; PASHLEY, D. H.; LING, J. Q. The effect of initial irrigation with two different sodium hypochlorite concentrations on the erosion of instrumented radicular dentin. Dental Materials, v. 26, n. 6 , p. 514-523, 2010.

ZOU, L., SHEN,Y., Li, W.; HAAPASALO, M. Penetration of sodium hypochlorite into dentin. Journal of Endodontics, v. 36, n.5, p. 793-706, 2010.

ZUOLO, M.; MURGEL, C.A.F.; PÉCORA, J.D.; ANTONIAZZI, J.H.; COSTA, W.F. Ação do EDTA e suas associações com tensoativos na permeabilidade da dentina radicular. Revista de Odontologia da Universidade de São Paulo, v. 1, n. 4, p. 1823, 1987. 
Anexos 
144 | Anexos 
Anexo I. Solicitação de aprovação do Projeto de Pesquisa junto ao Comitê de Ética em Pesquisa da FORP-USP

MINISTÉRIO DASAŨDE

Conselho Nacional de Saúde

Comissão Nacional de Ética em Pesquisa - CONEP

PROJETO RECEBIDO NO CEP

CAAE - 0058.0.138.000-11

Projeto de Pesquisa

AVALAC̆Ã DALIMPEZA DAS PAREDES DOS CANAIS RADICULARES PROMOVDA PELA TÉCNICA ROTATÓRIAE PELASELF-ADJUSTMENT SAF) COM USO DE DIFERENTES QUELANTES

Área(s) Temática(s) Especial(s)

Não se aplica

\begin{tabular}{|l|ll|l|}
\hline CPF Pesquisador Responsável & $\begin{array}{l}\text { Pesquisador Responsável } \\
\text { josé antonio brufato ferraz }\end{array}$ & \\
\hline $\begin{array}{c}\text { Data de Entrega } \\
\text { 26/09/2011 }\end{array}$ & Recebimento: & Assinatura \\
\hline
\end{tabular}

Este documento deverá ser, obrigatoriamente, anexado ao Projeto de Pesquisa. 
$146 \mid$ Anexos 
Anexo II. Aprovação do Projeto de Pesquisa pelo Comitê de Ética em Pesquisa da FORP-USP

Informamos que o Comitê de Ética em Pesquisa, em sua $125^{\text {a }}$ Sessão, realizada em 17 de novembro de 2011, aprovou o desenvolvimento do projeto de pesquisa envolvendo seres humanos, intitulado "Avaliaçăo da limpeza das paredes dos canais radiculares promovida pela técnica rotatória e pela Self-Adjustment (SAF) com uso de diferentes quelantes".

$\mathrm{Na}$ oportunidade, lembramos da necessidade de ser entregue, na secretaria do CEP, O Relatório Final em 17 de novembro de 2012, com o respectivo formulário preenchido pelo pesquisador responsável.

Lembramos ainda que, quando da submissão do relatório a este Comitê, quaisquer inclusões ou modificações no projeto original deverão ser comunicadas e justificadas ao CEP, através do formulário supracitado.

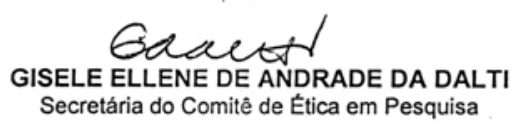

IImo(a). Sr(a).

PG. JOSÉ ANTONIO BRUFATO FERRAZ (Prof. Dr. Jesus Djalma Pécora) 
ANEXO III. Dados com os comprimentos de trabalho (CT) dos dentes do experimento em $\mathrm{mm}$ após a ressecção coronária e seus diâmetros anatômicos (DA) referenciados pela numeração das limas do tipo K correspondentes.

\begin{tabular}{|c|c|c|c|}
\hline \multicolumn{2}{|c|}{ ROTATÓRIO } & \multicolumn{2}{|c|}{ SAF } \\
\hline CT & DA & CT & DA \\
\hline 13 & 30 & 15 & 30 \\
\hline 14 & 35 & 15 & 30 \\
\hline 15 & 30 & 14 & 35 \\
\hline 16 & 30 & 16 & 30 \\
\hline 15 & 35 & 14 & 35 \\
\hline 14 & 30 & 14 & 30 \\
\hline 15 & 30 & 13 & 40 \\
\hline 14 & 40 & 14 & 30 \\
\hline 14 & 35 & 15 & 30 \\
\hline 13 & 30 & 15 & 40 \\
\hline 16 & 30 & 14 & 30 \\
\hline 15 & 30 & 14 & 30 \\
\hline 14 & 30 & 16 & 35 \\
\hline 15 & 35 & 15 & 30 \\
\hline 15 & 35 & 14 & 30 \\
\hline
\end{tabular}

